\title{
A Review of Supercapacitors: Materials Design, Modification, and Applications
}

\author{
Muhammad Yaseen ${ }^{1}$, Muhammad Arif Khan Khattak ${ }^{1}$, Muhammad Humayun ${ }^{2}{ }^{(}$, Muhammad Usman ${ }^{3}{ }^{10}$, \\ Syed Shaheen Shah ${ }^{3}$, , Shaista Bibi ${ }^{1}$, Bakhtiar Syed Ul Hasnain ${ }^{4}$, Shah Masood Ahmad ${ }^{5}$, Abbas Khan ${ }^{1, *(1)}$ \\ Nasrullah Shah ${ }^{1}$, Asif Ali Tahir ${ }^{6}(\mathbb{b})$ and Habib Ullah ${ }^{6, *(1)}$
}

1 Department of Chemistry, Abdul Wali Khan University Mardan, Mardan 23200, Pakistan; Yaseen.chemist@gmail.com (M.Y.); arifchem42@gmail.com (M.A.K.K.); shaistabibi.chemist@gmail.com (S.B.); nasrullah@awkum.edu.pk (N.S.)

2 Wuhan National Laboratory for Optoelectronics, School of Optical \& Electronics Information, Huazhong University of Science and Technology, Wuhan 430074, China; 2017511018@hust.edu.cn

3 Inter Disciplinary Research Center for Hydrogen and Energy Storage (IRC-HES), King Fahd University of Petroleum and Minerals (KFUPM), Dhahran 31261, Saudi Arabia; muhammadu@kfupm.edu.sa (M.U.); syedshaheenshah3@gmail.com (S.S.S.)

4 School of Material Science and Engineering, Wuhan University of Technology, Wuhan 430070, China; syedulhasnain@hotmail.com

5 Institute of Chemical Sciences, University of Peshawar, Peshawar 25120, Pakistan; shahmasoodchemist@gmail.com

6 Environment and Sustainability Institute, University of Exeter, Penryn TR10 9FE, UK; A.Tahir@exeter.ac.uk

* Correspondence: abbas053@gmail.com (A.K.); hu203@exeter.ac.uk (H.U.)

Citation: Yaseen, M.; Khattak, M.A.K.; Humayun, M.; Usman, M.; Shah, S.S.; Bibi, S.; Hasnain, B.S.U.; Ahmad, S.M.; Khan, A.; Shah, N.; et al. A Review of Supercapacitors: Materials Design, Modification, and Applications. Energies 2021, 14, 7779. https://doi.org/10.3390/en14227779

Academic Editor: Bashir A. Arima

Received: 23 September 2021

Accepted: 15 November 2021

Published: 19 November 2021

Publisher's Note: MDPI stays neutral with regard to jurisdictional claims in published maps and institutional affiliations.

Copyright: (c) 2021 by the authors. Licensee MDPI, Basel, Switzerland. This article is an open access article distributed under the terms and conditions of the Creative Commons Attribution (CC BY) license (https:/ / creativecommons.org/licenses/by/ $4.0 /)$.

\begin{abstract}
Supercapacitors (SCs) have received much interest due to their enhanced electrochemical performance, superior cycling life, excellent specific power, and fast charging-discharging rate. The energy density of SCs is comparable to batteries; however, their power density and cyclability are higher by several orders of magnitude relative to batteries, making them a flexible and compromising energy storage alternative, provided a proper design and efficient materials are used. This review emphasizes various types of SCs, such as electrochemical double-layer capacitors, hybrid supercapacitors, and pseudo-supercapacitors. Furthermore, various synthesis strategies, including sol-gel, electro-polymerization, hydrothermal, co-precipitation, chemical vapor deposition, direct coating, vacuum filtration, de-alloying, microwave auxiliary, in situ polymerization, electro-spinning, silar, carbonization, dipping, and drying methods, are discussed. Furthermore, various functionalizations of SC electrode materials are summarized. In addition to their potential applications, brief insights into the recent advances and associated problems are provided, along with conclusions. This review is a noteworthy addition because of its simplicity and conciseness with regard to SCs, which can be helpful for researchers who are not directly involved in electrochemical energy storage.
\end{abstract}

Keywords: supercapacitor; synthesis; functionalization; applications

\section{Introduction}

Nowadays, there is a need for clean energy sources to preserve natural resources and regulate global energy consumption. In different fields such as electric transit vehicles, hybrid cars and transportable electronic devices, including numerous non-conventional electrically driven devices, supercapacitors (SCs), batteries, and fuel cells are used [1,2]. SCs have gained scientists' attention due to their enhanced electrochemical performance, comprising a superior cycling life, high specific power, and a fast charge-discharge rate. Likewise, they also exhibit excellent reversibility and great power density along with their applications in electrical and renewable devices [3]. Moreover, supercapacitors are also denoted as ultra-capacitors, electrical double-layer capacitors (EDLCs), gold capacitors, electrochemical capacitors (ECs) [4], pseudo-capacitors, and/or power coaches [5,6]. SCs 
consist of electrolytes, current collectors, and electrodes. The broad specific surface area (SSA), which has been proven to be more powerful than standard batteries for SCs, is 10,000 times greater for traditional capacitors [7] and thin dielectric separators [8,9]. The charge-discharge system at the interface between electrode-electrolyte induces the energy storage capacity for SCs [10], based on the same principle with conventional capacitors, but with much faster charge-discharge (mechanism/phenomena/step/route) [11]. The charge storage range for the conventional capacitors exhibits a charge storage capacity within the micro to milli-Farads range, while SCs present a charge storage between 100 and $1000 \mathrm{~F}$, for each device maintaining specific power and low analogous series resistance (ESR). Compared to batteries, SCs can manage the power density in several orders of magnitude and comparable specific energy, making them a viable alternative energy storage system [12]. In comparison to batteries, supercapacitors have the ability to store one thousand times the power, making supercapacitors excellent candidates for use in various devices in which power bursts are required; however, SCs can accumulate 3-30 times less charge as compared to batteries. Moreover, they are also safe and reach a greater charging/discharging power rate. The electrode materials extensively used in supercapacitors are carbon materials [13], transition metal oxides/hydroxides, and conducting polymers. Among the metal oxides, $\mathrm{MnO}_{2}, \mathrm{NiO}, \mathrm{Co}_{3} \mathrm{O}_{4}$, and $\mathrm{ZnO}$ are better materials for pseudo-capacitance storing charge by means of the Faradaic redox method. Incorporation of nanoparticles in the metal oxides can enhance the capacity and the rate of intercalation from the electrolyte to the electrode and vice versa [14]; thus, hybridizing these oxides with other materials is necessary. Similarly, the metal oxides' capacitive efficiency can also be enhanced with the addition of conductive materials, i.e., carbon materials and conductive polymers. It has been found that nanostructured metal sulfides exhibit the best capacitive efficiency among the mentioned metal oxides. Sulfur-based compounds, especially the sulfides, have exhibited the best capacitance efficiency due to the transfer of two or more electrons from the electrolyte to the electrode. In recent years, sulfide of nanomaterials, such as $\mathrm{NiS}, \mathrm{Co}_{3} \mathrm{~S}_{4}, \mathrm{CuS}$, and $\mathrm{SnS}$, have also been used as an electrode for supercapacitor applications. The exceptional feature of SCs over traditional capacitor is the absence of dielectric material [15]. In contrast, the conventional capacitors store and provide a higher power density $\left(\mathrm{P}_{\mathrm{d}}\right)$ and lower energy density $\left(E_{d}\right)$ than SCs, showing a much faster charge and discharge time. Similarly, rigidity and their massive nature is another limitation of traditional capacitors. Furthermore, SCs also offer increased stability and protection of the system, light weight, low heating, and versatility [16]. A Ragone plot comparing several energy storage devices, e.g., conventional capacitors, batteries, fuel cells, and hybrid supercapacitors (HSCs) in terms of power density and energy density $[17,18]$, is shown in Figure 1. HSC s present a considerable power density resembling that of fuel cells and batteries, but substantially lower than typical capacitors.

Theoretically, electrons are loaded from the electrode to the electrode-electrolyte interface for storing and releasing electrical energy in the electrolyte [19]. Electrochemical condensers (ECs) and batteries are two separate energy storage systems, where they both store electricity by means of electrochemical methods while using two different processes [20]. Concerning the renewable energy process, Li-ion batteries (LIBs) became a hot research topic among scientists. LIB research mainly focuses on anodic and cathodic materials, which have significant capabilities for subsequent cycles [21,22]. A reversible redox reaction is performed at the cathode and anode for batteries during the charge-discharge phase. Although LIBs produce a high energy density and greater capacity due to the Faradic nature of charging storage, they display a lower power density and poor cycle life due to their sluggish nature. Recently, redox flow batteries (RFBs), as one of the most promising electrochemical energy storage devices, received tremendous attention from scientific research, thanks to their appealing qualities for large-scale energy storage $[23,24]$. However, because of their relatively high cost and low energy density, their actual applications on the industrial scale are still hindered. As a result, new redox-active electrolytes and innovative membranes with improved ionic selectivity and conductivity should be explored in the development of next-generation RFBs, which will help to achieve higher power and energy densities, longer 
life, and lower costs. Even though the cost of raw materials (i.e., iron and chromium) mostly used in the RFBs is $\sim 17 \mathrm{USD} / \mathrm{kWh}$, the first developed iron-chromium-based RFB caused serious cross-contamination problems in the use of a mixed solution as both the anolyte and catholyte [25]. On the other hand, supercapacitor control on the extremely porous surface of the electrode depends on the potential difference through adsorption/disposal of charge ions from the electrolyte [21]. This means that SCs can provide a much higher power density of 103-104 W/ kg. They can provide significantly higher energy consumption than Li-ion batteries at a far higher rate, thus meeting a significant demand in electric vehicles or other next-generation electronic devices. Meanwhile, SCs have a low cost, longer cycle life (approximately more than $10^{6}$ cycles), and better safety than batteries. All these characteristics make SCs much more suitable for renewable energy storage devices. Electrochemical supercapacitors (ESCs) have gained much importance in consumer electronics, digital cameras, computers, security installations, inverters, telecommunication, and regenerative braking, etc. With the use of grid substations as the storage system, primary and/or secondary power sources for transport vehicles, such as electric vehicles, hybrid vehicles, buses, and trains, may also extend into grid substations [26,27]. A comparative analysis of the selected technologies for the storage of electrical energy is shown in Table 1.

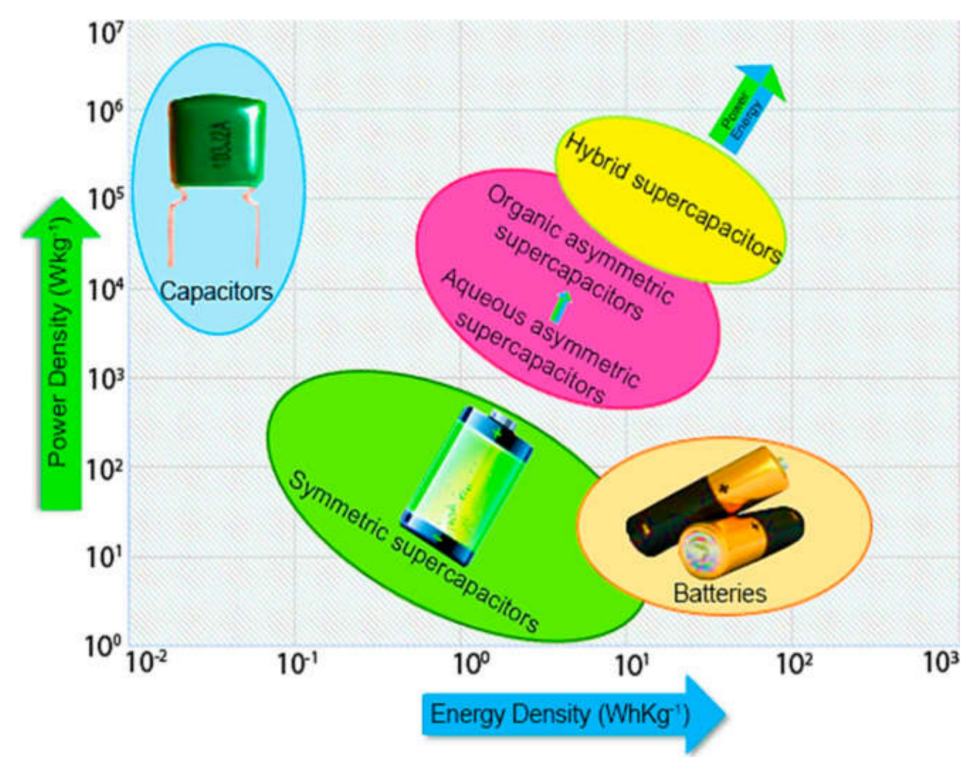

Figure 1. A Ragone plot for different electrochemical energy storage devices of the density versus energy density scale. Reproduced with permission from [17]. Catalysts, 2020.

Table 1. Comparative analysis of selected technologies for the storage of electrical energy. Reproduced with permission from [28] 2006, Elsevier.

\begin{tabular}{cccc}
\hline Properties & Capacitor & Super-Capacitor & Battery \\
\hline Specific energy $(\mathrm{Wh} / \mathrm{kg})$ & $<0.1$ & $1-10$ & $10-100$ \\
Specific power $(\mathrm{W} / \mathrm{kg})$ & 10,000 & $500-10,000$ & $<1000$ \\
Discharge time (s) & $10^{-6}$ to $10^{-3}$ & $\mathrm{~S}$ to $\mathrm{min}$ & $0.3-3 \mathrm{~h}$ \\
Charge time (s) & $10^{-6}$ to $10^{-3}$ & $\mathrm{~S}$ to $\mathrm{min}$ & $1-5 \mathrm{~h}$ \\
Coulombic efficiency (\%) & About 100 & $85-98$ & $70-85$ \\
Lifecycle (cycles) & Almost infinite & $>500,000$ & $\sim 1000$ \\
\hline
\end{tabular}

To the best of our knowledge, some reviews have been published that address the energy storage ability, performance [29], recent progress and improvement of supercapacitorbased devices [30], an improvement in the fabrication methods of electrochemical supercapacitors [9], and the enhancement of the technology used, and possible challenges. However, a concise summary of the synthetic methods, chemical functionalization approaches, and applications of all reported classes of supercapacitors is missing. Therefore, 
in the current review article, we aimed to summarize the various synthesis routes, modification, and functionalization strategies along with a brief overview of the applications of some important classes of SCs, such as electrochemical double-layer capacitors, hybrid supercapacitors, and pseudo-supercapacitors. Furthermore, the possible potential challenges and problems regarding the implementation and future of the above-mentioned types of supercapacitor-based devices are also discussed. Therefore, this article is a great addition due to its simplicity and conciseness with regard to SCs, which can be helpful for scholars not directly interested in electrochemical energy storage.

\section{History of Supercapacitors}

A supercapacitor is a device that stores energy electrochemically using a polarized electrolyte, which emerged back in the 1970s and 1980s. It very different from the conventional power supply, with energy storage between conventional capacitors and batteries [31]. The redox reactions at electrical power storage interfaces (EDLCs) stored at the non-Faradic double-layer charge at the electrode-electrolyte interface usually categorize SCs into pseudo-capacitors, depending on redox pseudo-capacity [32,33]. Research on supercapacitors originated in the United States, South Korea, Russia, Japan, France, Switzerland, and other American and European countries. Maxwell, NEC, Tokin, Panasonic and the Russian Econd company contributed most to the world market. Helmholtz developed the concept of double-layer capacitance by identifying its properties in 1879, but it took decades for double-layer capacitance to be exploited for energy storage [31,34]. In 1957, Becker reported that smaller capacitors could be used as energy storage devices. In 1968, Standard Oil Company Sohio submitted the first patent for double-layer carbon-based condensers with greater surface area. NEC eventually received the patent technology and began producing SCs for electric vehicle ignition systems in 1979. In the meantime, Panasonic created supercapacitors that use activated carbon as an electrode and an organic electrical solution [35]. Currently, Panasonic, Maxwell, EPCOS, NEC, and NESS are very active in the research and development of supercapacitors (Figure 2). Currently, supercapacitor devices based on SCs from the United States, Russia, and Japan almost entirely dominate the market. The SCs products of each country have distinct characteristics and ultimate benefits in terms of capacity, pricing, and power, among other things.

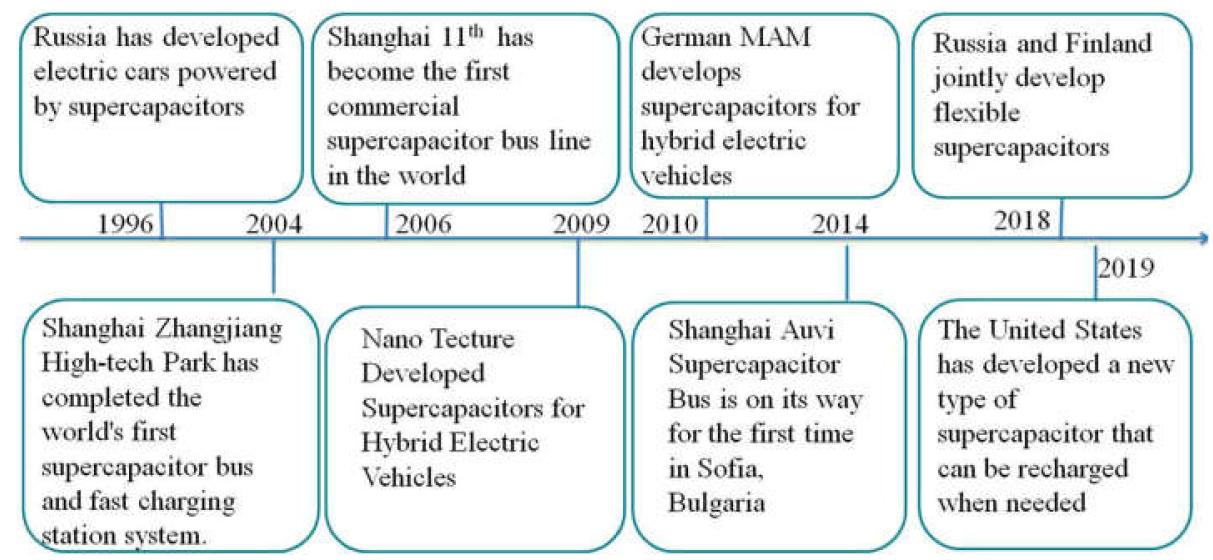

Figure 2. The development of supercapacitors in different countries. Reproduced with permission from [36]. AIP Publishing LLC, 2019.

Supercapacitors have received a lot of press since they were first introduced to the market. It has become a new trend in the world of chemical energy because of globalization and rising demand. According to Bosch's 2007-2022 Research Report on the Current Position and Investment Aspects of China's Supercapacitor Market, the global supercapacitor market reached USD $16 \times 10^{9}$ in 2015 , while analysts predicted the market would reach USD $92.3 \times 10^{9}$ by 2020 , with an annual growth rate of $39 \%$, as shown in Figure 3 . According to the report, the quality and performance of SCs have gradually increased to fulfill the growing 
demand for SCs in the global market. Furthermore, taking supercapacitors as a product, they are modified and have become well formed, while their application range has also been extending continuously. They have been used in industry, communications, consumer electronics, medical equipment, national defense, military equipment, transportation, and other industries $[37,38]$. Over the last few decades, the SCs have been developing from single power storage to hybrid battery and/or fuel-cell power storage, and have demonstrated many higher advantages as an energy store for small- to large-scale storage capacity. As a result, supercapacitors offer excellent performance, encouraging substantial research, storage applications, and huge potential in the electronic industry and consumer market. As a result, we anticipate a wide range of uses for supercapacitors in the future $[39,40]$.

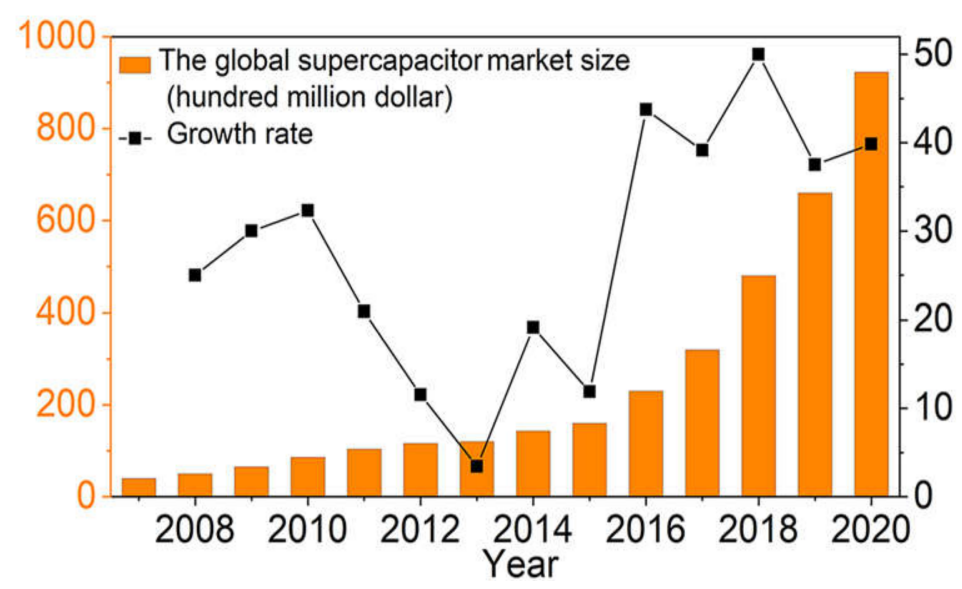

Figure 3. The size of the global supercapacitor market and its growth rate. Reproduced with permission from [36]. AIP Publishing LLC, 2019.

\section{Types and Classification of Supercapacitors}

Supercapacitors are classified into three main kinds, i.e., electrochemical double-layer capacitors (EDLCs), pseudo-capacitors, and hybrid SCs, as shown in Figure 4.

Electrochemical double-layer capacitors (EDLCs) operate on the basis of electrostatic charge storage. The primary operating principle of capacitors is represented by Equation (1):

$$
C=\frac{\varepsilon_{0} \varepsilon_{r} A}{d}
$$

where $A$ denotes the electrode surface area, $\varepsilon_{0}$ denotes the permittivity of empty space, $\varepsilon_{\mathrm{r}}$ denotes the relative permittivity of dielectric material, and $\mathrm{d}$ is the distance between two electrodes in opposing directions. Equation (1) indicates the direct relation between the capacitance with dielectric constant material and surface area, while inverse relation with the inter-planar thickness. Besides this, for energy density and power density determination, Equations (2) and (3) can be employed [41].

$$
\begin{aligned}
& E(W h / k g)=\frac{1}{2} \frac{C_{s} \Delta V^{2}}{3.6} \\
& P(W / k g)=\frac{E \times 3600}{\Delta t}
\end{aligned}
$$

The Coulumbic efficiency $(\eta)$, which is the ratio between discharging time $\left(t_{d}\right)$ and charging time $\left(t_{c}\right)$, is calculated by Equation (4) [42]:

$$
\eta=\frac{t_{d}}{t_{c}} \times 100 \%
$$

The electrical conductivity of the materials can be improved using metal doping ions, such as $\mathrm{Fe}, \mathrm{Cr}, \mathrm{Mn}$, and $\mathrm{Co}$. Bringing about modification in the design of capacitors, 
leading to the improvement in capacitance. For example, a capacitor consists of symmetric electrodes, or it is based on Faradic reactions, which enhances the electrochemical efficiency in this supercapacitor. The classification of EDLCs can be seen in Figure 4. A detailed discussion about the merits and demerits of EDLC devices is not within the scope of this brief review article. Here, in this review, more attention is paid to the most significant issues/characteristics. For instance, the non-Faradaic electrical mechanism results in highly reversible charging and discharging cycles, which leads to a higher load, releasing rate and a minor degradation. These characteristics can also lead to a very stable cycling ability up to $10^{6}$ or more. The main limitation of the EDLCs' is the restriction of electrode material selection because its equipment needs highly conductive electrodes, which is now overcome due to the discovery of ionic conducting electrolytes. That is the reason why the research into ionic electrolytes is a trending and hot topic among scientists nowadays [43-45]. As far as carbon contents are concerned, three principal types of EDLCs lead to various works and roles in the device. The properties of carbonate matter, e.g., morphology, hybridization, and structural defects [46], will identify these effective roles: (1) aerogels (nanoporous carbon), foams (microporous carbon), and carbide-derived carbon (CDC) (controllable pore size), (2) graphene and carbon nanotubes (CNTs), and (3) activated carbon. EDLC can be further classified into (1) carbon foam, (2) carbon aerogels, (3) carbide-derived carbon, (4) graphene, (5) carbon nanotubes, and (6) activated carbon, as discussed below.

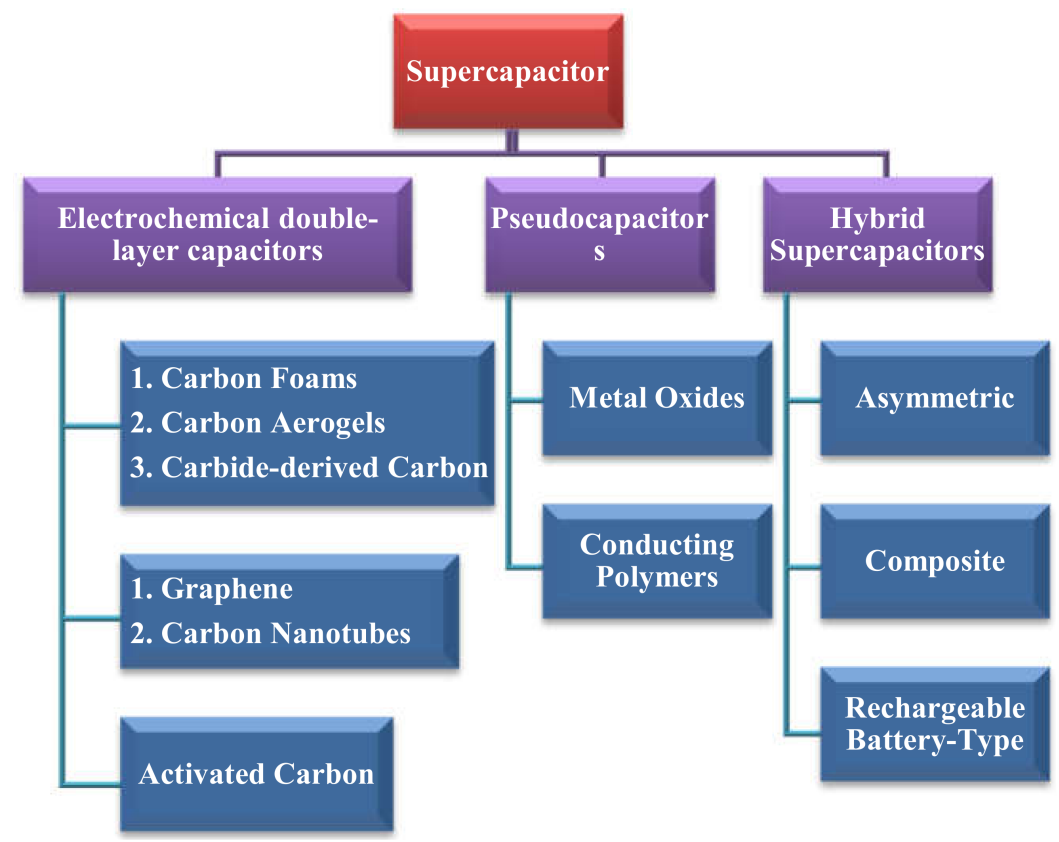

Figure 4. Overview of supercapacitor types and classification.

Carbon foams, carbide-derived carbon (CDC), and carbon aerogels are the lightest materials on the planet due to their huge surface area and a density of $200 \mathrm{mg} / \mathrm{cm}^{3}$. Due to their excellent thermal, electrical, and mechanical properties and their high compression and adsorption capacity, they have made it possible to clean large toxic solutions and petroleum dumps, as 900 times their mass of liquid oil would adsorb onto their surface [47]. Furthermore, the polymer binder can become a weak conducting structure instead of reinforcing its lightweight structure [48-50]. Two methods, i.e., sol-gel [51] and carbon suspension freeze-drying, are used for creating amorphous carbon aerogels. Recently, a carbon aerogel comprising a fine 3D network of CNTs with a larger Young's modulus, in addition to the current mechanical properties, super compression and flexibility, was present [52]. Despite its fragility, the material's mechanical and transport capabilities were improved due to van der Waals forces between neighboring CNTs. This material could be used as a lightweight energy storage device and a deformation detector for small pressure changes [53]. A decrease 
in elasticity could lead to an aerogel, as continuous cyclic compression could lead to cracks. Various preparation methods independently allow the control of pore concentration, creating a suitable electrode material from the carbon aerogel. It has been observed that the addition of the metal precursor into the carbon aerogel results in changing its $\mathrm{pH}$, activation and pyrolysis pattern, etc., and hence, it becomes difficult to control and monitor the homogeneity of the aerogel's pores [54,55]. Another carbon-based EDLC contains carbon nanotubes (CNTs) and graphene. Graphene is a substantial substance with good mechanical strength and chemical stability and high electrical and thermal conductivity [55-59]. Within its structure, it can also combine with many functional groups, resulting in its electrical and mechanical capabilities. These properties will be beneficial in combination with a high density, load/unload rate, and long lifecycle output in a built SC. Both 0D, 1D, 2D, and 3D graphene provide various structural elements that increase the required structure by providing the desired fine-tuned surface area. Examples include quantum dots, fibers, yarn graphene, graphene films, aerogenic carbon graphene, and foam graphene. There are also a large number of nanocomposites in graphene conductive polymers, graphene hydroxide, and metal-oxidized graphene with other elements or functional groups. These nanocomposites provide a greater surface area, increased power density, controllable pores, electrical conductivity, etc. Due to some unique characteristics of these compounds, their composites may not contribute well to the capacitance and/or may cause a reduction in the overall effective ion diffusion. A nanocomposite with greater conductivity, at the expense of mechanical strength, frequently has collaborative qualities [60]. Simply, a virtually gathered graphene sheet will form CNTs which are famous for their conductivity. They are of two types; single-walled (SWCNTs) and multi-walled nanotubes (MWCNTs). SWCNTs have high elasticity and a size of roughly $5 \mathrm{~nm}$ due to the difficulty in covering these highly sought-after assets, because they will participate in bundling. They may not have the same characteristics as perfect SWCNTs and cannot be separated. MWCNTs have a significant number of limitations relative to SWCNTs. This will change their composition and finally lead to higher resistance, depending on their intrinsic properties. However, relative to SWCNTs, the material sizes are longer, the abnormal length of $20 \mathrm{~nm}$ is better, and the amount is better than SWNTs [59,61]. CNTs are highly sought after; however, their composite forms are chemically altered, and the reinforced form of CNTs are also considered to have a very good grade and enhanced strengths. The processing of solutions, melting, compression molding, and chemical sample vapor removal, such as form-altered fibers, CNT composites, CNT composite fibers, and so on, are all utilized to prepare such varied versions of CNTs [62]. The other type is activated carbon (AC); due to its high surface area and oxidation ability, superior electrochemical efficiency is observed in EDLC devices based on the activated carbon electrodes $[41,63,64]$. The phonon density of the states is affected by mixing or substantial overlap of the Raman bands $D$ and $G$ as a result of the general oxidation of carbon materials. As a result, Raman's lines also show a noticeable red shift. Comprehensive pore size regulation and, as a result, defective structures, such as carbon hazard bonds and $\mathrm{C}-\mathrm{C}$ bonds, may be reported as a result of this activity. The low cost of graphene is another advantage in activated carbons. Large holes of less than $5 \mathrm{~nm}$ to more than $50 \mathrm{~nm}$ can also be monitored using activated carbons. The fundamental disadvantage of activated carbon electrodes may be that the various pore geometries are not always very capable, since electrolyte ion sizes alter. The pore size and ion size of an electrolyte are in fact connected, and a condenser that combines these two criteria delivers the best electrochemical output possible. The defect structures of the electrodes certainly play a major role at this point in concluding the entire system output [65]. In order to prevent low charge storage, the best match between the size of the electrolyte ion and the pores needs to be found. Recent supercapacitor studies can be performed elsewhere on activated carbon electrodes [66]. Another type is pseudo-capacitors, which help in redox processes or the transport of charge between electrolytes and electrodes. The various methods for their synthesis are electrospinning, redoxing, and intercalation. Because of the Faradaic mechanism, they have better energy densities relative to EDLCs. The most popular capacitor electrode materials are metal oxides, metal-doped carbon, and 
conductive polymers [67]. They have lower power density and a shorter life due to the redox reactions of the capacitors [68]. These capacitors may be conducting polymers and metal oxides. The pseudo-capacitors of conducting polymers are extremely competent, very conductive (i.e., low ESR), have great potential densities, and have a low cost relative to carbon-based EDLCs. Poly(pyrrole) (PPy), poly(aniline) (PANI) [69], and poly(thiophene) (Pth) are the conducting polymers commonly used for this purpose so far. They are also used as nano-fillers with a higher capacity than EDLCs because of their versatility and conductivity. Relative to carbon-based electrodes, polymer-based electrodes are often less stable in cycles. The doping of polymers can promote the conductivity on one side, but can also lead to a shift in volume, causing swelling and a rise in electrode thickness on the other side; hence, this is challenging for any good pseudo-capacitor/SC system [70]. Another type of pseudo-capacitor is based on the metal oxides, which are extremely conductive. Likewise, among the various transition metal oxides studied, $\mathrm{RuO}_{2}$ has a very high capacity and low ESR, but its high cost restricts its use as compared to other capacitor-based electrode materials/metal oxides. Different processing approaches such as inter-composition, anodic deposition, sol-gel, spray deposition, hydrothermal synthesis, etc., are used for the preparation of metal oxide-based materials [71]. It is believed that metal oxides themselves provide high capacity with low current density and high energy levels. However, they can cause cracks in electrodes and damage them because their pores cannot be changed or altered in any manner; hence, this leads to short-term electrode instability [72]. In general, they are used to shape composites with carbon to compensate for these characteristics. Furthermore, in the creation of pseudo-capacitor electrodes, materials based on carbon are frequently used as electrode materials, and their composition has been demonstrated to be capable of reaching high capacitance values for various capacitances, such as $\mathrm{Co}_{3} \mathrm{O}_{4}, \mathrm{MNO}_{2}$, $\mathrm{Fe}_{3} \mathrm{O}_{4}$, and $\mathrm{ZnO}$. The synergistic effects of nanocrystals of $\mathrm{ZnO}$ and the counter electrode were summarized previously in detail [30], and one can understand more by studying the synergetic effect of the composite hybrid supercapacitors as well. However, there are arguments that metal oxides, in terms of capacitance, are more capable than carbon-based and conductive polymers-based electrode materials. The tremendous popularity of the noble metals for supercapacitor electrode materials is due to their superior conductivity and electrochemical stability. Noble metal-based electrode materials have been extensively studied and found to be good electrode materials for SCs, as they can improve the specific capacitance, conductivity, chemical, and thermal stabilities of electrode materials [73]. These metals mostly consist of gold, silver, and the platinum group (i.e., platinum, palladium, osmium, ruthenium, iridium, and rhodium) [74-78]. Among these noble metals, platinum, palladium, gold, and silver are mostly engaged as electrode materials for SCs [79-81]. Due to their high conductivity, they can promote the efficient transfer of electrons from pseudocapacitors to the current collecting systems. However, their inclusion with other sustainable and cheap materials is seen as one of the most attractive means of optimizing their features and minimizing their usage because of the low abundance and high cost of noble metals. The last one is the hybrid super-capacitors, whose storage is led by polarizing (carbon) electrodes and non-polarizing elements (metal or conducting polymer). Because of the Faradaic and non-Faradaic processes, both the battery and the capacitor electrode result in higher cycling stability and lower costs relative to EDLCs' high energy storage. These are classified into asymmetric, composite, and battery types, as shown in Figure 4. The asymmetric hybrid supercapacitors have two different electrodes, i.e., capacitive electrodes and Faradaic, and are designed to meet the power and energy density requirements at the same time. The negative electrode, which can be made of metal or metal oxide, is mostly utilized for carbonbased materials. For metal elements, strong volumetric potential is considered to increase the energy densities [82]. Relative to symmetrical supercapacitors, these capacitors have a higher energy density and are more stable when cycling. This is the situation with a nickel foam carbon and $\mathrm{MnO}_{2}$ electrode [83]. Capacitor self-discharge is a big problem with all capacitors. It can be solved by integrating the basic rocking chair mechanism into an asymmetric condenser. Here, the optimum capacity at zero current is assured [82]. It is observed 
that in the case of almost all electrolytes, the depletion of electrolytic ions as well as electrodes results in the reduction in conductivity and, hence, an increase in internal resistance; however, this concern could be overcome by designing new electrolyte systems. Similarly, the enhancement of the working voltage of supercapacitors is another problem in research; if the carbon-based negative electrode is successfully $p$-doped, the voltage along with the rocking mechanism can be enhanced. The microporous carbon structure is also important for such improvements; these changes can lead to an increase in the capacitance of the material due to the convenient ionic mobility [82]. The composite-based hybrid super-capacitors (CHSs) are another type of hybrid supercapacitor based on composite materials because of their peculiar performance, cycling stability, and good conductance results. Supercapacitors with carbon-based capacitors have a large surface area, as shown above in EDLCs, no Joule heating, low resistance, and high mechanical power, although the density of carbon itself is low compared to the industrial batteries comprising plum acid and lithium-ion. Metal oxides such as $\mathrm{RuO}_{2}$ have poor conductivity and are under pressure, exhibit Joule heating and have a low surface area and structure. Nevertheless, in storing charge and energy, they are efficient. The composite supercapacitors have cycling stability, specific capacity, and high conductivity, possessing the characteristics of both carbon and metal oxides. Carbon acts as a charging line, while metal oxides are stored through redox processes, resulting in a high specific capacity and energy density. The conductivity of the composite, despite being extremely adaptable, relies on whether the carbon structure is microporous, mesoporous, or microporous [84]. This means that the diameter of a pore is necessary to consider when investigating whether the ions are to be adsorbed on the electrode surface or not, determining the charging/unloading EDLC function. If not, the conductivity will be insufficient. The composites are not without flaws; for example, the quality of the layer decreases as it thickens when vanadium oxide is generated on carbon nanofibers (18 $\mathrm{nm}$ ) [85]. Due to a compromise between the redox site and composite conductivity itself, this has evolved. Another barrier arises as the successful diffusion of ion dissipates as a result of projections of nanowhiskers on carbon nanofibers, while the metal oxide surface area increases [86]. This illustrates that the elements, their combinations, and the electrolyte employed in composite goods outside the scope of this study have a substantial impact on the disadvantages and benefits of the composite products.

The last type of hybrid supercapacitor is the rechargeable-type battery, which struggles to break through the midway diagonal of the Ragone plot, which governs promising features such as higher specific capacitance energy density and power density that still need to be achieved in comparison to the current supercapacitors. Surface modification, comprehensive nanocomposite material creation, and microstructure optimization are just a few covered topics. Introducing electroactive nanoparticles generates faster reactions with the electrolyte, and redox with electroactive nanoparticles should also result in quicker reactions. However, there is a risk of misleading electrolyte responses. Nanocomposite materials with certain metal oxides are designed to solve a variety of problems. $\mathrm{LiMnPO}_{4}$ has a higher potential than $\mathrm{LiFePO}_{4}$ and is more difficult to coat with carbon. The goal was accomplished; however, a broad strategic regulatory approach led to a multi-layered carbon structure, which sat on Fe and Mn. According to the research, the Mn metal oxide with electrolytes performed better than predicted at higher grades without direct exposure [87]. Electroactive species are valued for their ability to speed up electrode responses. On the electrode surface, one important strategy is to make granules in disproportionate fractions. Thus "fractal granularities" cause greater surface exposure at the electrolyte-electrode interface, thereby increasing the overall energy provided by the capacitor. The use of the double-layer principle for this type of supercapacitor is another important enhancement. It produces the Helmholtz double layer where the charge is deposited at the carbon electrodeelectrolyte interface. This happens due to the possible repulsion of similarly charged ions at the electrode-electrolyte interface and counter-ion attraction, which may lead to the charge-storage mechanism through the physical accumulation concept of the polar ions. 


\section{Components of Supercapacitor}

The main components of a supercapacitor are the electrode, the electrolyte, the separator, and the collector. The first one is the electrode, which serves as a storage site for energy. At the electrode-electrolyte interface, the ions interact with the electrode material and are stored in the active sites of the electrode. The three most important features of the electrode are the porosity, area, and conductivity. Such electrode settings highly influence the energy density. Optimizing these parameters will result in a high-performance supercapacitor that might be employed in contemporary electronics items such as laptops and cell phone devices to store data. It is observed that the quantity of energy stored in a supercapacitor electrode is generally related to the surface area of the electrode. Consequently, substantial research is underway across the globe to find large-surface-area materials for use in energy storage devices. By producing a Helmholtz double layer, the number of ions stored at the electrode increases with surface area, hence resulting in a higher energy density. Activated carbon is a useful electrode material, since it exhibits acceptable capacitance in both aqueous and organic electrolytes [88]. Additionally, high conductivity, high surface area (1 to $3000 \mathrm{~m}^{2}$ /gram), high-temperature stability, strong corrosion resistance, regulated pore structure, compatibility for composite production, and a relatively low cost are the main characteristics of carbon-based electrodes that make them suitable for energy storage applications [28]. Specific capacities grow in proportion to the surface area. A larger area does not necessarily involve high specific capacities; they are mostly based on the surface and pores accessible to the electrode material. The CNT bundles acquire high porosity because of the mesoporous network generated by their tangling; CNT bundles acquire high porosity. This attractive mesoporous network improves ion penetration while expanding the electrode's accessible surface area [12,28]. A greater pore density on the electrode has a detrimental influence on the system. This results in a greater resistance on the electrode, leading to undesired variation in pore size. The irreversible capacity of redox processes depends on the pores' size, and this parameter is controlled by ion intercalation. In addition, a consideration of the creation of breakdown products is included, which is necessary for creating the solid electrolyte interphase (SEI), which is crucial for supercapacitor aging [89]. Pore sizes of $2-5 \mathrm{~nm}$ are recommended for the best performance, depending on the size of the solvated ions [90]. The porosity of a material is determined by passing nitrogen gas through it at $77^{\circ} \mathrm{C}$. The pore radius $(b)$ and the distance at which ions reach the carbon material $(d)$ also affect the capacitance of a supercapacitor.

$$
C / A=\frac{\varepsilon_{r} \varepsilon_{o}}{b X \ln \left(\frac{b}{b-d}\right)}
$$

The conductivity of a supercapacitor electrode is another important parameter that mostly affects power density. The impedance of the electrode material adds up to ESR [91], which restricts the amount of power the supercapacitor device can store. Carbon nanotubes have greater conductivity than other forms of activated carbon in carbon-based materials, which is a large contributor to their high power density. Carbon nanotubes exhibit differing conductivity depending on the chiral angle, with armchair carbon nanotubes being metallic and zigzag and chiral carbon nanotubes being semi-conductive. Hereafter, armchair CNTs are recommended for supercapacitor systems [92,93]. Because of its usual features [94] that make it excellent for energy storage, CNTs are commonly utilized as an electrode material. The wide popularity of CNT-based electrodes is attributed to a variety of ways of improving CNTs' characteristics. Functionalization includes amplifying carbon nanotubes, introducing defects into CNTs, and utilizing CNTs with oxides to create composite electrode materials. Functional groups are bonded to carbon nanotubes and may participate in redox processes, resulting in pseudo-capacitance. Carbon nanotubes have functional groups linked to them that can engage in redox processes, resulting in pseudo-capacitance. The value of specific capacitance is greatly improved when carbon nanotubes are treated with a powerful oxidizing agent, such as nitric acid. This must be done by treating CNTs with 
strong nitric acid (6M) at $800{ }^{\circ} \mathrm{C}$ for one hour and then getting rid of the metal catalyst. After that, the functional group must be oxygenated. The porosity of multiwall carbon nanotubes (MWCNTs) is increased by treatment with $\mathrm{KOH}$ [95], and their capacitance is increased 3.2 times by the addition of a carboxyl group [95]. This is attributed to an increase in hydrophobicity in an MWCNT-based electrode in an aqueous electrolyte and the presence of a carboxyl group, which is owing to an increase in hydrophobicity in an MWCNTs-based electrode in an aqueous electrolyte [94]. In aqueous electrolyte settings, such as 0.1 molar $\mathrm{H}_{2} \mathrm{SO}_{4}$, adding a carboxylic group to CNTs has been found to boost electrochemical performance [94]. The roughness and flaws are beneficial in energy storage for EDLC, and growing this kind of carbon nanotube is known to boost charge storage capacity. It has been shown that a combination of acid treatment $\left(\mathrm{H}_{2} \mathrm{SO}_{4}, \mathrm{HNO}_{3}\right)$ and short-term ball milling may help to minimize CNT flaws, which are shown to decrease irreversible capacity and enhance cycle life owing to structural and orientation changes [89]. The nanotubes on the carbon fiber surface have defects that make it difficult for ions to get in. As a result, the open central channel in the carbon nanotube is accessible. To approximate the total concentration of solvated ions, the inner and outer diameters of the central channel should be around two to three times the solvated ion's diameter. The central channel of the CNT has a limited ion storage capacity. In order to produce a hybrid electrode that makes the use of both EDLC, and pseudo-capacitance, CNTs and oxide composites will be used. As a result, the mesoporous network of a CNT makes it easier for ions to move onto the active surface, and the oxide composites create a kind of pseudo-capacitance [10]. The overall capacitance/performance of the hybrid electrode material could be enhanced mutually by the pseudo-capacitor and the relative contribution of EDLC, and thereby result in the creation of greater power and higher energy density. Oxide composites include ruthenium oxide and CNTs composites, $\mathrm{Ni}(\mathrm{OH})_{2}$ and CNT composites, $\mathrm{Co}_{3} \mathrm{O}_{4}$ and CNT composites, polymer-CNT hybrid composites, and DNA and CNT composites [88,93].

The second component is the electrolyte $[34,55,58]$, a conduction source which can be found in every device [96-98]. In a typical capacitor, a dielectric is present. The electrolyte is also used for ion conduction or mobility in supercapacitors. When selecting an electrolyte, the size and type of ions, concentration, electrode materials, and ion-solvent interaction are all important elements to consider. Electrolytes can alter cycle life, capacitance, and energy or power density [99]. The kind of electrolyte has an impact on supercapacitor performance [100]. The electrolyte concentration in organic electrolytes should be sufficient to minimize depletion issues at some point [101]. The total performance of the supercapacitor may be inadequate if the electrolyte reservoir is small compared to the electrode surface area. In electrolytes, the coefficient of temperature and conductivity are crucial elements that determine the supercapacitor's equivalent series resistance (ESR). Non-aqueous electrolytes have a higher value than aqueous electrolytes in terms of potential thermodynamic stability [102]. Even though aqueous electrolytes can deliver high capacitance and conductivity values, their working voltage is limited due to their decomposition voltage. It is crucial that the ions in the electrolyte are the same size as or smaller than the electrode material's pore size. If the electrolyte is $\mathrm{NaOH}$ and the material is carbon, the pore size of the carbon should be bigger than the electrolyte ion present, resulting in high capacitance and power density. In some cases, however, freezing temperatures and electrolyte viscosity can compromise the supercapacitor's thermal stability $[103,104]$. There is no single electrolyte that can meet all of the requirements. Aqueous electrolytes, for example, can have high capacitance and ionic conductivity but a lower operating voltage due to their lower breakdown voltage. Even though ionic liquid and organic electrolytes have a high operating voltage, they usually have high internal resistance. As a result, aqueous electrolytes have a very small voltage window, as low as $1.2 \mathrm{~V}$, far lower than that of organic electrolytes [15]. Aqueous and organic electrolytes are the two main types of electrolytes used in supercapacitors. Aqueous electrolytes have a lower mobile voltage than organic electrolytes. Organic electrolytes have a greater resistance than aqueous electrolytes; hence, their power capacity is significantly lower. The aqueous electrolyte has a larger capacitance than the organic electrolyte due 
to its strong conductivity and small radius between ions. To keep moisture out of composite cleaning activities, ionic solutions and organic electrolytes are commonly utilized in a regulated atmosphere. The model is completely described by all of these aqueous electrolyte properties. The high conductivity of the aqueous electrolyte is suitable for lowering the equivalent series resistance (ESR), resulting in supercapacitors with excellent power density. $\mathrm{KOH}$, sulfuric acid, and phosphoric acid are the most commonly used aqueous electrolytes [105]. In organic electrolytes, acetonitrile (ACN) and propylene carbonate are two common solvents. Acetonitrile can liquefy a lot of salts, but it is toxic [106], whereas propylene carbonate-based electrolytes have very large voltage, temperature, and relatively appropriate conductivity [101]. Although acetonitrile has environmental and hazardous issues, it can dissolve more salt than other solvents. Propylene carbonate electrolytes are safe for the environment and feature a wide electrochemical window, a wide operating temperature range, and a high conductivity. Salts with fewer symmetric structures have a higher solubility and crystal-lattice energy. It is important to note that the water content of organic electrolytes should be kept below 3-5 ppm. Otherwise, the electrochemical supercapacitor's voltage will be drastically reduced. As opposed to aqueous electrolytes, organic electrolytes generate a wider voltage window. The three types of aqueous electrolytes are alkaline, acidic, and neutral electrolytes [105]. For the acid electrolyte, various types of acids are employed, mostly sulfuric acid. The concentration is affected by their conductivity (or mobility). The ionic conductivity results in reduction by enhancing or decreasing the concentration of an electrolyte. The energy density of EDLCs is considerably reduced due to the narrow potential window of aqueous electrolytes. A hybrid supercapacitor can increase the energy density of supercapacitors in aqueous electrolytes. In an aqueous electrolyte, combining two different electrodes in varied working potentials may increase the potential functional window [105]. Another type of aqueous electolyte is the alkaline electrolyte, which is more prominent because acids are not adequate for all metal complexes. The most aqueous alkaline is $\mathrm{KOH}$, which has a higher ionic conductivity. The energy density of EDLC-based supercapacitors in aqueous $\mathrm{KOH}$ is comparable to sulfuric acid electrolytes. As a result, researchers have attempted to increase capacitance and operating voltage to increase the EDLC material energy density in the alkaline electrolyte. The last type is the neutral electrolyte, which has a high operating potential and deficiency of corrosive properties. $\mathrm{LiCl}, \mathrm{NaCl}, \mathrm{KCl}, \mathrm{Na}_{2} \mathrm{SO}_{4}$, and $\mathrm{K}_{2} \mathrm{SO}_{4}$ have all been used as neutral electrolytes in supercapacitors. The most common neutral electrolyte utilized in electrochemical reactions is sodium sulfate, while $\mathrm{MnO}_{2}$ is the most common pseudo-capacitive material and it has been extensively studied in neutral electrolytes. Asymmetric supercapacitor devices also use neutral electrolytes, which give a larger potential window for reaching high energy density. Neutral electrolytes have also been used in asymmetric supercapacitor devices, which provided a greater potential window for achieving high energy density. Furthermore, neutral aqueous electrolytes offer a low-cost, environmentally friendly solution to overcome the challenges of electrochemical supercapacitor corrosion and enhance the performance of electrochemical supercapacitors with higher operating voltage and energy density; however, challenges remain in achieving better cycle stability [105,107].

The third component of the supercapacitor is the separator, which acts as an iontransporting permeable membrane inserted between the two electrodes [108]. A good selection of separators is essential for proper supercapacitor operation to provide appropriate energy density, power density, self-discharge, and cycle life. A good separator must have enough resistance, ionic flow permeability, appropriate thickness and porosity, proper interfacial contact, low cost [109], chemical stability, and electrolyte retention ability. The thickness of the separator is taken into consideration when determining its presentation. The ideal thickness for a separator formed of bacterial cellulose is 1-100 micrometers [108], and for other separators, such as polyester, polycarbonate, and nylon, it is 20-350 micrometers [110]. The use of a 100-3000-micrometer-thick separator made of normal writing paper was reported in the literature. The supercapacitor has less mechanical strength and is easily torn out if the thickness is less than 1-10 micrometers; if the thickness is greater, it has a 
lower capacitance due to the increased distance between the electrodes, as well as a lower power density due to the increased ESR. A separator with a high pore density is required to contain the electrolyte and allow for easy ion movement across it. Porosity can be assessed using the ASTM D-2873 gas and liquid absorption method, and the pores of the separator can be analytically analyzed via the SEM. To prevent short circuiting, the separator's pore size must be less than the electrode material's size and higher than the electrolyte's ionic radius for correct ion passage between the electrodes. Ion-exchange membranes (IEMs) can also be used as separators in supercapacitors, which can block the migration of the active electrolyte. However, IEM-based separators are expensive, increasing the cost of SCs and ultimately limiting their practical applications [111].

The fourth and the last component is the current collector, which connects the electron flow from the active electrode material to the external circuit. It must have good conductivity for electron paths, adhesive contact with the electrode material, enough stability during the charging/discharging process, and good corrosion resistance behavior for a high-performance supercapacitor system [112]. Due to their strong conductive characteristics, several metallic foils, such as nickel, aluminum, and copper, with thicknesses varying from 20 to 80 micrometers [113], are used as current collectors in supercapacitors and batteries. On the other hand, silver and gold have strong metallic conductivity, and due to cost restrictions, they are usually used for current collectors. Corrosion and poor performance are the main disadvantages of employing metallic foil as a collection plate. When the collector plate comes into contact with the electrolyte, it dissolves electrochemically and corrodes, causing improper contact with the electrode material, which results in poor performance and cycle life [114]. Contaminants, the electrolyte's sensitivity toward the collector plate, and the production of gases such as oxygen, all contribute to electrode corrosion, which causes corrosion during charging at a high voltage. A conductive layer should be put between the collector plate and the electrode material to prevent corrosion. A conductive layer of zirconium nitride or titanium nitride can be placed on the collector plate, or a separate polymer layer can be placed within collector-electrode gaps. According to studies, the optimal resistance for a conductive layer is less than $100 \mathrm{ohm}$ per $\mathrm{cm}$. Polypropylene sheets containing 50\% fine carbon particles by volume increased stability, conductivity, and wear resistance [115]. Improper contact lowers the power density by increasing interface resistance; this can be avoided by acid treating the collector plate with $\mathrm{H}_{2} \mathrm{SO}_{4}$ and $\mathrm{HNO}_{3}$ to remove impurities, oxides, and imperfections. Figure 5 describes different electrode material synthesis methods for SCs.

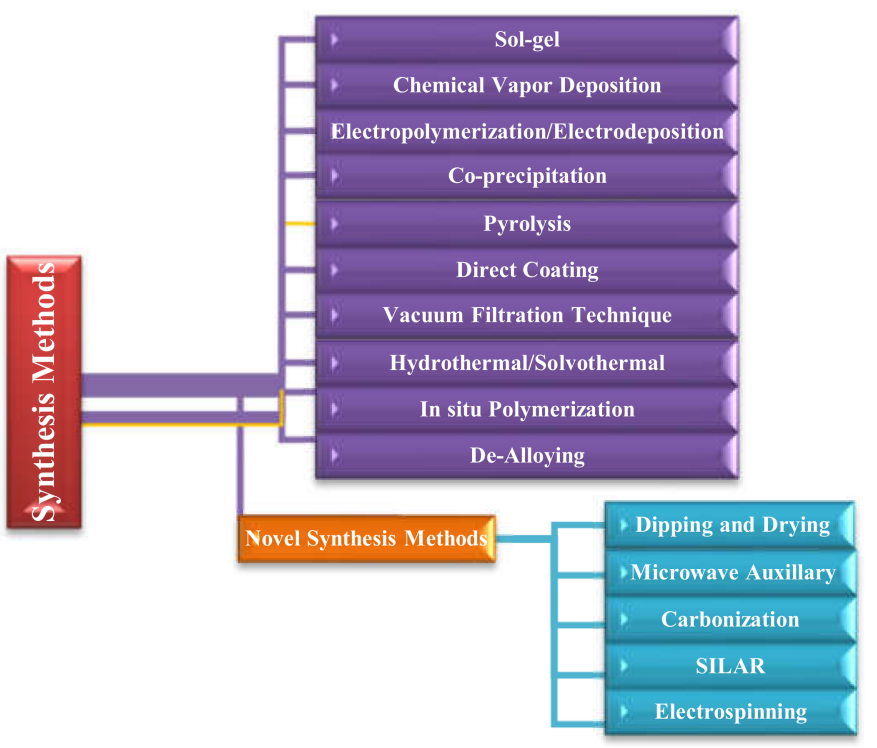

Figure 5. Different electrode material synthesis methods for SCs. 


\section{Synthesis Methods of Electrode Materials for Supercapacitors}

The various methods used for the synthesis of supercapacitors electrode materials are summarized in this section. These methods include sol-gel [116], hydrothermal [117], coprecipitation [118], dip-coating, chemical vapor deposition [119], electro polymerization or electrodeposition [120], vacuum filtration [121], in situ polymerization [122], dealloying [123], dipping and drying [124], microwave auxiliary [125], carbonization [126], SILAR [127], and electrospinning [128].

\subsection{Sol-Gel Method}

Zhang Yong et al. [116] reported the preparation of $\mathrm{NiCo}_{2} \mathrm{O}_{4}$ with a diameter in the range of $20-30 \mathrm{~nm}$ through the sol-gel method using the $\mathrm{Ni}\left(\mathrm{NO}_{3}\right)_{2} \cdot 6 \mathrm{H}_{2} \mathrm{O}$ and $\mathrm{CoCl}_{2} \cdot 6 \mathrm{H}_{2} \mathrm{O}$ as precursors, and utilized as electrode material in supercapacitors. They performed various characterizations such as SEM, TEM, XRD, RS, CV, and GCD tests in a $3 \mathrm{M} \mathrm{KOH}$ aqueous solution. They confirmed that the material exhibited excellent performance, high stability, high specific capacitance characteristics. Similarly, $\mathrm{NiO} / \mathrm{NiCo}_{2} \mathrm{O}_{4} / \mathrm{Co}_{3} \mathrm{O}_{4}$ [129], $\mathrm{NiCo}_{2} \mathrm{O}_{4}$ [116], $\left(\mathrm{Ni}-\mathrm{MnO}_{2}\right)$ [130], $\mathrm{NiO}-\mathrm{CeO}_{2}$ [131], $\mathrm{Co}_{3} \mathrm{O}_{4}$ [132], $\mathrm{MnO}_{2}$ [133], mixed ternary transition metal ferrite (MTTMF) [134] etc., were also prepared using the sol-gel method. Figure 6 indicates the sol-gel process for the synthesis of supercapacitor electrode materials.

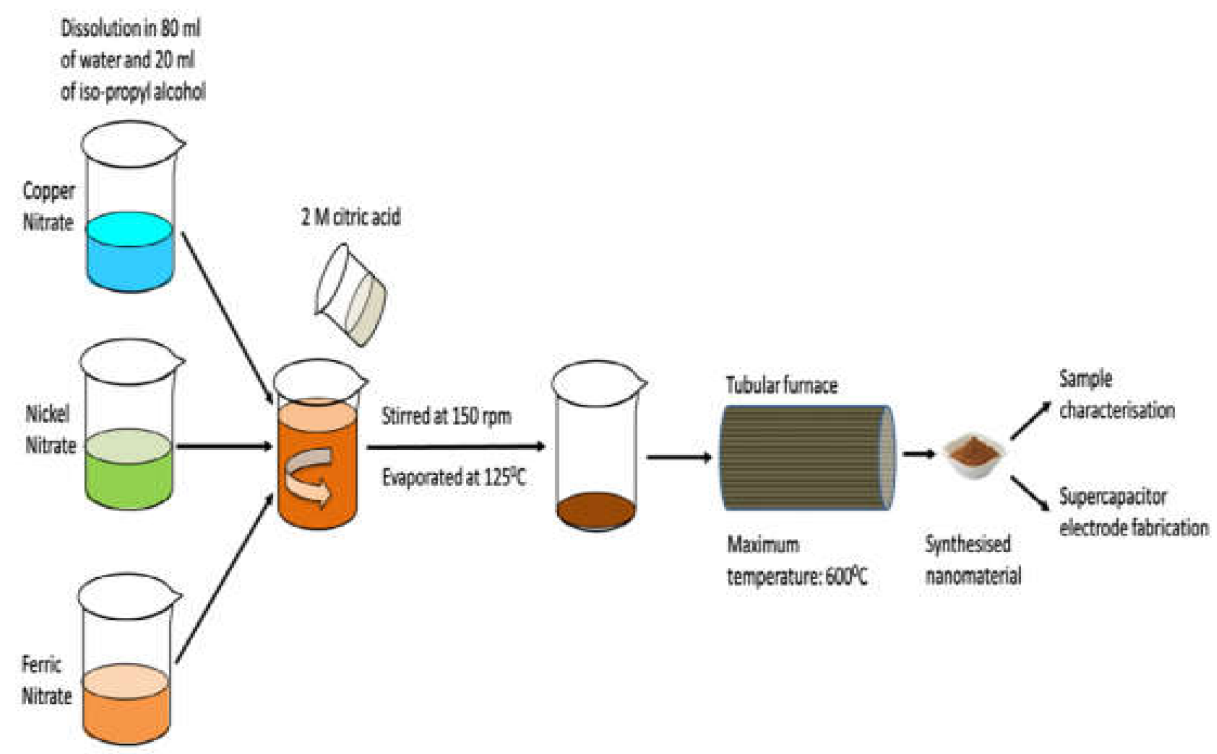

Figure 6. Sol-gel process for the preparation of (MTTMF) as electrode materials for supercapacitors. Reproduced with permission from [134]. Elsevier, 2016.

\subsection{Hydrothermal Synthesis}

Chen Huiyu et al. [117] prepared $\mathrm{MgCo}_{2} \mathrm{O}_{4}$ nanoflakes $\left(\mathrm{MgCo}_{2} \mathrm{O}_{4} \mathrm{NFs}\right)$ and $\mathrm{MgCo}_{2} \mathrm{O}_{4}$ nanocubes $\left(\mathrm{MgCo}_{2} \mathrm{O}_{4} \mathrm{NCs}\right)$ via the hydrothermal process. They confirmed from experimental results that these materials are the best candidates as electrode materials for supercapacitors due to their high specific capacitance, and best electrochemical performance. Similarly, CoS/NF, CuS/NF, FeS/NF, and NiS/NF [135], $\mathrm{CoMoO}_{4}$ [136]. $\mathrm{NiMnO}_{3}$ [137], $\mathrm{Co@NiSe} 2$ [138], $\mathrm{C} @ \mathrm{Ni}_{0.9} \mathrm{Cu}_{0.1-\mathrm{S}}$ [139], $\alpha-\mathrm{MnO}_{2}, \beta-\mathrm{MnO}_{2}$ and $\mathrm{Mn}_{3} \mathrm{O}_{4}$ [140], $\mathrm{CuCo}_{2} \mathrm{~S}_{4}$ [141], $\mathrm{Ni}_{3} \mathrm{~S}_{2} / \mathrm{MoS}_{2}$ [142], Cu-MnS with PVP [143] etc., were also successfully synthesized for a supercapacitor as electrode materials by measn of the hydrothermal method. The developed hydrothermal process showed promising effects for the synthesis of $\mathrm{Cu}-\mathrm{MnS}$ with PVP nanocomposite for a high-performance supercapacitor. In Figure 7, we have shown the whole hydrothermal synthesis of $\mathrm{Cu}-\mathrm{MnS}$ with a PVP nanocomposite for a high-performance supercapacitor, in seven steps and Labelled as (a) to (f). 


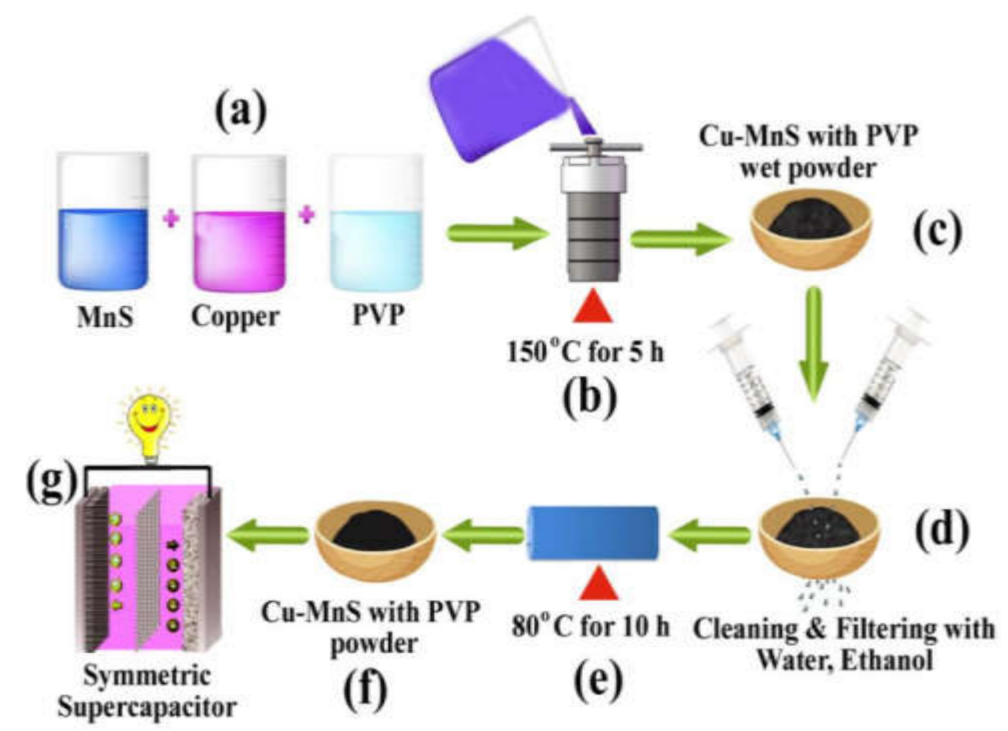

Figure 7. Hydrothermal synthesis process for Cu-MnS with a PVP nanocomposite for a highperformance supercapacitor. Reproduced with permission from [143]. Energies, 2018.

\subsection{Vacuum Filtration Process}

Xu Lanshu et al. [121] prepared a graphene/activated carbon/polypyrole (GN/AC/PPy) ternary composite material via the vacuum filtration method. It was confirmed through the results that the synthesized composite has a high specific capacitance of $178 \mathrm{~F} / \mathrm{g}$ at a current density of $0.5 \mathrm{~mA} \mathrm{~cm}{ }^{-2}$, which is 8.6 times greater than that of the pure GN $\left(104 \mathrm{mF} \mathrm{cm}^{-2}\right)$. It was found to be an excellent electrode material in energy storage devices. Additionally, RGO and $\mathrm{MnO}_{2}$ / RGO hydrogels [144], graphene-based nickel foam [145], graphene/activated carbon/polypyrrole (GN/AC/PPy) [121], GO/CNTs hybrid film [146], $\mathrm{rGO} / \mathrm{MWCNT}$ film [147] were reported. RGO synthesized via vacuum filtration was used as an electrode material for supercapacitors. Figure 8 summarizes the synthesis of RGO and $\mathrm{MnO}_{2} / \mathrm{RGO}$ for supercapacitors through the vacuum filtration method.

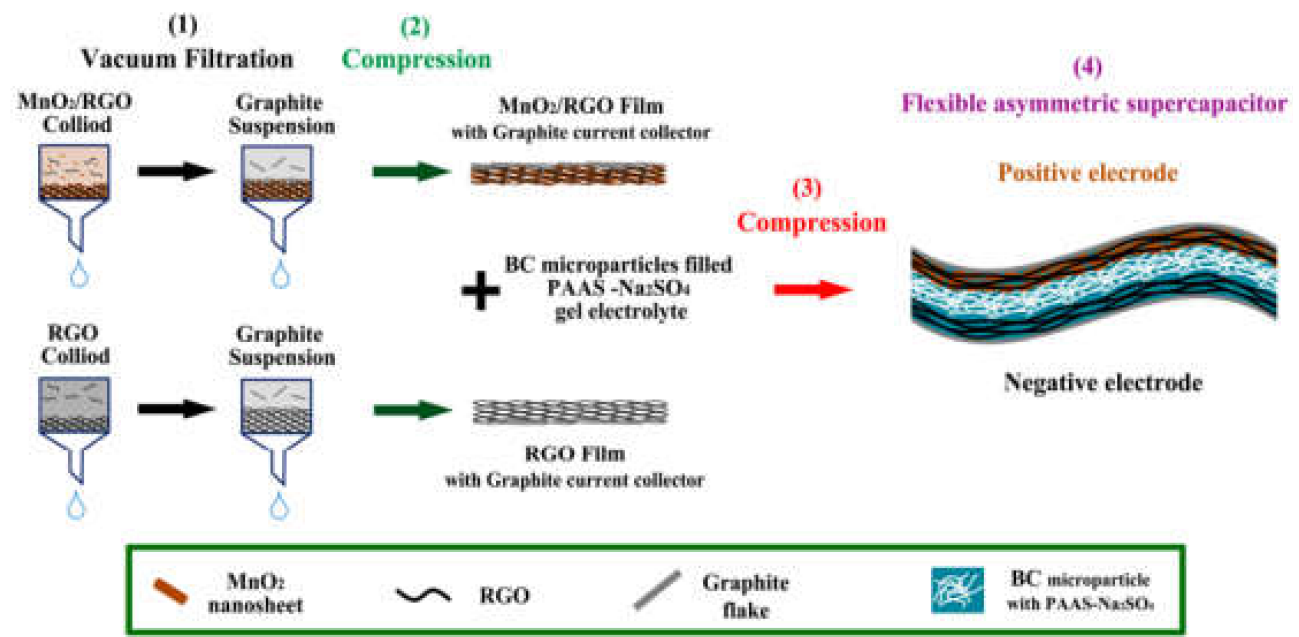

Figure 8. Synthesis of $\mathrm{RGO}$ and $\mathrm{MnO}_{2}$ / RGO for supercapacitors through the vacuum filtration method. Reproduced with permission from [144]. Materials, 2017.

\subsection{Synthesis by Electro-Polymerization (Electrodeposition)}

Imran Sohail et al. [120] prepared $\mathrm{NiO}$ film on an electrode-grade carbon plate through electrochemical deposition. In the first step, a $0.15 \mathrm{M} \mathrm{Ni}\left(\mathrm{NO}_{3}\right)_{2}$ hexahydrate aqueous electrolytes nickel oxide/hydroxide was deposited on the carbon substrate. The second step included the heat treatment of deposited film at $250{ }^{\circ} \mathrm{C}$, which entirely transformed 
any remaining hydroxides into nickel oxide. XRD confirmed the $\mathrm{NiO}$ in a thin film, while the EDS spectrum determined the NiO film's surface composition for quantitative analysis. The specific capacitance of $475 \mathrm{~F} / \mathrm{g}$ for as prepared and $800 \mathrm{~F} / \mathrm{g}$ for annealed $\mathrm{NiO}$ thin films was calculated by means of cyclic voltammeter at a scan rate of $30 \mathrm{mV} / \mathrm{s}$. The best cyclic stability and low-cost $\mathrm{NiO}$ modified carbon electrode is a good option as a positive electrode for supercapacitors. Similarly, PANI/ $\mathrm{Co}_{3} \mathrm{O}_{4}$ [148], $\mathrm{RuO}_{2} / \mathrm{CNT}$ [149], $\mathrm{PANI} / \mathrm{MnO}_{2}$ [150], a $\mathrm{Co}(\mathrm{OH})_{2}$ film [151] $\mathrm{MnO}_{2}$ [152], and a PTh/MWCNT composite [153] were also studied for supercapacitor applications.

\subsection{In Situ Polymerization}

Ran Fen et al. [122] reported the fabrication of a AuNP/PANI nanocomposite via the in situ polymerization technique using the $\mathrm{HAuCl}_{4}$ and $\mathrm{PA}$ as precursors and ammonium peroxydisulfate as the cooxidant. They concluded from their results that increasing the Au NPs contents could first increase and then decrease the specific capacitance of the composite, meaning that an optimum $\mathrm{Au} /$ polymer ratio should be used for composites with better capacitance. Furthermore, the asymmetric supercapacitor AuNP/PANI I I AC showed better results than the symmetric supercapacitor of AuNP/PANI | I AuNP/PANI. Finally, these materials were found to be promising for supercapacitors. Similarly, PANI/graphene [154], melamine foam/polypyrrole (MF/PPy) [155], Pani/TiO 2 /GN [156], NG-PAA/PANI [157], etc., were also investigated.

\subsection{Direct Coating}

Sudha Murali et al. [158] investigated the formation of $\mathrm{ZnO}$ nanostructures with the role of polyols such as ethylene glycol, diethylene glycol and polyethene glycols (PEG, $\mathrm{Mw}=400$ and 1000). The XRD and TG analysis was used for the confirmation of the $\mathrm{ZnO}$ phase and the coating with polyol. The FESEM image exposed the morphology of $\mathrm{ZnO}$ particles in different proportions, such as nanospheres, nano-assemblies, nanorods, and hexagonal. The cyclic voltammetry method was used to measure the specific capacitance of the nanomaterials in a three electrodes system with $1 \mathrm{M} \mathrm{KCl}$ solution as electrolyte. Hexagonally shaped rigid $\mathrm{ZnO}$ gives a better capacitance value of $6.42 \mathrm{~F} / \mathrm{g}$, followed by hexagonal cup-shaped $(6.4 \mathrm{~F} / \mathrm{g})$, nanoassembly $(5.75 \mathrm{~F} / \mathrm{g})$, nanorod $(4.03 \mathrm{~F} / \mathrm{g})$, and nanosphere $(3.67 \mathrm{~F} / \mathrm{g}) \mathrm{ZnO}$ at $10 \mathrm{mV} / \mathrm{s}$. Similarly, nickel telluride treated with selenide doping and poly(N-methylpyrrole) coating [159], N, P and S tri-doped hollow carbon nanocapsules [160], $\mathrm{Ag}_{2} \mathrm{~S}$ on Ni mesh [161], carbon nanotube@ $\mathrm{MnO}_{2} @$ polypyrrole composites [162], and nickel sulphide [163] were also prepared by means of the direct coating method for supercapacitor applications. MXene and $\varepsilon-\mathrm{MnO}_{2} / \mathrm{MXene}$ [164] were also investigated. Due to their unrivalled construction, hollow $\mathrm{CeO}_{2}$ graphene carbon-coated nanospheres have a high specific capacity, high energy/specific strength, high-rate capability, and long service life, as described in Figure 9. 


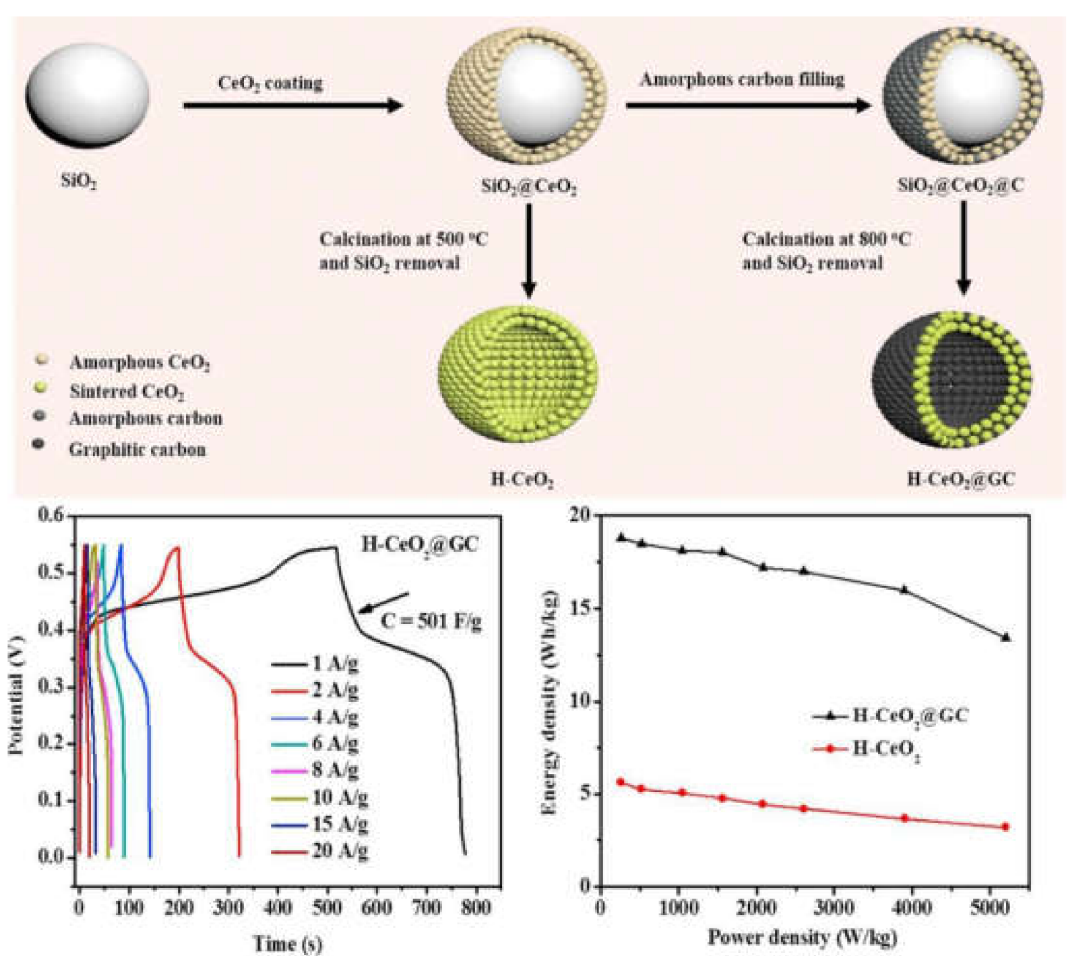

Figure 9. Due to their unrivalled construction, hollow $\mathrm{CeO}_{2}$ graphene carbon-coated nanospheres have a high specific capacity, high energy/specific strength, high-rate capability, and long service life. Reproduced with permission from with permission from [165]. Elsevier, 2020.

\subsection{Chemical Vapor Deposition (CVD)}

V. Thirumal et al. [119] used the thermal CVD method for the synthesis of pure CNTs and nitrogen-doped carbon nanotubes by using a Ni catalyst on the stainless-steel substracts. The SEM and TEM confirmed the coiled-shaped morphological structure. The XPS spectrum showed a nitrogen content of 0.86 at. $\%$, and the FTIR spectrum determined the nitrogen functional groups. The Raman spectrum was used to calculate the D-band and G-band intensity in N-DWCNTs, and a ID/IG ratio of 1.14 was calculated. Cyclic voltammeter was used for the electrochemical properties for pure and N-doped DWCNTs, and at different scan rates $(\mathrm{mV} / \mathrm{s})$, pseudocapacitance behaviour was observed for N-DWCNTs. Similarly, $\mathrm{PPy} / \mathrm{MnO}_{2}$ [166], $\mathrm{TiO}_{2}$ nanotubes/boron-doped diamond electrodes [167], CNTs on graphene [168], and NGF/CNT/ $\mathrm{MnO}_{2}$ [169] were also prepared as electrode materials for supercapacitors. Figure 10 describes the chemical vapor deposition process for the preparation of CNTs and nitrogen-doped carbon nanotubes for supercapacitors.

\subsection{Co-Precipitation Process}

P. M. Shaf et al. [118] fabricated $\alpha-\mathrm{MnO}_{2}$ via the coprecipitation method and employed for applications in supercapacitor electrodes. The XRD analysis confirmed the formation of hydrated amorphous $\mathrm{MnO}_{2}$. Nanosized particles provide a large surface area to increase electrochemical activities. The cyclic voltammetry was used to investigate electrochemical behaviour and material conductivity with charge-discharge techniques and an AC impedance analyzer. $\alpha-\mathrm{MnO}_{2}$ is excellent for supercapacitor electrodes based on its economic, natural abundance and environmentally friendly nature and outstanding capacitive properties. Similarly, pure $\mathrm{Cu}$ and $\mathrm{Zn}$-doped $\mathrm{CdO}$ nanoparticles [170], cobalt phosphate $\mathrm{Co}_{3}\left(\mathrm{PO}_{4}\right)_{2}$ and cobalt phosphate/graphene foam composites $\mathrm{Co}_{3}\left(\mathrm{PO}_{4}\right)_{2} / \mathrm{GF}$ [171], $\mathrm{CeMoO}_{4}$ nanostructure [172], $\left(\mathrm{Mn}_{2} \mathrm{O}_{3}-\mathrm{Mn}_{3} \mathrm{O}_{4}\right)$ nanoparticles [173], $\mathrm{PEG}-\mathrm{MnMoO}_{4}$ [174] were also prepared by means of the co-precipitation method for supercapacitor applications. 


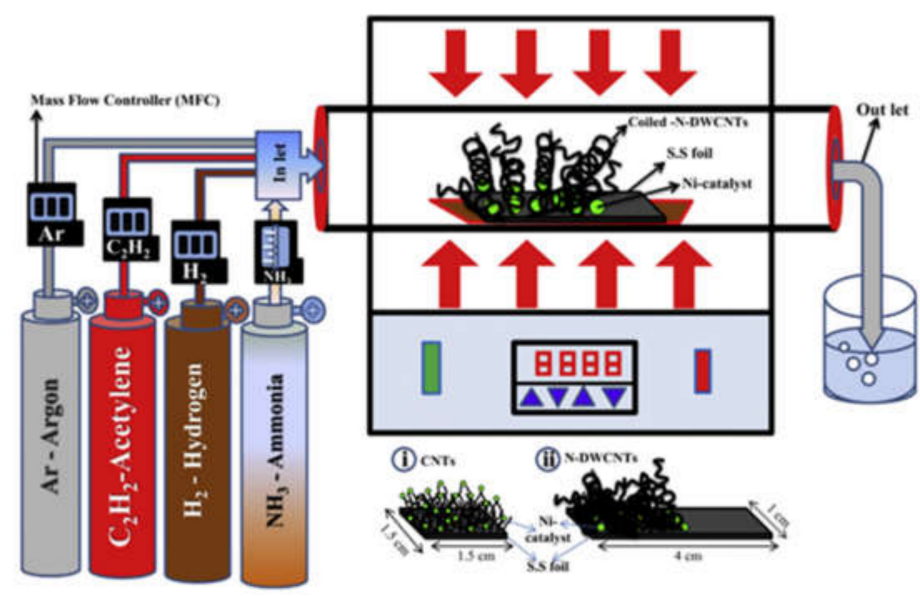

Figure 10. Chemical vapor deposition process for the preparation of CNTs and nitrogen-doped carbon nanotubes for supercapacitors. Reproduced with permission from [119]. Elsevier, 2016.

\subsection{Dealloying Method}

Chunling Qin et al. [123] synthesized CuO by one-step dealloying with spontaneous oxidation as a kind of transition metal oxide and an excellent supercapacitor electrode material. $\mathrm{CuO}$ was determined to be prepared by dealloying a brass foil at $40{ }^{\circ} \mathrm{C}$ in an oxygen-rich $10 \% \mathrm{HNO}_{3}$ solution for $20 \mathrm{~min}$. The electrode displays a superior specific capacitance value of $934.2 \mathrm{~F} / \mathrm{g}\left(308.6 \mathrm{mF} / \mathrm{cm}^{2}\right)$ with $87.8 \%$ capacitance retention at $2 \mathrm{~mA} / \mathrm{cm}^{2}$ and, after 5000 cycles, showed good cycling stability. The cost-effective and high electrochemical performance of the $\mathrm{CuO}$-brass foil electrode is highly favorable as a flexible electrode material in supercapacitors. Similarly, $\mathrm{NiS} / \mathrm{NiO}$ nanoparticles [175], $\mathrm{NiCo}_{2} \mathrm{~S}_{4}$ nanoparticles [176], $\mathrm{Ni}(\mathrm{OH})_{2}$ nanopetals [177], and $\mathrm{Cu}_{2} \mathrm{O}$ [178] were also prepared for supercapacitor applications.

\subsection{Pyrolysis}

Fangyan Liu et al. [179] synthesized nitrogen, oxygen and sulfur co-doped by means of the direct pyrolysis of kraft lignin. This method is highly simple, environmentally friendly, and low-cost. The carbon materials of kraft lignin have large specific surface areas of 338-1307 $\mathrm{m}^{2} \mathrm{~g}^{-1}$, and the synthesized symmetric supercapacitor possesses high specific capacitance of $244.5 \mathrm{~F} / \mathrm{g}$ at $0.2 \mathrm{~A} \mathrm{~g}^{-1}$, excellent rate capability of $81.8 \%$ at $40.0 \mathrm{~A} / \mathrm{g}$ and great cycling stability of $91.6 \%$ retention over 10,000 cycles. Similarly, $\mathrm{FeCl}_{3}$ preloaded with rice husk [180], nitrogen-doped biocarbon materials [181], in situ N-doped activated carbon materials derived from beanpulp [182], carbon nanofibers [7], and yolk-shell carbon spheres (YCS) [183] are also valuable.

\subsection{Electrospinning}

Muhamed et al. [128] reported the preparation of $\mathrm{MnO}_{2}$-coated $\mathrm{TiO}_{2}$ nanofibers through electrospining. They concluded that the composites exhibit high electrochemical stability and act as the best electrode material for supercapacitors, as indicated by their high operating voltage window $(2.2 \mathrm{~V})$ with gravimetric capacitance of $111.5 \mathrm{~F} / \mathrm{g}$. Additionally, $\mathrm{NiFe}_{2} \mathrm{O}_{4} @ \mathrm{CoFe}_{2} \mathrm{O}_{4}$ core-shell nanofibers [184], MnMoO4 nanotubes [185], PTA/PVA/GO [186], $\mathrm{TiO}_{2}$-carbon NFs [187], $\mathrm{MnO}_{2}$ / carbon nanofibers [188], $\mathrm{Ti}_{3} \mathrm{C}_{2}$ TxMXene/ PAN nanofibers [189], etc., were successfully synthesized and utilized as electrode materials in supercapacitors.

\subsection{Carbonization Method}

Hong Soonsang et al. [126] synthesized the hierarchical porous carbons (HPCs) by carbonization. The synthesized composite showed high specific capacitance, porosity and conductivity and found to be a promising electrode material for use in supercapacitors. Furthermore, porous carbon [190], bamboo fibers [191], Jatropha oil cake-based activated 
carbon [192], birnessite-type $\mathrm{MnO}_{2}$ /carbon [193], palm oil-based supercapacitor [194], $\mathrm{Co} / \mathrm{MnO} / \mathrm{CoMn}_{2} \mathrm{O}_{4} @ \mathrm{RHs}$ [195], polythiophene (PTh) nanofibers [196], hierarchical porous carbons (HPCs) [126], and porous carbons derived from laminaria japonica [190] were used as electrode materials in supercapacitors, which were synthesized through carbonization technique. Figure 11 represents a schematic illustration of the synthesis of porous carbons derived from Laminaria japonica.

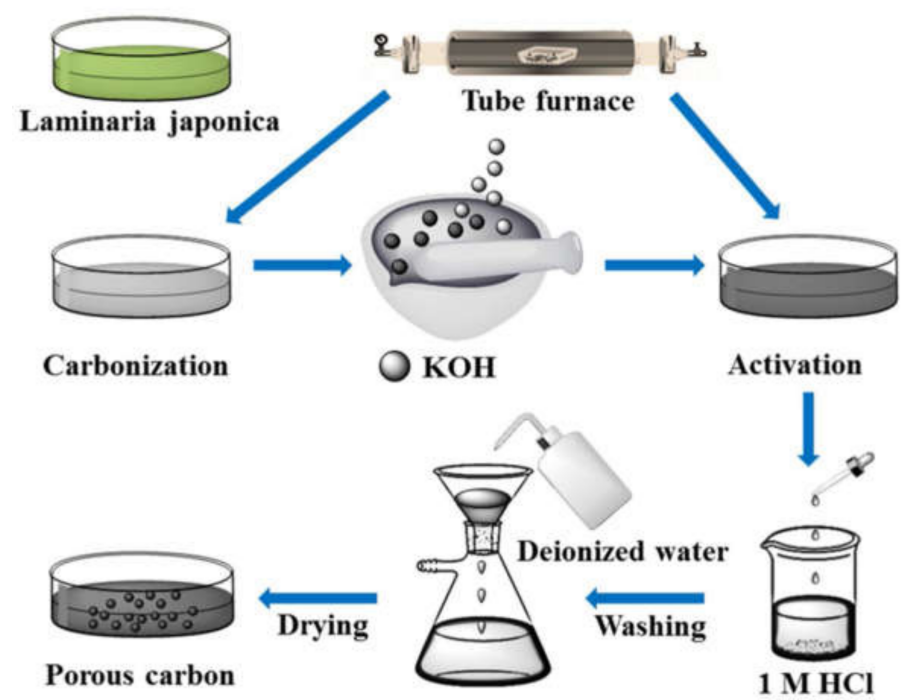

Figure 11. The schematic illustration for the synthesis of porous carbons derived from Laminaria japonica. Reproduced with permission from [190]. Elsevier, 2020.

\subsection{Successive Ionic Layer Adsorption and Reaction (SILAR)}

Ubale S. B. et al. [127] reported the fabrication of a ytterbium sulfide $\left(\mathrm{Yb}_{2} \mathrm{~S}_{3}\right)$ thin film via the SILAR method. They confirmed through various techniques that the prepared composite exhibits promising supercapacitor performance and can be used as an electrode material in supercapacitors. Some other examples such as ytterbium sulfide $\left(\mathrm{Yb}_{2} \mathrm{~S}_{3}\right)$ thin films [127], $\mathrm{La}_{2} \mathrm{Se}_{3}$ [197], $\mathrm{WO}_{3}$ thin films [198], polyaniline nanofibers [199], birnessite$\mathrm{MnO}_{2}$-based materials [200], Y-doped $\mathrm{Sr}(\mathrm{OH})_{2}$ [201], etc., were also synthesized for use as electrode materials in supercapacitors. The step-wise synthesis procedure of $\mathrm{La}_{2} \mathrm{Se}_{3}$ via the SILAR method and its FESEM image and CV curves are shown in Figure 12.

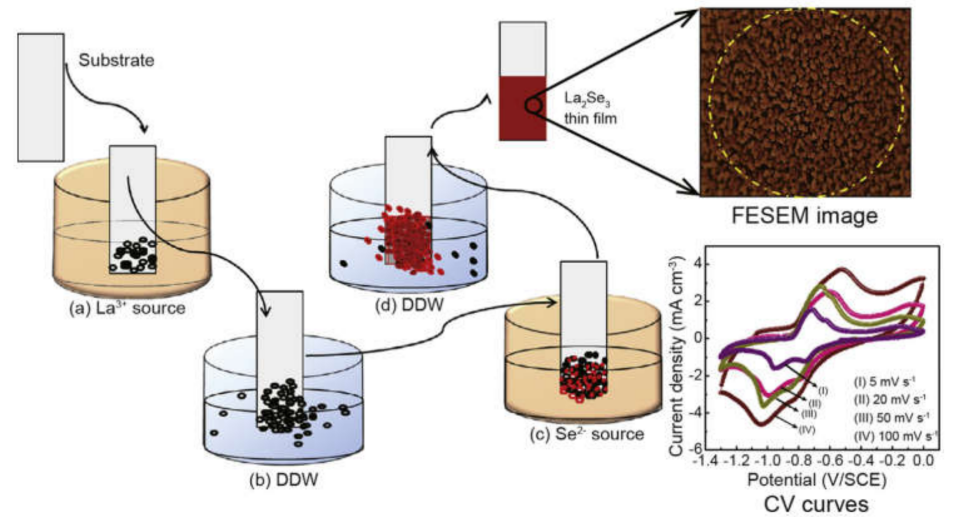

Figure 12. Stepwise synthesis procedure of $\mathrm{La}_{2} \mathrm{Se}_{3}$ via the SILAR method and its FESEM image and CV curves. Reproduced with permission from [197]. Elsevier, 2020.

\subsection{Microwave Auxiliary Method}

Van Hoa Nguyen et al. [125] used a one-step microwave-assisted method to synthesize a high-performance material electrode in ionic liquid. The $\mathrm{NiCo}_{2} \mathrm{O}_{4}$ nanosheets exhibited 
a high specific capacitance of $879 \mathrm{~F} / \mathrm{g}$ at $0.5 \mathrm{~A} \mathrm{~g}^{-1}$ and $343 \mathrm{~F} / \mathrm{g}$ at $20 \mathrm{~A} \mathrm{~g}^{-1}$ of current densities. After 1500 cycles, only a $4.7 \%$ decrease in capacitance was observed, confirming its excellent cycle stability. This simple, efficient, rapid and green route is an excellent experimental method for developing other materials for electrochemical capacitors. Similarly, flower-shaped $\mathrm{NiCo}_{2} \mathrm{O}_{4}$ microspheres [202], the graphene/PEDOT hybrid [203], zeolitic imidazolate frameworks (ZIF-8) [204], carbon-supported $\mathrm{MnO}_{2}$ nanocomposites [205], and $\mathrm{MoS}_{2} / \mathrm{MoO}_{2} @ \mathrm{CNT}$ nanocomposites [206] were also synthesized by means of the microwave-assisted method for supercapacitor applications. Figure 13 shows the schematic diagram of the preparation of the G/PEDOT hybrid through the microwave-assisted auxillary process for applications in supercapacitors.

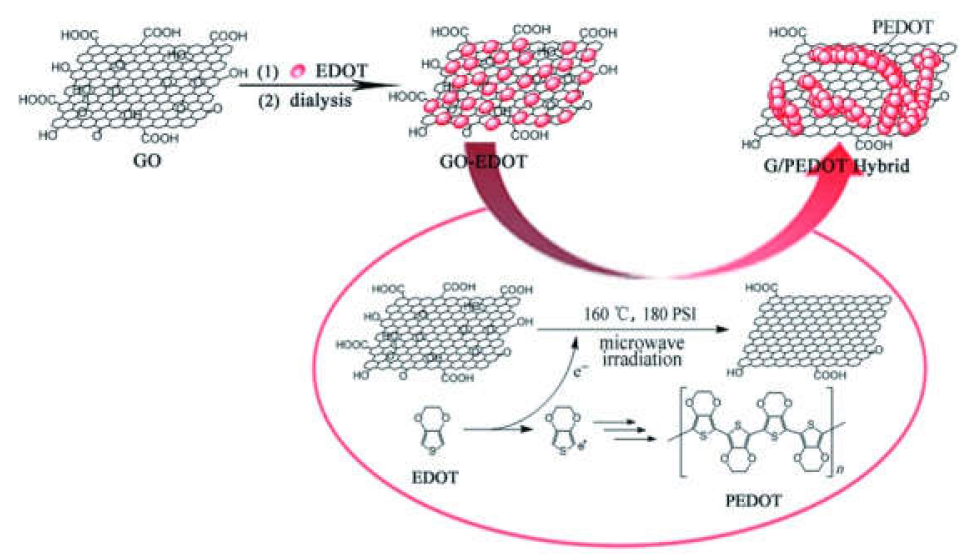

Figure 13. Schematic diagram of the preparation of the G/PEDOT hybrid through the microwaveassisted auxillary process for supercapacitor. Reproduced with permission from [203]. ChemPlusChem, 2013.

\subsection{Dipping and Drying Method}

A. J. Paleo et al. [124] synthesized flexible carbon composite electrodes by dip-coating carbon nanofibers (CNFs) with cotton fabric. In addition, layers of activated carbon and $\mathrm{MnO}_{2}$ materials were later added to increase the electrochemical activities of positive and negative electrodes. With the porous paper and Nafion membrane, these hybrid carbon-based textile SCs showed capacitance performance of 138 and $134 \mathrm{~F} / \mathrm{g}$, respectively, and low self-discharge rates. In short, the hybrid supercapacitor developed with lowcost materials and simple techniques reported in this study exhibited excellent results for flexible energy storage applications. Similarly, $\mathrm{MnO}_{2} /$ carbon nanotube/activated carbon [207], ultrafine $\mathrm{Fe}_{3} \mathrm{O}_{4}$ nanoparticles/graphene on carbon cloth [208], and $\mathrm{MoSe}_{2}$ on functionalized multiwalled carbon nanotubes [209] also exhibited high performance. Graphene fiber electrodes were also prepared for supercapacitor applications [210]. A schematic representation of the synthesis of AD:Ti@RGO via the drying and dipping method for applications in supercapacitors is shown in Figure 14, where AD stands for "alternately dipping".

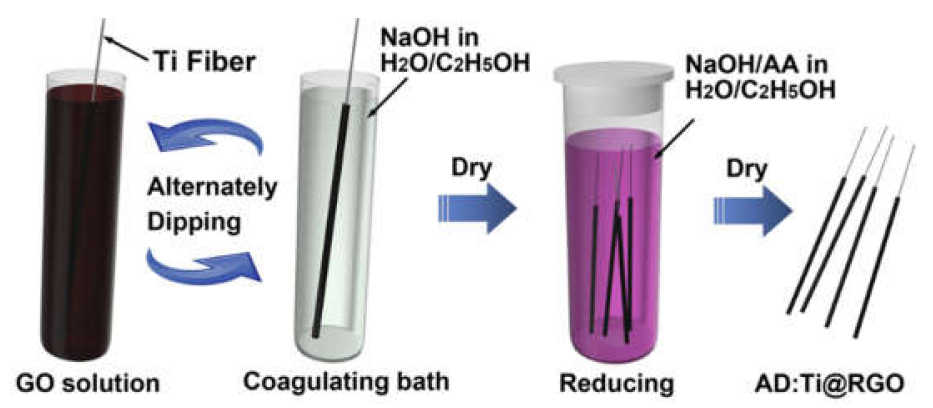

Figure 14. Schematic representation of the synthesis of AD:Ti@RGO via the drying and dipping method for applications in supercapacitors. Reproduced with permission from [210]. IScience, 2020. 


\section{Functionalization of Electrode Materials for SCs}

If the materials employed in a supercapacitor are functionalized with other materials such as metal oxides, composites, etc., this enhances its specific capacitance and will have an outstanding performance in comparison to the individual components as excellent electrode materials. Here, some functionalized materials such as metal oxides, non-metal oxides, and polymers are summarized as electrode materials in supercapacitors.

\subsection{Functionalization with Metal Oxides}

The quality of supercapacitor-based electrode materials can also be enhanced by their functionalization with various metal oxides, such as $\mathrm{MnO}_{2}, \mathrm{RuO}_{2}, \mathrm{Co}_{3} \mathrm{O}, \mathrm{Ni}(\mathrm{OH})_{2}$, $\mathrm{Co}(\mathrm{OH})_{2}, \mathrm{NiO}$, etc., and as compared to the unfunctionalized material, their capacitance value could be improved, which makes them the best candidates for utilization as electrode materials. Some of the functionalized nanocomposite materials synthesized by different researchers through various methods that showed higher electrochemical performances and specific capacitance are summarized here. These include $\mathrm{TiO}_{2}-\mathrm{SnO}_{2}$-doped $\mathrm{RuO}_{2}$, $\mathrm{RuO}_{2}$ / GC nanocomposites, $\mathrm{MnO}_{2} /$ nitrogen-doped, $\mathrm{MnO}_{2}$-nitrogen/graphene-doped, $\mathrm{Co}_{3} \mathrm{O}_{4} @ \mathrm{NiO}, \mathrm{Co}_{3} \mathrm{O}_{4} @ \mathrm{NiO}, \mathrm{Co}_{3} \mathrm{O}_{4} @ \mathrm{NiO}, \mathrm{ZnO} @ \mathrm{C} @ \mathrm{NiO}, \mathrm{Ni} / \mathrm{Ni}(\mathrm{OH})_{2}, \mathrm{NiMoO}_{4} / \mathrm{CC}$, 6amino-4-hydroxy-2-naphthalenesulfonic acid-modified reduced graphene oxide (ANSrGO), activated carbon-phosphotungstate (PW12) hybrid materials, rGO-PMo12 and rGO-PW12 hybrid electrodes, MWCNTs-POMs, Mn-MOFs, $\mathrm{Mn}_{2} \mathrm{O}_{3} / \mathrm{NiO}, \mathrm{MnO}_{2} @ \mathrm{NiO}$, $\mathrm{NiO} @ \mathrm{Co}_{3} \mathrm{O}_{4}, \mathrm{CuO} @ \mathrm{MnO}_{2}, \mathrm{ZnO} @ \mathrm{MnO}_{2}, \mathrm{NiCo}_{2} \mathrm{O}_{4} @ \mathrm{NiO}$, and $\mathrm{Li}_{4} \mathrm{Ti}_{5} \mathrm{O}_{12}-\mathrm{C}$, etc. For instance, Xiao et al. [211] modified the rice husk-based activated carbon (RHAC) with a high-performance hybrid supercapacitor of metal oxide nano-composite, which that revealed a high specific capacitance of $147 \mathrm{~F} / \mathrm{g}$ relative to the unmodified RHAC $(116 \mathrm{~F} / \mathrm{g})$ at a current density of $0.5 \mathrm{~A} \mathrm{~g}^{-1}$. Ni et al. [212] synthesized $\mathrm{Li}_{4} \mathrm{Ti}_{5} \mathrm{O}_{12}-\mathrm{C}$ composites by means of in situ and ex situ methods. The synthesized hybrid supercapacitor material showed excellent performance. Karuppaiah et al. [213] prepared the composite of $\mathrm{Mn}_{2} \mathrm{O}_{3} / \mathrm{NiO}$ via the solvothermal method. The synthesized composite revealed a larger specific capacitance of $566.21 \mathrm{~F} / \mathrm{g}$ at a current density of $0.5 \mathrm{~A} / \mathrm{g}$ and was found to be the best electrode supercapacitor. Jana et al. [214] prepared a 6-amino-4-hydroxy-2-naphthalenesulfonic acidmodified reduced graphene oxide (ANS-rGO) composite and examined its electrochemical performance via the cyclic voltammetry $(\mathrm{CV})$ and impedance spectroscopy. It was found that the prepared materials have shown high capacitance performance $(375 \mathrm{~F} / \mathrm{g}$ at a current density of $1.3 \mathrm{~A} \mathrm{~g}^{-1}$ ) and very good electrochemical cyclic stability (97.5\% retention in specific capacitance after 1000 charge-discharge cycles) and, hence, is considered to be one of the best electrode materials. Liu et al. [215] reported the fabrication of $\mathrm{NiO} / \mathrm{MnO}_{2}$ composite via the sol-gel process. They found that the as-synthesized composite exhibits higher electrochemical performance with specific capacitance greater than that of the single components of the composite. Wang et al. [216] reported the synthesis of $\mathrm{NiO}-\mathrm{Co}_{3} \mathrm{O}_{4}$ composites through the hydrothermal method. They concluded that the composites exhibit excellent electrochemical performance with specific capacitance values of $844,801,757$, 699,584 , and $483 \mathrm{~F} / \mathrm{g}$ at the current densities of $0.5,1,2,4,8,15 \mathrm{~A} / \mathrm{g}$, respectively. Zhang et al. [217] synthesized the $\mathrm{MnO}_{2} / \mathrm{CuO}$ nanocomposite via the hydrothermal method and examined it through cyclic voltammograms, galvanostatic charge/discharge analyses and electrochemical impedance spectroscopy. The nanocomposite showed a specific capacitance of $167.2 \mathrm{~F} / \mathrm{g}$ and excellent cycling stability which enabled it to be used as efficient electrode material in a supercapacitor. Xu et al. [218] reported the synthesis of $\mathrm{ZnO} @ \mathrm{MnO}_{2} / \mathrm{Ni}$ composites via the hydrothermal and electrodeposition processes. They stated that the synthesized composites exhibit high cyclic stability and specific capacitance of $586.8 \mathrm{~F} / \mathrm{g}$ at a current density of $2 \mathrm{~A} \mathrm{~g}^{-1}$, which is higher relative to the $\mathrm{MnO}_{2}$ and regarded as an excellent supercapacitor-based material. Ouyang et al. [219] prepared the composite of ZnO@C@NiO via the hydrothermal and chemical bath processes. They found that the composites exhibit higher cyclic stability and can be used as electrode materials for all-solid-state flexible supercapacitors. Ates et al. [220] reported the preparation of the 
$\mathrm{RuO}_{2} /$ fullerene and $\mathrm{RuO}_{2} / \mathrm{MWCNT}$ nanocomposites via the sol-gel method. The results clarify that the $\mathrm{RuO}_{2} / \mathrm{MWCNT}$ and $\mathrm{RuO}_{2}$ / fullerene nanocomposites exhibit excellent cycle stability $\sim 100 \%$ and specific capacitance at component ratios of $\left[\mathrm{RuO}_{2}\right] /[\mathrm{MWCNT}]=1: 1$; 2:1 and $\left[\mathrm{RuO}_{2}\right] /[$ Fullerene $]=2: 1$. The detailed characterization of the materials further confirmed their excellent supercapacitor-based applications. Li et al. [221] reported the synthesized $\mathrm{TiO}_{2}-\mathrm{SnO}_{2}$ doped $\mathrm{RuO}_{2}$ composite via wet ball milling and precipitation methods. The composite exhibited specific capacitance value of $571 \mathrm{~F} / \mathrm{g}$ and can be regarded as an excellent electrode material for use in supercapacitors. Yedluri et al. [222] fabricated the synthesized of $\mathrm{NF} / \mathrm{NiMoO}_{4} / \mathrm{NiMoO}_{4}$ composite through hydrothermal method. They stated that the synthesized composite exhibits high electrochemical performance with a specific capacitance of $2121 \mathrm{~F} / \mathrm{g}$, and was found to be a better electrode material compared to the NF/NiMoO 4 composite. Pang et al. [223] prepared a $\mathrm{ZnO}-\mathrm{NiO}$ composite via the mild chemical precipitation process. The as-synthesized composite showed outstanding results as an electrode material in supercapacitors. The $\mathrm{SnO}_{2} / \mathrm{Co}_{3} \mathrm{O}_{4} / \mathrm{rGO}$ composite prepared via the co-precipitation method showed a specific capacitance value of $317.2 \mathrm{~F} / \mathrm{g}$ at $1 \mathrm{~A} / \mathrm{g}$, and can be considered as a potential candidate for supercapacitor-based applications. Schematic representations of the synthesis of the (a) $\mathrm{RuO}_{2} / \mathrm{MWCNT}$ and (b) $\mathrm{RuO}_{2} /$ fullerene nanocomposites are given in Figure 15.

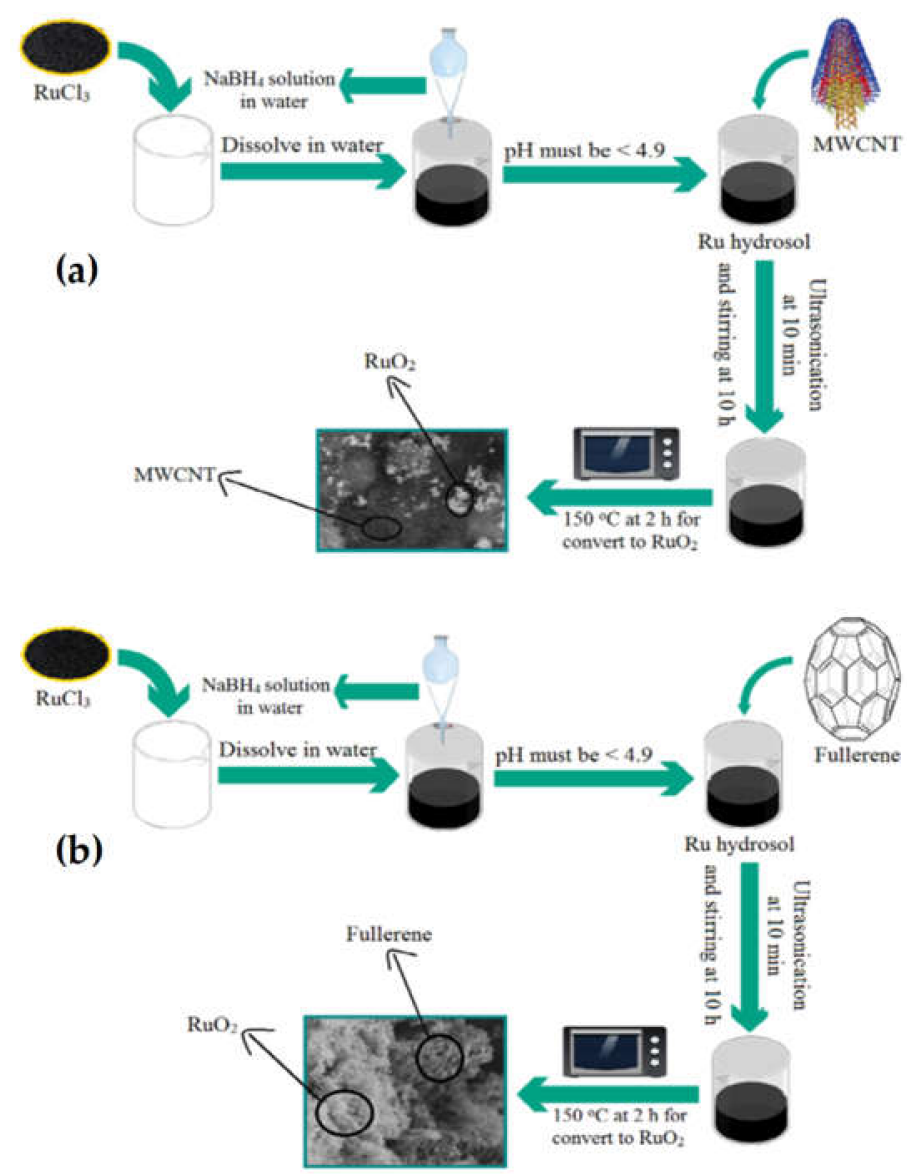

Figure 15. Schematic representation of the synthesis of the (a) $\mathrm{RuO}_{2} / \mathrm{MWCNT}$ and (b) $\mathrm{RuO}_{2} /$ fullerene nanocomposites. Reproduced with permission from [220]. Energy Storage, 2019.

\subsection{Functionalization with Polymers}

The polymer-based nanocomposite materials were also functionalized and were used as supercapacitor materials. A few of the polymer composites-based supercapacitor materials reported by various researchers include $\mathrm{NiMoO}_{4} / \mathrm{PANI} / \mathrm{CC}$, carbon/PDA/PMA, PMA modified pinecone biochar carbon, hybrid carbon-PMA. Ajami et al. [224] reported the synthesis of $\mathrm{MnO}_{2} /$ poly(o-aminophenol) composite via the pulse potential electrodeposi- 
tion method. They concluded that the as-synthesized poly(o-aminophenol) doped with $\mathrm{MnO}_{2}$ material exhibited outstanding cyclic recital, load discharge, and electrochemical characteristics. Furthermore, it was also shown that the capacitive property of $\mathrm{MnO}_{2-}$ poly(o-aminophenol) is higher relative to the poly(o-aminophenol), and the composite was used as a promising material in supercapacitors. Melo et al. [225] reported the preparation of the graphene/polythiophene (GR/PT) composite via the spray coating technique. The composite exhibited a higher specific capacitance of (365 F/g at $1 \mathrm{~A} \mathrm{~g}^{-1}$ ) relative to the single components and employed as electrode material in supercapacitors. Anjana et al. [226] prepared the composite polyoxomolybdate/polyindole $\left(\mathrm{PIn} / \mathrm{PV}_{2} \mathrm{Mo}_{10}\right)$ via the in situ oxidative polymerization process. The composite was found to have higher specific capacitance, faster charge/discharge rates, and greater cycle stability and was used as a promising electrode material in a supercapacitor. Narges [227] reported the fabrication of the PANOA/ $\mathrm{MnO}_{2} / \mathrm{MWCNT}$ composite via the electrochemical polymerization method, which revealed a specific capacitance of $560 \mathrm{~F} / \mathrm{g}$ at a scan rate of $25 \mathrm{mV} \mathrm{s}^{-1}$, and was regarded as an excellent electrode material to be used in supercapacitors. Zhang et al. [228] fabricated the composite of carbon-polydopamine (PDA)/phosphomolybdic acid (C-PDA/PMA) via the sol-gel method. The characterization results confirm that the composite possesses a high specific capacitance of $101 \mathrm{~F} / \mathrm{g}$ at $1 \mathrm{~A} / \mathrm{g}$ and cycling performance of $108 \%$ within 10,000 cycles. Hence, it can be used as an excellent electrode material for supercapacitors. Oliveira et al. [162] fabricated the composite of MWCNT@MnO $@ P P y$ through the in situ polymerization process. The results confirm that the composite possess a capacitance of $272.7 \mathrm{~F} / \mathrm{g}$ and a higher cyclic stability. Hence, the material can be used in supercapacitors. Su et al. [229] reported the synthesis of the PANI/ $\mathrm{TiO}_{2} / \mathrm{GO}$ composite via the in situ polymerization technique, which revealed a higher specific capacitance $\left(1020 \mathrm{~F} / \mathrm{g}\right.$ at $2 \mathrm{mV} / \mathrm{s}, 430 \mathrm{~F} / \mathrm{g}$ at $1 \mathrm{~A} \mathrm{~g}^{-1}$ ) and extended life cycle (over 1000 times), and can be used as electrode material in supercapacitors. Gao et al. [230] synthesized the composite of $\mathrm{NiMoO}_{4}$-PANI via the chemical polymerization method that revealed higher cyclic stability, best electrical conductivity, and specific electrical conductivity capacitance and is promising for use as an electrode material in supercapacitors relative to the constituent components. Ramesh et al. [231] synthesized the composite of $\mathrm{MnO}_{2} @ \mathrm{NGO} / \mathrm{PPy}$ via the hydrothermal method. They concluded that the synthesized composites exhibit a higher capacity of $480 \mathrm{~F} / \mathrm{g}$ relative to the composite of $\mathrm{MnO}_{2} @ \mathrm{NGO}$ (i.e., $360 \mathrm{~F} / \mathrm{g}$ ). They confirmed that the $\mathrm{MnO}_{2} @ \mathrm{NGO} / \mathrm{PPy}$ ternary polymer composite can be used as an excellent electrode material in supercapacitors. Feng et al. [232] reported the synthesis of ppy/npcM composite via the Hummer process, which revealed outstanding supercapacitance value relative to the constituent components, i.e., PPy and PPy/rGO. Thus, the material can be used as a promising electrode in supercapacitors. Wang et al. [233] reported the fabrication of the $\mathrm{CeO}_{2} / \mathrm{PPy}$ functionalized 3-triethoxysilylpropylamine (PABA) composite via the in situ chemical oxidative process. They concluded that the composite possesses higher electrochemical performance in comparison to the pure PPy. Furthermore, it was concluded that the $\mathrm{P}-\mathrm{CeO}_{2} / \mathrm{Ppy}$ composite exhibits higher specific capacitance relative to the $\mathrm{A}-\mathrm{CeO}_{2} /$ ppy composite. Hence, the $\mathrm{P}-\mathrm{CeO}_{2} / \mathrm{PPy}$ composite was regarded as an outstanding electrode material to be use in supercapacitors. Yu et al. [234] reported the synthesis of $\mathrm{PANi}^{-\mathrm{TiO}_{2}}$ composite via the electrochemical deposition and electrospinning processes and confirmed that the composite exhibits higher specific capacitance $(306.5 \mathrm{~F} / \mathrm{g})$ at the scan rate of $20 \mathrm{mV} / \mathrm{s}$. The material was regarded as an excellent candidate to be employed as an electrode material in a supercapacitor. At last, it can be stated in the light of various results with regard to the metal oxides, nonmetal oxides, and composites that the composites are excellent for use as electrode materials in supercapacitors relative to their single counterparts. Figure 16 represents the schematic of the synthesis and electrochemical system of the $\mathrm{NiMoO}_{4}$-PANI polymer nanocomposite, whereas Figure 17 shows the schematic representation of the synthesis of the $\mathrm{MnO}_{2} @ \mathrm{NGO} / \mathrm{PPy}$ polymer composite. 


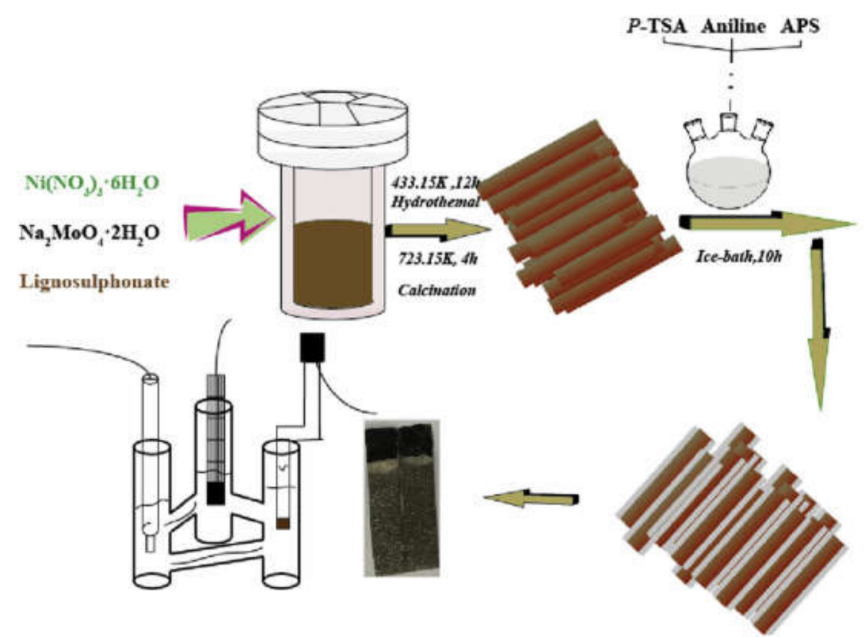

Figure 16. Schematic representation of the preparation and electrochemical system of the $\mathrm{NiMoO}_{4}{ }^{-}$ PANI polymer nanocomposite. Reproduced with permission from [230]. Elsevier, 2018.

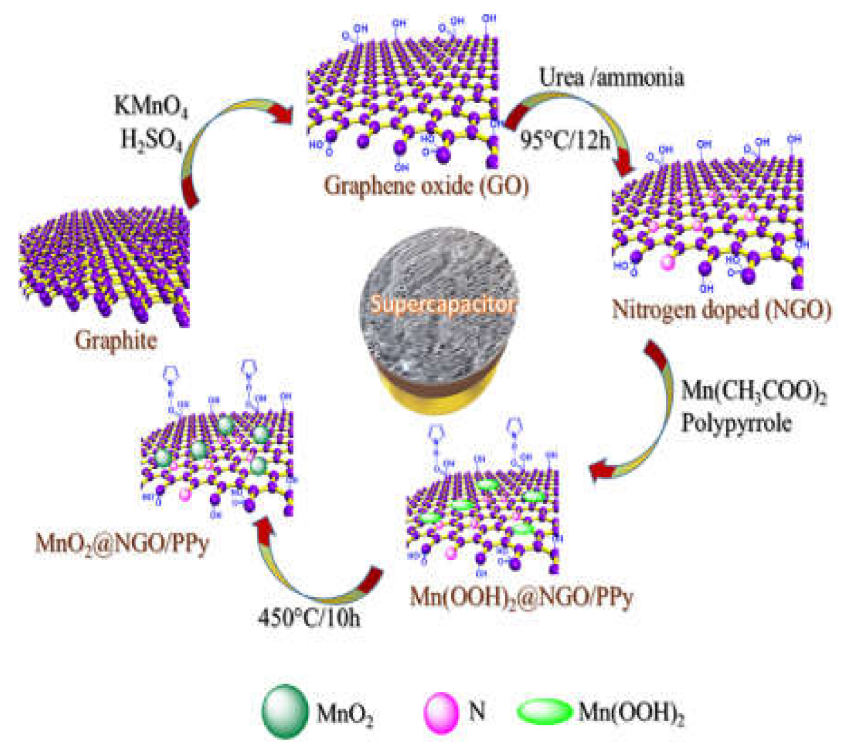

Figure 17. Schematic representation of the preparation of the $\mathrm{MnO}_{2} @ \mathrm{NGO} / \mathrm{PPy}$ polymercomposite. Reproduced with permission from [231]. Elsevier, 2019.

\section{Applications of Supercapacitors}

Supercapacitors have broad applications in various fields [165]; these include electrochromism, SC-battery-hybrid (BSH) devices, electro-chemical-flow capacitors (EFC), line-filtering alternating current (AC) SCs, micro-SCs, photo-SCs, thermally chargeable SCs, self-healing SCs, shape memory SC (SMSC), shape memory SC (SMSC), piezoelectric SCs. These applications are summarized in the following sub-sections.

\subsection{As a Source of Energy}

Supercapacitors are employed in energy storage suppliers' systems, such as uninterruptible power supply (UPS), which functions as an emergency power device, flow defense, and supply movable charging solutions. It supplies an instant holdup to sensitive masses to link the start-up of a generator. These are also employed in supercapacitor-based UPS, $10 \mathrm{~A}$ UPSU, human-made in a lab at a voltage range of 12 or $24 \mathrm{~V} \mathrm{[235].}$ 


\subsection{Electrochromism}

Supercapacitors have been applied in electrochromism. Ashraf et al. [236] stated that $\mathrm{WO}_{3}$ is a suitable $\mathrm{SC}$ material because of the large difference between its transparent, white, and blue states. Cai et al. [237] found that an electrode's smart functioning is illustrated by a color shift in its voltage or EES. Using an electro-deposition process, Zhang et al. [228] prepared a smarter electrode based on the $\mathrm{WO}_{3}$, via an electro-deposition method (e- $\left.\mathrm{WO}_{3}\right)$. Through the optical density, they measured the color change of the $\mathrm{WO}_{3}$ film-based SCs. The optical density was linearly linked to the EES. The EES indicators were then built to assess a multitude of efficient color-shift-based SCs; due to this property of $\mathrm{WO}_{3}$, it can be integrated in a range of materials for the development of hybrid SCs.

\subsection{Electric Composite Automobiles}

Supercapacitors also have applications in electric composite automobiles; these supercapacitors have provided the required energy for their acceleration as well as reclaiming brake power. These are environmentally friendly and causes no pollution relative to the other automobiles using engines of diesel and petrol. The Chinese company "Ningbo CSR New Energy Technology" has also produced electric buses furnished with CSRCAP supercapacitors, consuming 30-50\% of the energy compared to other electric vehicles. PSA, in 2010, introduced the first car employing the idea of supercapacitors, maximizing the beginning mechanism, where the machine is split if the car is stopped with the gear stick in neutral to save energy, which is better relative to ordinary cars based on petrol and diesel engines [238].

\subsection{Supercapacitor Battery-Hybrid Device}

BSH devices, among other uses, are vital for the intended use of optoelectronic devices, smart electric networks, electro cars, and so on. Batteries, such as Li-air, Li-sulfur, Al-ion, $\mathrm{Na}$-ion, and aqueous metal ions, have been designed for the replacement of traditional $\mathrm{P}$-acid, Ni-Cd, Ni-MH, and Li-ion batteries (LIBs). Zhang et al. [239] stated that the BSH is one of the best methods for generating a battery-powered and SC-powered device with a higher Cs and more powerful power density electrode. Carbon materials (e.g., CNT $\mathrm{AC}$, graphene, and others) are normally used as electrode SC materials in Li-ion BSH. In contrast, the battery content is composed of MOs, intercalating compounds, and their various composites. Zhang et al. [239] also reported a unique system that delivers energy density as $147 \mathrm{Wh} / \mathrm{kg}$, i.e., with remarkable electrochemical properties, at a power density of $150 \mathrm{Wh} / \mathrm{kg}$ and significant retention capacitance by integrating the EDLC type positive electrode with the battery type negative electrode. Peng et al. [240] tested the hybrid energy storage system (HESS), a novel battery system, i.e., SC/Li-ion (SC/BT) technology for electric vehicles, using a simulator (EV) called ADVISOR. The SC kit provides the necessary energy for this brake repair. Due to a scarcity of Li resources, researchers have been compelled to rely on other more demanding elements. SCs are employed in this Na-ion investigation to combine a high-Cs battery electrode with a high-rate power surface adsorption-based SC electrode. Lu et al. [241] created an advanced Na-ion SC electrode with energy density of $27.9 \mathrm{Wh} / \mathrm{kg}$ and power density of $2183.5 \mathrm{~W} / \mathrm{kg}$. Furthermore, it displayed strong stability of $82.2 \%$ after 1000 cycles, while using Mn hexacyanoferrate as the cathode and $\mathrm{Fe}_{3} \mathrm{O}_{4} / \mathrm{rGO}$ as the anode in an aqueous electrolyte working in the $1.8 \mathrm{~V}$ potential window. The BSH with potassium ions as the base material is more enticing than the sodium ion-based BSH, since it is less expensive and more readily available in nature. A graphite-polyacrylate negative electrode has been developed by Komaba et al. for the $4 \mathrm{~V}$ $\mathrm{K}$-ion SC [242]. Multivalent ions $\left(\mathrm{Al}^{3+}\right)$ and monovalent metal ions, both of which have a higher energy density $\left(E_{d}\right)$, are key difficulties in BSH devices. Li et al., developed a $\mathrm{BSH}$ device with an $\mathrm{AC}$ positive electrode and an $\mathrm{Al}_{0.2} \mathrm{CuFe}-\mathrm{PBA}$ negative electrode. Peng et al. [243] stated that the Al-ion BSH technique was used, which achieved a good Ed of $30 \mathrm{Wh} / \mathrm{kg}$ when operating in the $1.5 \mathrm{Vin}$ aqueous electrolyte potential window, utilizing $\mathrm{AC}$ as a positive electrode and $\mathrm{PPy} @ \mathrm{MoO}_{3}$ as a negative electrode. 


\subsection{Electro-Chemical-Flow Capacitor (EFC)}

Carbon molecule charge is employed to store energy in the EFC's twin electrical layers. A slurry consisting of carbon electrolytes and an active ingredient is used to manage charge. The EFC is made up of a cell that regulates the electrolyte and carbon-based reservoir deposits on the outside. The carbon content of the reservoir tanks is transported into the flow cell by the uncharged mixture, where it is excited. Once the charge has been stored, the slurry may be maintained in big tanks until a need for energy arises, at which point the entire process can be reversed. EFCs have a large capacity for load (charge/discharge) cycles. The Cs of the HQ/carbon spheres-based liquid electrode is $64 \mathrm{~F} / \mathrm{g}$, about $50 \%$ greater than flowable-form electrodes with carbon as the base material [244-246].

\subsection{Line-Filtering Alternating Current Supercapacitors}

SC may be employed by substituting bulky $\mathrm{Al}$ electrical condensers (AEC) to minimize system size. Rangom et al. [247] reported outstanding self-sustaining composite electrodes based on SWCNTs. Mesoporous 3D electrodes based on SWCNTs increased the ion transport and improved performance in thick films with a $120 \mathrm{~Hz}$ cline frequency. A phase angle of $-81^{\circ}$ and a time constant of $199 \mathrm{~s}$, a CV parallel tube with $1 \mathrm{kV}^{-1}$ and the possibility to produce electrodes in cycling with more than $200 \mathrm{Vs}^{-1}$ were found to get $601 \mathrm{~F} \mathrm{~cm}^{-2}$ observational. Current densities exceeded $6400 \mathrm{~A} / \mathrm{g}$ for over a million cycles, and electrodes maintained more than $98 \%$ Cs. Wu et al. [248] investigated the development of ac line filters on large-scale graphene. The reduced GO used as the electrode in this study was modelled using metal joints, yielding a system with a phase angle of $-75.4^{\circ}$ at $120 \mathrm{~Hz}$, a time constant of $0.35 \mathrm{~ms}$, a Cs of $316 \mathrm{~F} \mathrm{~cm}^{-2}$, and a $2.8 \%$ reduction in Cs after 10,000 cycles. Kurra et al. [249] carried out their work on PEDOT micro-SC at $500 \mathrm{~V} / \mathrm{s}$ in $1 \mathrm{M} \mathrm{H}_{2} \mathrm{SO}_{4}$, which showed increased scanning capabilities of $400 \mathrm{~Hz}$ with an estimated phase angle of $-45^{\circ}$. In addition, with precision of $9 \mathrm{mF} \mathrm{cm}^{-2}$, a real capacitance was obtained with an estimated phase angle of $-45 \%$. At the volumetric energy density $\left(E_{d}\right)$ of $7.7 \mathrm{mWh} \mathrm{cm}^{-3}$, the material showed $100 \%$ efficiency $(\eta)$; furthermore, $80 \%$ capacitance retention was obtained after 10,000 cycles. This system possesses good capacitance and high power as well as energy density for a longer duration.

\subsection{Micro Supercapacitors}

A short life cycle, a small Ps, and a complex structure limit the application of thin films and small batteries in portable devices. Qi et al. [250] stated that in the production of small electronics, micro-SCs with planar structure have an advantage. In a PVA $/ \mathrm{H}_{3} \mathrm{PO}_{4}$ gel-type electrolyte, As a dynamic material, Shao et al. [251] introduced cellular graphene sheets of quasi-solid state micro integrated SC. These three-dimensional graphene films acted as high-activity SC electrodes as well as an ion pool for the electrolyte. Liu et al. [252] investigated a photo switchable micro-SC film-based diarylethene-graphene with up to $20 \%$ Cs modulation. Photo-switching studies the effects of ion transport at the diarylethenegraphene interface on light modulation. Lee et al. [253] constructed a multifunctional microSC out of self-generated silver through the laser-induced growth sintering process. The SC exhibited a lower (volumetric) power density of $3.54 \mathrm{~W} / \mathrm{cm}^{3}$ but a higher (volumetric) energy density of $16.3 \mathrm{mWh} / \mathrm{cm}^{3}$.

\subsection{Photo Supercapacitors}

Photovoltaic power production is one of the most energy-efficient technologies [254,255] in photo-SC, and the changing power of the solar cells is supplied with a SC $[256,257]$. SCs with a photoactive layer and a huge capacity layer is implemented on a single computer. This object has the potential to self-light with a charge of self-storage. The picture-producing current with Cs $140 \mathrm{~F} / \mathrm{g}$ is about $2 \mathrm{~mA} / \mathrm{g}$. Xu et al. [258] used a hydrogenation method through the plasma to assist SC performance in a stack-integrated photo-SC device with color-sensitized solar cells (DSSCs) and an SC fabricated on an anode titanium oxide (ATO) nanotube display. The hydrogenated ATOs' Cs (area) varied from $1.0 \mathrm{mF} / \mathrm{cm}^{2}$ to 
$1 \mathrm{~mA} / \mathrm{cm}^{2}$. Photo-SCs with optimal storage productivity (about $1.64 \%$ ), strong cycle power, and rapid response time have shown high photoelectric conversion efficiency [256,257].

\subsection{Upheaval Chargeable Supercapacitors}

The heat energy that was previously wasted can now contribute to powering sensors and portable gadgets. Waste heat can be handled with proper thermoelectric energy conversion. Still, issues such as a low output voltage and a lack of power to stock energy necessitate the use of other factors (such as capacitors and voltage amplifiers). The beck effect is used in thermal self-charging SC, accelerated thermal ion diffusion, and temperature-dependent electrochemical redox potential. It is made up of two electrodes that are at different temperatures [258]. Conventional thermoelectricity is reported with a temperature gradient to produce a high voltage in a novel process [259]. Thermally induced electrochemical processes are recharging without the need for external energy in PANI, employing graphene-coated and CNT electrodes with tri-polystyrene sulfonic acid sheets (PSSH). With only a few degrees of temperature difference, i.e., $5 \mathrm{~K}$, the SC thermal charger delivers $38 \mathrm{mV}$ of voltage and larger Cs $\left(1200 \mathrm{~F} / \mathrm{m}^{2}\right)$. The development of thermal induction at the solid-liquid interface and in the ionic electrolyte was defined by Al-zubaidi et al. [260]. Furthermore, when the SC is thermally excited, the self-charging is revealed in it. Wang et al. [261] reported that upon the achievement of the chargingdischarging process, the $\mathrm{SC}$ regains the wasted energy by the thermal charge phenomenon of the SC's electrode material. Zhao et al. [262] reported the production of stress in SCs by heat induction $(\mathrm{PEO}-\mathrm{NaOH})$, when an asymmetric polymer-based electrolyte is generated from $\mathrm{NaOH}$-treated polyethene oxide. They used Au electrodes and MWCNTs to produce a thermal voltage of $10 \mathrm{mV} \mathrm{K}^{-1}$ at a temperature of $4.5 \mathrm{~K}$, with an energy density of $1.35 \mathrm{~mJ} / \mathrm{cm}^{2} \mathrm{Cs}$ and (area) of $1.03 \mathrm{mF} \mathrm{cm}^{-2}$.

\subsection{Self-Healing Supercapacitors}

Using polyampholytic gel-type electrolytes and biochar electrodes, Li et al. [263] produced self-healing SCs with a higher energy density value. Polyampholyte is a strong hydrogel with mechanical stability and self-healing properties. Biochar (BC) is a carbon material with high electrical conductivity and mechanical strength created by pyrolyzing biological waste at low temperatures and then mixing it with rGO. SC with BC-rGO electrodes has an energy density value over $30 \mathrm{Wh} / \mathrm{kg}$ at an ambient temperature with $90 \%$ power retention after 5000 cycles and a larger energy density of $10.5 \mathrm{Wh} / \mathrm{kg}$ at a power density of $500 \mathrm{~W} / \mathrm{kg}$ to $300{ }^{\circ} \mathrm{C}$. Alternatively, this could lead researchers to look at polyampholyte chains' water phase activity. Wang et al. [264] investigated rGO-based electrodes for flexible SCs made by encasing fiber springs in self-healing polymers. They observed that the material retained $82.4 \%$ capacity after stretching and $54.2 \%$ capacity after the third remedial.

\subsection{Form Memory CS (SMSC)}

SCs with abnormalities, which are expandable and elastic, cannot endure repetitive stress, leading to functional and structural collapse. Huang et al. [265] reported an SMSC that is elastic and somewhat deformed but recovers to its original form after cooling, when heated at a specified temperature. These SMSCs can also make memory textile fabric, which remembers its previous pattern and takes automated cooling steps when it becomes too hot.

\subsection{Piezoelectric Supercapacitors}

While the degree of consolidation is raised, energy losses in power management circuits must be reduced. A piezoelectric nanogenerator and a full-wave rectifier with a storage unit are typically employed to reduce energy loss and boost integration density. Xing et al. [266] recently identified using a piezoelectric separator in conjunction with a Li-ion battery and a self-charged cell for energy conversion and storage. However, since Li-ion batteries have a shorter life and charge slowly, there has been a surge in interest in SCs. The energy storage was stated by Armadas et al. [267] by combining the piezoelectric 
form and pseudo-capacitors. Song et al. [268] demonstrated the use of a PVDF film as a separator and energy collector in conjunction with SC. A PVDF film with $\mathrm{H}_{2} \mathrm{SO}_{4} / \mathrm{PVA}$ gel was as an anode and a carbon cloth with $\mathrm{H}_{2} \mathrm{SO}_{4}$ / PVA electrolyte was used as the cathode to create the SC. With a Cs of $357.6 \mathrm{Fm}^{-2}$, an energy density of $400 \mathrm{mAW} / \mathrm{m}^{2}$, and a power density of $49.67 \mathrm{mAWh} / \mathrm{m}^{2}$, the PVDF piezoelectric film's mechanical power showed the SC charge. Maitra et al. [269] reported a self-charging asymmetric supercapacitor (ASC) with bio-piezoelectric characteristics and a fish swimming bladder pore as a bio piezoelectric separator, using a positive electrode of $\mathrm{NiCoOH}-\mathrm{CuO} @ \mathrm{Cu}$ film and a negative electrode of rGO@Cu foil with an electrolyte of PVA-KOH gel. This SC can be rapidly charged to $281.3 \mathrm{mV}$ and $80 \mathrm{~s}$. In the previous part, we discussed how advances in SC technology have been investigated to fit into diverse applications. When choosing them for optimal efficiency, physical parameters such as strain, stress, temperature, self-healing capability, size, battery type, AC type, and others should be considered. Piezoelectric SCs are extensively used in many implantable healthcare organisms, where microwatts to milliwatts of power is necessary. These supercapacitors can be employed in cardiac pacemakers, insulin pumps, healthcare uses, etc. [238].

\subsection{Aircrafts and Protection}

Supercapacitors also have applications in aircraft due to their capacity for quick power supply, extended lifespan cycle, and low-temperature processes such as power backup in military vehicles and electronics, armoured vehicles, fire control systems in tanks, black boxes on helicopters, backup power/memory hold-up for disaster handheld radios, GPSguided missiles and projectiles, airbag organization, etc. [238]. They are also employed in aerospace due to their high power density, such as in actuator systems for step departure approaches in launch vehicles, satellites, and spacecraft on-board organisation.

\subsection{As Energy Storage Devices}

Supercapacitors also act as energy storage devices by gaining solar energy from the sun and energy from the wind using turbines with no sunlight and wind. These supercapacitors are available in cells and modules depending on the system voltage requirements and are ideal for energy storage and circuit-charging schemes in various solar power systems. Integrated solar-supercapacitor systems can be used as charging stations in different places, such as gardens, streets or parking areas, to charge portable electronic devices and vehicles [238].

Several commercially available SCs from their source companies' website include: APowerCap, Asahi Glass, BatScap, Fuji, Ioxus, JSR Micro, LS Mtron, Maxwell, NessCap, Panasonic, PowerStor, Skeleton, VinaTech, and Yunasko. The properties of the commercial SCs are presented in Table 2.

Table 2. Commercially available SCs and their properties.

\begin{tabular}{cccc}
\hline Company & Voltage $(\mathbf{V})$ & Capacitance (F) & ESR (mS) \\
\hline APowerCap & 2.70 & 55 & - \\
Asahi Glass & 2.70 & 1375 & 0.20 \\
BatScap & 2.70 & 2680 & 1.50 \\
Fuji & 3.80 & 1800 & 0.45 \\
Ioxus & 2.70 & 3000 & 1.15 \\
JSR Micro & 3.80 & 1100 & 0.25 \\
LS Mtron & 2.80 & 3200 & 0.38 \\
Maxwell & 2.70 & 2885 & 0.55 \\
NessCap & 2.70 & 1800 & 0.08 \\
Panasonic & 2.30 & 0.10 & 4.57 \\
PowerStor & 2.50 & 2.20 & 0.47 \\
Skeleton & 3.40 & 3200 & 3.50 \\
VinaTech & 2.70 & 336 & 0.90 \\
Yunasko & 2.70 & 510 & \\
\hline
\end{tabular}




\section{Conclusions, Challenges, and Future Prospects}

This review covers the significance of supercapacitors, which have recently received much interest due to their enhanced electrochemical performance, superior cycling life, excellent specific power, and fast charging-discharging rate. In addition, we highlighted that SCs could overcome the power density and specific energy to several orders of magnitude relative to batteries, making them a flexible and compromising energy storage alternative. This review emphasizes various types of SCs, such as electrochemical double-layer capacitors, hybrid supercapacitors, and pseudo-supercapacitors. Finally, we discussed various synthetic strategies such as the sol-gel, electro-polymerization, hydrothermal, coprecipitation, chemical vapor deposition, direct coating, vacuum filtration, de-alloying, microwave auxiliary, in situ polymerization, electro-spinning, silar, carbonization, and dipping and drying methods.

In general, a supercapacitor is an efficient storage device that has great potential in many industries in the near future. However, there are a few problems associated with supercapacitors so as to make some electronic devices useful and popular-it is necessary to make them low cost, durable and possessing a wide range of applications, while in supercapacitor fields, the electrode materials not only restrict their application windows, but also make them expensive for marketed consumers. By selecting the electrolyte and electrode material, some other factors must also be kept in mind, such as the operating range of the temperature, rate of self-discharge, life span, deterioration of the current collectors, separators and the packaging, etc., to increase the cumulative cell efficiency. Synthesizing novel fabrication methods to achieve the tremendously porous nature of the material, with hollow structures, improves the charge storage, which enhances energy density. Although ASCs have greater energy density and power density, more attention should be given to improve the ASCs. Constant improvement in electrolytes with the exclusive extensive and stable potential gap and excellent ionic conductivity with the electrode materials should be the main concern. The maximum consumption of the pore size and compatibility with the electrolyte should be reflected.

Based on the available knowledge and our understanding, it is clear that the storage and performance of recently developed supercapacitors are low compared to batteries. Thus, to make an advanced supercapacitor with appreciable charge storage capacity and low-cost material, one should focus not only on the improvement of the synthesis, fabrication, and modification approaches, but also on the selection of suitable chemical composition, inorganic-organic hybridization strategy, controlling the size, morphology, pore size, phase of the material, and enhancing the electrode-substrate compatibility of the resultant SCs. SCs have received much research attention in the market due to their high electrochemical performance compared to the already developed energy storage systems. However, extensive developments are required for the proper commercialization and utilization of SCs in the energy sector. Their energy storage mechanism needs to be further studied to overcome the performance of their market competitors, i.e., batteries. Exploring and developing new electrode materials/electrolytes (to broaden the operating potential window and enhance energy density) and low-cost metals is necessary to improve the overall device performance. More advanced in situ characterization techniques are needed to study the structure of redox-active materials. Severe self-discharge limits the wide application of SCs, slowing down the self-discharge process need more focus and attention. The energy storage process in the confined pores is difficult to observe in situ. Advanced calculation methods could potentially fit the material's structure and analyze the dynamic process under the potential operating windows.

Author Contributions: Conceptualization, M.Y., M.A.K.K., M.H., M.U., S.S.S., S.B., A.K. and H.U.; validation, M.H., M.U., A.K., A.A.T., B.S.U.H., S.M.A., N.S. and H.U.; writing-original draft preparation, M.Y. and M.A.K.K.; writing-review and editing, A.K., M.H., S.M.A. and M.U.; visualization, M.H., A.K., A.A.T., M.U. and H.U.; supervision, M.H., M.U., A.K. and H.U. All authors have read and agreed to the published version of the manuscript. 
Funding: We are thankful to the Engineering and Physical Science Research Council, UK (EPSRC under research grant no. EP/V049046/1 and EP/T025875/1) for financial support.

Institutional Review Board Statement: Not applicable.

Informed Consent Statement: Not applicable.

Data Availability Statement: Not applicable.

Acknowledgments: M.U. also acknowledges the support from Saudi Aramco Chair Programme (ORCP2390).

Conflicts of Interest: The authors declare no conflict of interest.

\section{References}

1. Simon, P.; Gogotsi, Y.; Dunn, B. Where do batteries end and supercapacitors begin? Science 2014, 343, 1210-1211. [CrossRef] [PubMed]

2. Li, C.; Islam, M.M.; Moore, J.; Sleppy, J.; Morrison, C.; Konstantinov, K.; Dou, S.X.; Renduchintala, C.; Thomas, J. Wearable energy-smart ribbons for synchronous energy harvest and storage. Nat. Commun. 2016, 7, 1-10. [CrossRef] [PubMed]

3. Boukhalfa, S.; Evanoff, K.; Yushin, G. Atomic layer deposition of vanadium oxide on carbon nanotubes for high-power supercapacitor electrodes. Energy Environ. Sci. 2012, 5, 6872-6879. [CrossRef]

4. Kötz, R.; Carlen, M. Principles and applications of electrochemical capacitors. Electrochim. Acta 2000, 45, 2483-2498. [CrossRef]

5. Lewandowski, A.; Galinski, M. Practical and theoretical limits for electrochemical double-layer capacitors. J. Power Sources 2007, 173, 822-828. [CrossRef]

6. Bohlen, O.; Kowal, J.; Sauer, D.U. Ageing behaviour of electrochemical double layer capacitors: Part II. Lifetime simulation model for dynamic applications. J. Power Sources 2007, 173, 626-632. [CrossRef]

7. Wang, T.; Rony, A.H.; Sun, K.; Gong, W.; He, X.; Lu, W.; Tang, M.; Ye, R.; Yu, J.; Kang, L.; et al. Carbon Nanofibers Prepared from Solar Pyrolysis of Pinewood as Binder-free Electrodes for Flexible Supercapacitors. Cell Rep. Phys. Sci. 2020, 1, 100079. [CrossRef]

8. Lu, Z.; Raad, R.; Safaei, F.; Xi, J.; Liu, Z.; Foroughi, J. Carbon nanotube based fiber supercapacitor as wearable energy storage. Front. Mater. 2019, 6, 138. [CrossRef]

9. Lokhande, P.E.; Chavan, U.S.; Pandey, A. Materials and fabrication methods for electrochemical supercapacitors: Overview. Electro. Energy Rev. 2020, 3, 155-186. [CrossRef]

10. Kakaei, K.; Esrafili, M.D.; Ehsani, A. Graphene-based electrochemical supercapacitors. In Interface Science and Technology; Kakaei, K., Esrafili, M.D., Ehsani, A., Eds.; Elsevier: Maragheh, Iran, 2019; Volume 27, pp. 339-386.

11. Zhang, L.L.; Zhao, X. Carbon-based materials as supercapacitor electrodes. Chem. Soc. Rev. 2009, 38, 2520-2531. [CrossRef]

12. Chmiola, J.; Yushin, G.; Gogotsi, Y.; Portet, C.; Simon, P.; Taberna, P.-L. Anomalous increase in carbon capacitance at pore sizes less than 1 nanometer. Science 2006, 313, 1760-1763. [CrossRef] [PubMed]

13. Vijayakumar, S.; Nagamuthu, S.; Muralidharan, G. Supercapacitor studies on NiO nanoflakes synthesized through a microwave route. ACS Appl. Mater. Interfaces 2013, 5, 2188-2196. [CrossRef] [PubMed]

14. Usman, M.; Humayun, M.; Garba, M.D.; Ullah, L.; Zeb, Z.; Helal, A.; Suliman, M.H.; Alfaifi, B.Y.; Iqbal, N.; Abdinejad, M.; et al. Electrochemical Reduction of $\mathrm{CO}_{2}$ : A Review of Cobalt Based Catalysts for Carbon Dioxide Conversion to Fuels. Nanomaterials 2021, 11, 2029. [CrossRef]

15. Wang, G.; Zhang, L.; Zhang, J. A review of electrode materials for electrochemical supercapacitors. Chem. Soc. Rev. 2012, 41, 797-828. [CrossRef]

16. Forse, A.C.; Merlet, C.L.; Griffin, J.M.; Grey, C.P. New perspectives on the charging mechanisms of supercapacitors. J. Am. Chem. Soc. 2016, 138, 5731-5744. [CrossRef]

17. Forouzandeh, P.; Kumaravel, V.; Pillai, S.C. Electrode Materials for Supercapacitors: A Review of Recent Advances. Catalysts 2020, 10, 969. [CrossRef]

18. Humayun, M.; Ullah, H.; Shu, L.; Ao, X.; Tahir, A.A.; Wang, C.; Luo, W. Plasmon Assisted Highly Efficient Visible Light Catalytic $\mathrm{CO}_{2}$ Reduction Over the Noble Metal Decorated Sr-Incorporated $g-\mathrm{C}_{3} \mathrm{~N}_{4}$. Nano-Micro Lett. 2021, 13, 1-18. [CrossRef]

19. Khan, S.A.; Ali, S.; Saeed, K.; Usman, M.; Khan, I. Advanced cathode materials and efficient electrolytes for rechargeable batteries: Practical challenges and future perspectives. J. Mater. Chem. A 2019, 7, 10159-10173. [CrossRef]

20. Xie, J.; Yang, P.; Wang, Y.; Qi, T.; Lei, Y.; Li, C.M. Puzzles and confusions in supercapacitor and battery: Theory and solutions. J. Power Sources 2018, 401, 213-223. [CrossRef]

21. Shetti, N.P.; Dias, S.; Reddy, K.R. Nanostructured organic and inorganic materials for Li-ion batteries: A review. Mater. Sci. Semicond. Process. 2019, 104, 104684. [CrossRef]

22. Yusoff, A.R.M.; Vasilopoulou, M.; Mahata, A.; Ullah, H.; Hu, B.; Silva, W.J.; Gao, P.; Ievlev, A.V.; Liu, Y.; Angelis, F.D.; et al. Observation of large Rashba spin-orbit coupling at room temperature in compositionally engineered perovskite single crystals and application in high performance photodetectors. Mater. Today 2021, 46, 18-27. [CrossRef]

23. Zhang, C.; Zhang, L.; Ding, Y.; Peng, S.; Guo, X.; Zhao, Y.; He, G.; Yu, G. Progress and prospects of next-generation redox flow batteries. Energy Storage Mater. 2018, 15, 324-350. [CrossRef] 
24. Zhang, H.; Sun, C. Cost-effective iron-based aqueous redox flow batteries for large-scale energy storage application: A review. J. Power Sources 2021, 493, 229445. [CrossRef]

25. Sun, C.-Y.; Zhang, H. Investigation of Nafion series membranes on the performance of iron-chromium redox flow battery. Int. J. Energy Res. 2019, 43, 8739-8752. [CrossRef]

26. Lin, Z.; Goikolea, E.; Balducci, A.; Naoi, K.; Taberna, P.-L.; Salanne, M.; Yushin, G.; Simon, P. Materials for supercapacitors: When Li-ion battery power is not enough. Mater. Today 2018, 21, 419-436. [CrossRef]

27. Zhu, J.; Wei, S.; Gu, H.; Rapole, S.B.; Wang, Q.; Luo, Z.; Haldolaarachchige, N.; Young, D.P.; Guo, Z. One-pot synthesis of magnetic graphene nanocomposites decorated with core@ double-shell nanoparticles for fast chromium removal. Environ. Sci. Technol. 2012, 46, 977-985. [CrossRef]

28. Pandolfo, A.G.; Hollenkamp, A.F. Carbon properties and their role in supercapacitors. J. Power Sources 2006, 157, 11-27. [CrossRef]

29. Saikia, B.K.; Benoya, S.M.; Bora, M.; Tamuly, J.; Pandey, M.; Bhattachary, D. A brief review on supercapacitor energy storage devices and utilization of natural carbon resources as their electrode materials. Fuel 2020, 282, 118796. [CrossRef]

30. Najib, S.; Erdem, E. Current progress achieved in novel materials for supercapacitor electrodes: Mini review. Nanoscale Adv. 2019, 1, 2817-2827. [CrossRef]

31. Shah, S.A.; Xu, L.; Sayyar, R.; Bian, T.; Liu, Z.; Yuan, A.; Shen, X.; Khan, I.; Tahir, A.A.; Ullah, H. Growth of MoS 2 Nanosheets on $\mathrm{M} @ \mathrm{~N}$-doped Carbon Particles $(\mathrm{M}=\mathrm{Co}$, Fe or CoFe Alloy) as an Efficient Electrocatalyst toward Hydrogen Evolution Reaction. Chem. Eng. J. 2021, 15, 132126.

32. Ma, Z.; Zhang, Z.; Qu, Y.; Lai, F.; Li, Q.; Wu, X.; Wu, Q.; Li, Q.; Wang, H.; Huang, Y. Yeast protein derived hierarchical mesoporous carbon for symmetrical capacitor with excellent electrochemical performances. Microporous Mesoporous Mater. 2019, $281,50-56$. [CrossRef]

33. Tang, H.; Wang, J.; Yin, H.; Zhao, H.; Wang, D.; Tang, Z. Growth of polypyrrole ultrathin films on MoS 2 monolayers as high-performance supercapacitor electrodes. Adv. Mater. 2015, 27, 1117-1123. [CrossRef]

34. Shakil, R.; Shaikh, M.N.; Shah, S.S.; Reaz, A.H.; Roy, C.K.; Chowdhury, A.-N.; Aziz, M.A. Development of a Novel Bio-based Redox Electrolyte using Pivalic Acid and Ascorbic Acid for the Activated Carbon-based Supercapacitor Fabrication. Asian J. Org. Chem. 2021, 10, 2220-2230. [CrossRef]

35. Mohamedkhair, A.K.; Aziz, M.A.; Shah, S.S.; Shaikh, M.N.; Jamil, A.K.; Qasem, M.A.A.; Buliyaminu, I.A.; Yamani, Z.H. Effect of an activating agent on the physicochemical properties and supercapacitor performance of naturally nitrogen-enriched carbon derived from Albizia procera leaves. Arab. J. Chem. 2020, 13, 6161-6173. [CrossRef]

36. Huang, S.; Zhu, X.; Sarkar, S.; Zhao, Y. Challenges and opportunities for supercapacitors. APL Mater. 2019, 7, 100901. [CrossRef]

37. Yaseen, M.; Humayun, M.; Khan, A.; Usman, M.; Tahir, A.A.; Ullah, H. Preparation, Functionalization, Modification, and Applications of Nanostructured Gold: A Critical Review. Energies 2021, 14, 1278. [CrossRef]

38. Ju, F.; Zhang, Q.; Deng, W.; Li, J. In Review of structures and control of battery-supercapacitor hybrid energy storage system for electric vehicles. In Proceedings of the 2014 IEEE International Conference on Automation Science and Engineering (CASE), New Taipei, Taiwan, 18-22 August 2014; IEEE: New Taipei, Taiwan, 2014; pp. 143-148.

39. Wang, Q.; Yan, J.; Fan, Z. Carbon materials for high volumetric performance supercapacitors: Design, progress, challenges and opportunities. Energy Environ. Sci. 2016, 9, 729-762. [CrossRef]

40. Eftekhari, A.; Fang, B. Electrochemical hydrogen storage: Opportunities for fuel storage, batteries, fuel cells, and supercapacitors. Int. J. Hydrog. Energy 2017, 42, 25143-25165. [CrossRef]

41. Shah, S.S.; Cevik, E.; Aziz, M.A.; Qahtan, T.F.; Bozkurt, A.; Yamani, Z.H. Jute Sticks Derived and Commercially Available Activated Carbons for Symmetric Supercapacitors with Bio-electrolyte: A Comparative Study. Synth. Met. 2021, $277,116765$. [CrossRef]

42. Zhong, C.; Deng, Y.; Hu, W.; Sun, D.; Han, X.; Qiao, J.; Zhang, J. Electrolytes for Electrochemical Supercapacitors; CRC Press: Boca Raton, FL, USA, 2016.

43. de Klerk, N.J.; van der Maas, E.; Wagemaker, M. Analysis of diffusion in solid-state electrolytes through MD simulations, improvement of the Li-ion conductivity in $\beta-\mathrm{Li}_{3} \mathrm{PS}_{4}$ as an example. ACS Appl. Energy Mater. 2018, 1, 3230-3242. [CrossRef]

44. Kwon, S.J.; Kim, T.; Jung, B.M.; Lee, S.B.; Choi, U.H. Multifunctional epoxy-based solid polymer electrolytes for solid-state supercapacitors. ACS Appl. Mater. Interfaces 2018, 10, 35108-35117. [CrossRef] [PubMed]

45. Anothumakkool, B.; Torris, A.A.; Veeliyath, S.; Vijayakumar, V.; Badiger, M.V.; Kurungot, S. High-Performance Flexible Solid-State Supercapacitor with an Extended Nanoregime Interface through in Situ Polymer Electrolyte Generation. ACS Appl. Mater. Interfaces 2016, 8, 1233-1241. [CrossRef] [PubMed]

46. DebNath, N.C.; Shah, S.S.; Qasem, M.A.A.; Zahir, M.H.; Aziz, M.A. Defective Carbon Nanosheets Derived from Syzygium cumini Leaves for Electrochemical Energy-Storage. ChemistrySelect 2019, 4, 9079-9083. [CrossRef]

47. Sun, H.; Xu, Z.; Gao, C. Multifunctional, ultra-flyweight, synergistically assembled carbon aerogels. Adv. Mater. 2013, 25, 2554-2560. [CrossRef]

48. Usman, M.; Ali, M.; Al-Maythalony, B.A.; Ghanem, A.S.; Saadi, O.W.; Ali, M.; Jafar Mazumder, M.A.; Abdel-Azeim, S.; Habib, M.A.; Yamani, Z.H.; et al. Highly Efficient Permeation and Separation of Gases with Metal-Organic Frameworks Confined in Polymeric Nanochannels. ACS Appl. Mater. Interfaces 2020, 12, 49992-50001. [CrossRef]

49. Ghanem, A.S.; Ba-Shammakh, M.; Usman, M.; Khan, M.F.; Dafallah, H.; Habib, M.A.M.; Al-Maythalony, B.A. High gas permselectivity in ZIF-302/polyimide self-consistent mixed-matrix membrane. J. Appl. Polym. Sci. 2020, 137, 48513. [CrossRef] 
50. Saravanan, J.; Vignesh, A.; Shah, S.S.; Aziz, M.A.; Pannipara, M.; Al-Sehemi, A.G.; Phang, S.-M.; Ng, F.-L.; Abdul, B.A.A.; Kumar, G.G. Binder-less and free-standing Co-Fe metal nanoparticles-decorated PVdF-HFP nanofiber membrane as an electrochemical probe for enzyme-less glucose sensors. Res. Chem. Intermed. 2021. [CrossRef]

51. Din, I.U.; Nasir, Q.; Garba, M.D.; Alotaibi, M.A.; Alharthi, A.; Usman, M. A Review of Preparation Methods for Heterogeneous Catalysts. Mini Rev. Org. Chem. 2021, 18, 1-19.

52. Cichero, M.C.; Santos, J.H.Z.D. Hybrid Silica Aerogel. Mater. Res. Found. 2020, 84, 83-108.

53. Hu, Y.; Zhuo, H.; Chen, Z.; Wu, K.; Luo, Q.; Liu, Q.; Jing, S.; Liu, C.; Zhong, L.; Sun, R. Superelastic carbon aerogel with ultrahigh and wide-range linear sensitivity. ACS Appl. Mater. Interfaces 2018, 10, 40641-40650. [CrossRef] [PubMed]

54. Moreno-Castilla, C.; Maldonado-Hódar, F. Carbon aerogels for catalysis applications: An overview. Carbon 2005, 43, 455-465. [CrossRef]

55. Roy, C.K.; Shah, S.S.; Reaz, A.H.; Sultana, S.; Chowdhury, A.-N.; Firoz, S.H.; Zahir, M.H.; Qasem, M.A.A.; Aziz, M.A. Preparation of Hierarchical Porous Activated Carbon from Banana Leaves for High-performance Supercapacitor: Effect of Type of Electrolytes on Performance. Chem. Asian J. 2021, 16, 296-308. [CrossRef]

56. Usman, M.; Humayun, M.; Shah, S.S.; Ullah, H.; Tahir, A.A.; Khan, A.; Ullah, H. Bismuth-Graphene Nanohybrids: Synthesis, Reaction Mechanisms, and Photocatalytic Applications-A Review. Energies 2021, 14, 2281. [CrossRef]

57. Islam, S.; Shah, S.S.; Naher, S.; Ehsan, M.A.; Aziz, M.A.; Ahammad, A.J.S. Graphene and Carbon Nanotubes-based Electrochemical Sensing Platforms for Dopamine. Chem. Asian J. 2021, 16, 3516-3543. [CrossRef]

58. Aziz, M.A.; Shah, S.S.; Mazumder, M.A.J.; Oyama, M.; Al-Betar, A.-R. Carbon nanofiber and poly[2-(methacryloyloxy) ethyl] trimethylammonium chloride composite as a new benchmark carbon-based electrocatalyst for sulfide oxidation. Chem. Asian $\mathrm{J}$. 2021, 16, 1570-1583. [CrossRef] [PubMed]

59. Abu Nayem, S.M.; Shaheen Shah, S.; Sultana, N.; Aziz, M.A.; Saleh Ahammad, A.J. Electrochemical Sensing Platforms of Dihydroxybenzene: Part 1-Carbon Nanotubes, Graphene, and their Derivatives. Chem. Rec. 2021, 21, 1039-1072. [CrossRef]

60. Ke, Q.; Wang, J. Graphene-based materials for supercapacitor electrodes-A review. J. Mater. 2016, 2, 37-54. [CrossRef]

61. Abu Nayem, S.M.; Shaheen Shah, S.; Sultana, N.; Aziz, M.A.; Saleh Ahammad, A.J. Electrochemical Sensing Platforms of Dihydroxybenzene: Part 2-Nanomaterials Excluding Carbon Nanotubes and Graphene. Chem. Rec. 2021, 21, $1073-1097$. [CrossRef]

62. Coleman, J.N.; Khan, U.; Blau, W.J.; Gun'ko, Y.K. Small but strong: A review of the mechanical properties of carbon nanotubepolymer composites. Carbon 2006, 44, 1624-1652. [CrossRef]

63. Islam, T.; Hasan, M.M.; Shah, S.S.; Karim, M.R.; Al-Mubaddel, F.S.; Zahir, M.H.; Dar, M.A.; Hossain, M.D.; Aziz, M.A.; Ahammad, A.J.S. High yield activated porous coal carbon nanosheets from Boropukuria coal mine as supercapacitor material: Investigation of the charge storing mechanism at the interfacial region. J. Energy Storage 2020, 32, 101908. [CrossRef]

64. Shah, S.S.; Qasem, M.A.A.; Berni, R.; Del Casino, C.; Cai, G.; Contal, S.; Ahmad, I.; Siddiqui, K.S.; Gatti, E.; Predieri, S.; et al. Physico-chemical properties and toxicological effects on plant and algal models of carbon nanosheets from a nettle fibre clone. Sci. Rep. 2021, 11, 6945. [CrossRef] [PubMed]

65. Heimböckel, R.; Hoffmann, F.; Fröba, M. Insights into the influence of the pore size and surface area of activated carbons on the energy storage of electric double layer capacitors with a new potentially universally applicable capacitor model. Phys. Chem. Chem. Phys. 2019, 21, 3122-3133. [CrossRef] [PubMed]

66. Ma, X.; Zhao, L.; Yu, Z.; Wang, X.; Song, X.; Ning, G.; Gao, J. Excellent Compatibility of the Gravimetric and Areal Capacitances of an Electric-Double-Layer Capacitor Configured with S-Doped Activated Carbon. ChemSusChem 2018, 11, 3766-3773. [CrossRef]

67. Vangari, M.; Pryor, T.; Jiang, L. Supercapacitors: Review of materials and fabrication methods. J. Energy Eng. 2013, 139, 72-79. [CrossRef]

68. Stoller, M.D.; Park, S.; Zhu, Y.; An, J.; Ruoff, R.S. Graphene-based ultracapacitors. Nano Lett. 2008, 8, 3498-3502. [CrossRef]

69. Shah, S.S.; Alfasane, M.A.; Bakare, I.A.; Aziz, M.A.; Yamani, Z.H. Polyaniline and heteroatoms-enriched carbon derived from Pithophora polymorpha composite for high performance supercapacitor. J. Energy Storage 2020, 30, 101562. [CrossRef]

70. Kausar, A. Polymer and modified chitosan-based nanocomposite: Impending material for technical application. Polym-Plast. Tech Mat. 2019, 58, 934-947. [CrossRef]

71. Ho, M.; Khiew, P.; Isa, D.; Tan, T.; Chiu, W.; Chia, C. A review of metal oxide composite electrode materials for electrochemical capacitors. Nano 2014, 9, 1430002. [CrossRef]

72. Reddy, A.L.M.; Ramaprabhu, S. Nanocrystalline metal oxides dispersed multiwalled carbon nanotubes as supercapacitor electrodes. J. Phys. Chem. C 2007, 111, 7727-7734. [CrossRef]

73. Yan, Y.; Wang, T.; Li, X.; Pang, H.; Xue, H. Noble metal-based materials in high-performance supercapacitors. Inorg. Chem. Front. 2017, 4, 33-51. [CrossRef]

74. Jain, P.K.; Huang, X.; El-Sayed, I.H.; El-Sayed, M.A. Noble Metals on the Nanoscale: Optical and Photothermal Properties and Some Applications in Imaging, Sensing, Biology, and Medicine. Acc. Chem. Res. 2008, 41, 1578-1586. [CrossRef]

75. Adeyeye Nafiu, S.; Shaheen Shah, S.; Aziz, A.; Shaikh, M.N. Biogenic Synthesis of Gold Nanoparticles on a Green Support as a Reusable Catalyst for the Hydrogenation of Nitroarene and Quinoline. Chem. Asian J. 2021, 16, 1956-1966. [CrossRef]

76. Hasan, M.M.; Islam, T.; Imran, A.; Alqahtani, B.; Shah, S.S.; Mahfoz, W.; Karim, M.R.; Alharbi, H.F.; Aziz, M.A.; Ahammad, A.J.S. Mechanistic Insights of the Oxidation of Bisphenol A at Ultrasonication Assisted Polyaniline-Au Nanoparticles Composite for Highly Sensitive Electrochemical Sensor. Electrochim. Acta 2021, 374, 137968. [CrossRef] 


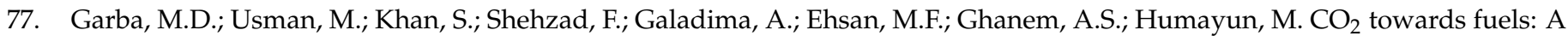
review of catalytic conversion of carbon dioxide to hydrocarbons. J. Environ. Chem. Eng. 2021, 9, 104756. [CrossRef]

78. Din, I.U.; Usman, M.; Khan, S.; Helal, A.; Alotaibi, M.A.; Alharthi, A.I.; Centi, G. Prospects for a green methanol thermo-catalytic process from $\mathrm{CO}_{2}$ by using MOFs based materials: A mini-review. J. CO2 Util. 2021, 43, 101361. [CrossRef]

79. Wang, Y.; Zhitomirsky, I. Cathodic electrodeposition of Ag-doped manganese dioxide films for electrodes of electrochemical supercapacitors. Mater. Lett. 2011, 65, 1759-1761. [CrossRef]

80. Ola, O.; Ullah, H.; Yu, C.; Thummavichai, K.; Wang, N.; Zhu, Y. DFT and Experimental Studies of Iron Oxide-based Nanocomposites for Efficient Electrocatalysis. J. Mater. Chem. C 2021, 9, 6417. [CrossRef]

81. Li, R.; Liu, X.; Wang, H.; Wu, Y.; Lu, Z.P. Development of electrochemical supercapacitors with uniform nanoporous silver network. Electrochim. Acta 2015, 182, 224-229. [CrossRef]

82. Yoo, H.D.; Han, S.-D.; Bayliss, R.D.; Gewirth, A.A.; Genorio, B.; Rajput, N.N.; Persson, K.A.; Burrell, A.K.; Cabana, J. “Rockingchair"-type metal hybrid supercapacitors. ACS Appl. Mater. Interfaces 2016, 8, 30853-30862. [CrossRef]

83. Gao, H.; Xiao, F.; Ching, C.B.; Duan, H. High-performance asymmetric supercapacitor based on graphene hydrogel and nanostructured $\mathrm{MnO}_{2}$. ACS Appl. Mater. Interfaces 2012, 4, 2801-2810. [CrossRef]

84. Zhi, M.; Xiang, C.; Li, J.; Li, M.; Wu, N. Nanostructured carbon-metal oxide composite electrodes for supercapacitors: A review. Nanoscale 2013, 5, 72-88. [CrossRef] [PubMed]

85. Ghosh, A.; Ra, E.J.; Jin, M.; Jeong, H.K.; Kim, T.H.; Biswas, C.; Lee, Y.H. High pseudocapacitance from ultrathin $\mathrm{V}_{2} \mathrm{O}_{5}$ films electrodeposited on self-standing carbon-nanofiber paper. Adv. Funct. Mater. 2011, 21, 2541-2547. [CrossRef]

86. Zhi, M.; Manivannan, A.; Meng, F.; Wu, N. Highly conductive electrospun carbon nanofiber $/ \mathrm{MnO}_{2}$ coaxial nano-cables for high energy and power density supercapacitors. J. Power Sources 2012, 208, 345-353. [CrossRef]

87. Dubal, D.P.; Ayyad, O.; Ruiz, V.; Gomez-Romero, P. Hybrid energy storage: The merging of battery and supercapacitor chemistries. Chem. Soc. Rev. 2015, 44, 1777-1790. [CrossRef]

88. Pan, H.; Li, J.; Feng, Y. Carbon nanotubes for supercapacitor. Nanoscale Res. Lett. 2010, 5, 654-668. [CrossRef] [PubMed]

89. Frackowiak, E.; Beguin, F. Electrochemical storage of energy in carbon nanotubes and nanostructured carbons. Carbon 2002, 40, 1775-1787. [CrossRef]

90. Simon, P.; Gogotsi, Y. Review: Materials for electrochemical capacitors. Nat. Mater. 2008, 7, 845-854. [CrossRef]

91. Conway, B. Elements of Electrostatics Involved in Treatment of Double Layers and Ions at Capacitor Electrode Interphases. In Electrochemical Supercapacitors; Springer: Boston, MA, USA, 1999; pp. 67-86.

92. Béguin, F.; Presser, V.; Balducci, A.; Frackowiak, E. Carbons and electrolytes for advanced supercapacitors. Adv. Mater. 2014, 26, 2219-2251. [CrossRef]

93. Kiamahalleh, M.V.; Zein, S.H.S.; Najafpour, G.; Sata, S.A.; Buniran, S. Multiwalled carbon nanotubes based nanocomposites for supercapacitors: A review of electrode materials. Nano 2012, 7, 1230002. [CrossRef]

94. Frackowiak, E.; Metenier, K.; Bertagna, V.; Beguin, F. Supercapacitor electrodes from multiwalled carbon nanotubes. Appl. Phys. Lett. 2000, 77, 2421-2423. [CrossRef]

95. Frackowiak, E.; Delpeux, S.; Jurewicz, K.; Szostak, K.; Cazorla-Amoros, D.; Beguin, F. Enhanced capacitance of carbon nanotubes through chemical activation. Chem. Phys. Lett. 2002, 361, 35-41. [CrossRef]

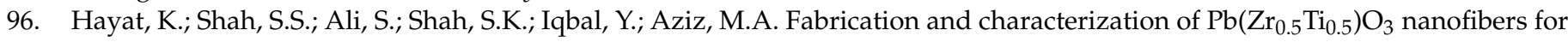
nanogenerator applications. J. Mater. Sci. Mater. Electron. 2020, 31, 15859-15874. [CrossRef]

97. Humayun, M.; Ullah, H.; Cao, J.; Pi, W.; Ali, S.; Tahir, A.A.; Yue, P.; Khan, A.; Zheng, Z.; Fu, Q.; et al. Au Deposition Over $\mathrm{WO}_{3} / \mathrm{g}-\mathrm{C}_{3} \mathrm{~N}_{4}$ Z-Scheme Heterojunction Can Remarkably Improve its Catalytic Function and Stability: Experimental and DFT Studies. Nano-Micro Lett. 2020, 12, 1-18. [CrossRef] [PubMed]

98. Shah, S.S.; Hayat, K.; Ali, S.; Rasool, K.; Iqbal, Y. Conduction mechanisms in lanthanum manganite nanofibers. Mater. Sci. Semicond. Process. 2019, 90, 65-71. [CrossRef]

99. Raza, W.; Ali, F.; Raza, N.; Luo, Y.; Kim, K.-H.; Yang, J.; Kumar, S.; Mehmood, A.; Kwon, E.E. Recent advancements in supercapacitor technology. Nano Energy 2018, 52, 441-473. [CrossRef]

100. Lai, L.; Yang, H.; Wang, L.; Teh, B.K.; Zhong, J.; Chou, H.; Chen, L.; Chen, W.; Shen, Z.; Ruoff, R.S. Preparation of supercapacitor electrodes through selection of graphene surface functionalities. ACS Nano 2012, 6, 5941-5951. [CrossRef]

101. Pell, W.G.; Conway, B.E. Voltammetry at a de Levie brush electrode as a model for electrochemical supercapacitor behaviour. J. Electroanal. Chem. 2001, 500, 121-133. [CrossRef]

102. González, A.; Goikolea, E.; Barrena, J.A.; Mysyk, R. Review on supercapacitors: Technologies and materials. Renew. Sust. Energ. Rev. 2016, 58, 1189-1206. [CrossRef]

103. Zheng, H.; Zhang, H.; Fu, Y.; Abe, T.; Ogumi, Z. Temperature effects on the electrochemical behavior of spinel $\mathrm{LiMn}_{2} \mathrm{O}_{4}$ in quaternary ammonium-based ionic liquid electrolyte. J. Phys. Chem. B 2005, 109, 13676-13684. [CrossRef]

104. Girard, G.M.; Hilder, M.; Zhu, H.; Nucciarone, D.; Whitbread, K.; Zavorine, S.; Moser, M.; Forsyth, M.; Macfarlane, D.R.; Howlett, P.C. Electrochemical and physicochemical properties of small phosphonium cation ionic liquid electrolytes with high lithium salt content. Phys. Chem. Chem. Phys. 2015, 17, 8706-8713. [CrossRef]

105. Ramachandran, R.; Wang, F. Electrochemical capacitor performance: Influence of aqueous electrolytes. In SupercapacitorsTheoretical and Practical Solutions; Liudvinavičius, L., Ed.; IntechOpen: London, UK, 2017. 
106. Ashraf, M.; Khan, I.; Usman, M.; Khan, A.; Shah, S.S.; Khan, A.Z.; Saeed, K.; Yaseen, M.; Ehsan, M.F.; Tahir, M.N.; et al. Hematite and Magnetite Nanostructures for Green and Sustainable Energy Harnessing and Environmental Pollution Control: A Review. Chem. Res. Toxicol. 2020, 33, 1292-1311. [CrossRef]

107. Khan, I.; Baig, N.; Ali, S.; Usman, M.; Khan, S.A.; Saeed, K. Progress in layered cathode and anode nanoarchitectures for charge storage devices: Challenges and future perspective. Energy Storage Mater. 2021, 35, 443-469. [CrossRef]

108. Tanaka, Y.; Ishii, N.; Okuma, J.; Hara, R. Electric Double-Layer Capacitor and Method of Making a Separator Therefor. U.S. Patent US6190501B1, 20 February 2001.

109. Mayer, S.T.; Kaschmitter, J.L.; Pekala, R.W. Aquagel Electrode Separator for Use in Batteries and Supercapacitors. U.S. Patent US5402306A, 28 March 1995.

110. Dyatkin, B.; Presser, V.; Heon, M.; Lukatskaya, M.R.; Beidaghi, M.; Gogotsi, Y. Development of a green supercapacitor composed entirely of environmentally friendly materials. ChemSusChem 2013, 6, 2269-2280. [CrossRef] [PubMed]

111. Chen, L.; Chen, Y.; Wu, J.; Wang, J.; Bai, H.; Li, L. Electrochemical supercapacitor with polymeric active electrolyte. J. Mater. Chem. A 2014, 2, 10526-10531. [CrossRef]

112. Hu, Q.; Kang, C.; Cao, S.; Zhou, C.; Liu, Q. NiMoO 4 nanosheets grown on MOF-derived leaf-like $\mathrm{Co}_{3} \mathrm{O}_{4}$ nanosheet arrays for high-performance supercapacitors. J. Alloys Compd. 2021, 883, 160867. [CrossRef]

113. Yu, A.; Chabot, V.; Zhang, J. Electrochemical Supercapacitors for Energy Storage and Delivery: Fundamentals and Applications; Taylor \& Francis: London, UK, 2013.

114. Kazaryan, S.A.; Nedoshivin, V.P.; Kazarov, V.A.; Kharisov, G.G.; Litvinenko, S.V.; Razumov, S.N. Current Collector for a Double Electric Layer Capacitor. U.S. Patent US7446998B2, 11 April 2008.

115. Dasgupta, S.; Jacobs, J.K. Current Collector for Lithium Ion Battery. U.S. Patent US5464706A, 7 November 1995.

116. Zhang, Y.; Ru, Y.; Gao, H.-L.; Wang, S.-W.; Yan, J.; Gao, K.-Z.; Jia, X.-D.; Luo, H.-W.; Fang, H.; Zhang, A.-Q.; et al. Sol-gel synthesis and electrochemical performance of $\mathrm{NiCO}_{2} \mathrm{O}_{4}$ nanoparticles for supercapacitor applications. J. Electrochem. Sci. Eng. 2019, 9, 243-253. [CrossRef]

117. Chen, H.; Du, X.; Wu, R.; Wang, Y.; Sun, J.; Zhang, Y.; Xu, C. Facile hydrothermal synthesis of porous $\mathrm{MgCo}_{2} \mathrm{O}_{4}$ nanoflakes as an electrode material for high-performance asymmetric supercapacitors. Nanoscale Adv. 2020, 2, 3263-3275. [CrossRef]

118. Shafi, P.M.; Bose, A.C. Synthesis and characterization of $\alpha-\mathrm{MnO}_{2}$ electrode for supercapacitor application. AIP Conf. Proc. 2019, $1665,050079$.

119. Thirumal, V.; Pandurangan, A.; Jayavel, R.; Krishnamoorthi, S.R.; Ilangovan, R. Synthesis of nitrogen doped coiled double walled carbon nanotubes by chemical vapor deposition method for supercapacitor applications. Curr. Appl. Phys. 2016, 16, 816-825. [CrossRef]

120. Sohail, I.; Hussain, Z.; Khan, A.N.; Yaqoob, K. Synthesis and characterization of electrodeposited NiO thin film on electrode grade carbon plate for supercapacitor applications. Mater. Res. Express 2017, 4, 116412. [CrossRef]

121. Xu, L.; Jia, M.; Li, Y.; Zhang, S.; Jin, X. Design and synthesis of graphene/activated carbon/polypyrrole flexible supercapacitor electrodes. RSC Adv. 2017, 7, 31342-31351. [CrossRef]

122. Raj, C.J.; Kim, B.C.; Cho, W.-J.; Lee, W.-G.; Seo, Y.; Yu, K.-H. Electrochemical capacitor behavior of copper sulfide (CuS) nanoplatelets. J. Alloys Compd. 2014, 586, 191-196.

123. Qin, C.; Zhang, Y.; Wang, Z.; Xiong, H.; Yu, H.; Zhao, W. One-step synthesis of CuO@brass foil by dealloying method for low-cost flexible supercapacitor electrodes. J. Mater. Sci. Mater. Electron. 2016, 27, 9206-9215. [CrossRef]

124. Paleo, A.J.; Staiti, P.; Brigandì, A.; Ferreira, F.N.; Rocha, A.M.; Lufrano, F. Supercapacitors based on $\mathrm{AC} / \mathrm{MnO}_{2}$ deposited onto dip-coated carbon nanofiber cotton fabric electrodes. Energy Storage Mater. 2018, 215, 204-215. [CrossRef]

125. Nguyen, V.H.; Shim, J.-J. Microwave-assisted synthesis of porous nickel cobaltite with different morphologies in ionic liquid and their application in supercapacitors. Mater. Chem. Phys. 2016, 176, 6-11. [CrossRef]

126. Hong, S.; Kim, Y.; Kim, Y.; Suh, K.; Yoon, M.; Kim, K. Hierarchical Porous Carbon Materials Prepared by Direct Carbonization of Metal-Organic Frameworks as an Electrode Material for Supercapacitors. Bull. Korean Chem. Soc. 2020, 42, 309-314. [CrossRef]

127. Ubale, S.B.; Kale, S.B.; Mane, V.J.; Bagwade, P.P.; Lokhande, C.D. SILAR synthesized nanostructured ytterbium sulfide thin film electrodes for symmetric supercapacitors. J. Solid State Electrochem. 2021, 25, 1753-1764. [CrossRef]

128. Kolathodi, M.S.; Palei, M.; Natarajan, T.S.; Singh, G. $\mathrm{MnO}_{2}$ encapsulated electrospun $\mathrm{TiO}_{2}$ nanofibers as electrodes for asymmetric supercapacitors. Nanotechnology 2020, 31, 125401. [CrossRef]

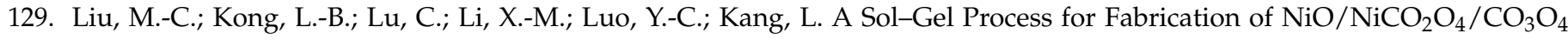
Composite with Improved Electrochemical Behavior for Electrochemical Capacitors. ACS Appl. Mater. Interfaces 2012, 4, $4631-4636$. [CrossRef]

130. Dong, J.; Hou, Z.; Zhao, Q.; Yang, Q. Synthesis and Characterization of Nickel-doped Manganese Dioxide Electrode Materials for Supercapacitors. In Proceedings of the International Symposium on Architecture Research Frontiers and Ecological Environment (ARFEE 2018), Wuhan, China, 14-16 December 2018.

131. Padmanathan, N.; Selladurai, S. Electrochemical capacitance of porous $\mathrm{NiO}-\mathrm{CeO}_{2}$ binary oxide synthesized via sol-gel technique for supercapacitor. Ionics 2013, 20, 409-420. [CrossRef]

132. Lima-Tenório, M.K.; Ferreira, C.S.; Rebelo, Q.H.F.; de Souza, R.F.B.; Passos, R.R.; Pineda, E.A.G.; Pocrifka, L.A. Pseudocapacitance Properties of $\mathrm{CO}_{3} \mathrm{O}_{4}$ Nanoparticles Synthesized Using a Modified Sol-Gel Method. Mater. Res. 2017, 21, e20170521. [CrossRef] 
133. Liu, T.-T.; Shao, G.-J.; Ji, M.-T.; Ma, Z.-P. Research progress in nano-structured $\mathrm{MnO}_{2}$ as electrode materials for supercapacitors. Asian J. Chem. 2013, 25, 7065-7070. [CrossRef]

134. Bhujun, B.; Tan, M.T.T.; Shanmugam, A.S. Study of mixed ternary transition metal ferrites as potential electrodes for supercapacitor applications. Results Phys. 2016, 7, 345-353. [CrossRef]

135. Ikkurthi, K.D.; Rao, S.S.; Jagadeesh, M.; Reddy, A.E.; Anitha, T.; Kim, H.J. Synthesis of nanostructured metal sulfides via a hydrothermal method and their use as an electrode material for supercapacitors. New J. Chem. 2018, 42, 19183-19192. [CrossRef]

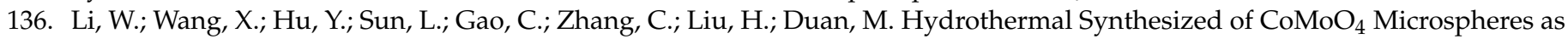
Excellent Electrode Material for Supercapacitor. Nanoscale Res. Lett. 2018, 13, 120. [CrossRef] [PubMed]

137. Kim, H.-Y.; Shin, J.; Jang, C.; Ju, Y.-W. Hydrothermal Synthesis of Three-Dimensional Perovskite $\mathrm{NiMnO}_{3}$ Oxide and Application in Supercapacitor Electrode. Energies 2020, 13, 11. [CrossRef]

138. Gu, Y.; Fan, L.Q.; Huang, J.-L.; Geng, C.-L.; Lin, J.-M.; Huang, M.-L.; Huang, Y.-F.; Wu, J.-H. Hydrothermal Synthesis of Co-Doped $\mathrm{NiSe}_{2}$ Nanowire for High-Performance Asymmetric Supercapacitors. Mater. Res. 2018, 11, 1468. [CrossRef]

139. Zheng, J.; Wang, F.; Ma, J.; Zhou, K.; Zheng, J.; Wang, D.F.; Ma, J.; Zhou, K. One-Step Hydrothermal Synthesis of Carbon-Coated Nickel-Copper Sulfide Nanoparticles for High-Performance Asymmetric Supercapacitors. Eur. J. Inorg. Chem. 2018, 2019, 1740-1747. [CrossRef]

140. Shinde, P.A.; Lokhande, V.C.; Patil, A.M.; Yadav, A.A.; Lokhande, P.C.D. Hydrothermal synthesis of manganese oxide thin films using different oxidizing agents for supercapacitor application. Int. J. Eng. Res. Technol. 2017, 10, 532-537.

141. Dong, H.; Li, Y.; Chai, H.; Cao, Y.; Chen, X. Hydrothermal Synthesis of $\mathrm{CuCO}_{2} \mathrm{~S}_{4}$ Nano-structure and N-Doped Graphene for High-Performance Aqueous Asymmetric Supercapacitors. ES Energy Environ. 2019, 4, 19-26.

142. Wei, W.; Liu, B.; Gan, Y.; Ma, H.; Chen, D.; Qi, J.; Li, S. One-step hydrothermal synthesis of $\mathrm{Ni}_{3} \mathrm{~S}_{2} / \mathrm{MoS}_{2}$ nanocomposites on rGO: Structural evolution and supercapacitor performance. Surf. Coat. Technol. 2020, 403, 126442. [CrossRef]

143. Rao, S.S.; Durga, I.K.; Naresh, B.; Jin-Soo, B.; Krishna, T.N.V.; In-Ho, C.; Ahn, J.-W.; Kim, H.-J. One-Pot Hydrothermal Synthesis of Novel Cu-MnS with PVP Cabbage-Like Nanostructures for High-Performance Supercapacitors. Energies 2018, 11, 1590. [CrossRef]

144. Fei, H.; Saha, N.; Kazantseva, N.; Moucka, R.; Cheng, Q.; Saha, P. A Highly Flexible Supercapacitor Based on MnO $2 /$ RGO Nanosheets and Bacterial Cellulose-Filled Gel Electrolyte. Materials 2017, 10, 1251. [CrossRef] [PubMed]

145. Zhang, S.; Li, Y.; Pan, N. Graphene based supercapacitor fabricated by vacuum filtration deposition. J. Power Sources 2012, 206, 476-482. [CrossRef]

146. Yang, Z.G.; Liu, N.N.; Dong, S.; Tian, F.S.; Gao, Y.P.; Hou, Z.Q. Supercapacitors based on free-standing reduced graphene oxides/carbon nanotubes hybrid films. SN Appl. Sci. 2019, 1, 47. [CrossRef]

147. Kumar, A.; Kumar, N.; Sharma, Y.; Leu, J.; Tseng, T.Y. Synthesis of Free-Standing Flexible rGO/MWCNT Films for Symmetric Supercapacitor Application. Nanoscale Res. Lett. 2019, 14, 17. [CrossRef] [PubMed]

148. Padwal, P.M.; Kadam, S.L.; Mane, S.M.; Kulkarni, S.B. Synthesis and characterization of supercapacitive behavior of electrodeposited PANI $/ \mathrm{Co}_{3} \mathrm{O}_{4}$ layered composite electrode. J. Chin. Adv. Mater. Soc. 2016, 4, 13-23. [CrossRef]

149. Kim, I.-H.; Kim, J.-H.; Lee, Y.-H.; Kim, K.-B. Synthesis and Characterization of Electrochemically Prepared Ruthenium Oxide on Carbon Nanotube Film Substrate for Supercapacitor Applications. J. Electrochem. Soc. 2005, 152, A2170. [CrossRef]

150. Kharade, P.M.; Chavan, S.G.; Salunkhe, D.J.; Joshi, P.B.; Mane, S.M.; Kulkarni, S.B. Synthesis and characterization of PANI/MnO 2 bi-layered electrode and its electrochemical supercapacitor properties. Mater. Res. Bull. 2014, 52, 37-41. [CrossRef]

151. Zhou, W.-J.; Xu, M.-W.; Zhao, D.-D.; Xu, C.-L.; Li, H.-L. Electrodeposition and characterization of ordered mesoporous cobalt hydroxide films on different substrates for supercapacitors. Microporous Mesoporous Mater. 2009, 117, 55-60. [CrossRef]

152. Dai, X.; Zhang, M.; Li, J.; Yang, D. Effects of electrodeposition time on a manganese dioxide supercapacitor. RSC Adv. 2020, $10,15860$.

153. Zhang, H.; Hu, Z.; Li, M.; Hu, L.; Jiao, S. A high-performance supercapacitor based on a polythiophene/multiwalled carbon nanotube composite by electropolymerization in an ionic liquid microemulsion. J. Mater. Chem. A 2014, 2, 17024-17030. [CrossRef]

154. Ahmad, A.; Azam, P.A.; Parveen, D.A.; Raushan, M.A.; Ahmad, F. Synthesis and Characterization of Polyaniline@ Graphene Nanocomposite by in-situ Polymerization for Supercapacitor Application. In Proceedings of the First International Conference on Advanced Materials for Power Engineering (ICAMPE), Kottayam Kerala, India, 11-13 December 2015.

155. Sun, Y.; Jia, D.; Zhang, A.; Tian, J.; Zheng, Y.; Zhao, W.; Cui, L.; Liu, J. Synthesis of polypyrrole coated melamine foam by in-situ interfacial polymerization method for highly compressible and flexible supercapacitor. J. Colloid Interface Sci. 2019, 557, 617-627. [CrossRef] [PubMed]

156. Parveen, N.; Ansari, M.O.; Han, T.H.; Cho, M.H. Simple and rapid synthesis of ternary polyaniline/titanium oxide/graphene by simultaneous $\mathrm{TiO}_{2}$ generation and aniline oxidation as hybrid materials for supercapacitor applications. J. Solid State Electrochem. 2017, 21, 57-68. [CrossRef]

157. Wang, Y.; Tang, S.; Vongehr, S.; Syed, J.A.; Wang, X.; Meng, X. High-Performance Flexible Solid-State Carbon Cloth Supercapacitors Based on Highly Processible N-Graphene Doped Polyacrylic Acid/Polyaniline Composites. Sci. Rep. 2016, 6, 12883. [CrossRef] [PubMed]

158. Murali, S.; Dammala, P.K.; Rani, B.; Santhosh, R.; Jadhao, C.; Sahu, N.K. Polyol mediated synthesis of anisotropic ZnO nanomaterials and composite with rGO: Application towards hybrid supercapacitor. J. Alloys Compd. 2019, 844, 156149. [CrossRef] 
159. Deshagani, S.; Ghosal, P.; Deepa, M. Altered crystal structure of nickel telluride by selenide doping and a poly(N-methylpyrrole) coating amplify supercapacitor performance. Electrochim. Acta 2020, 345, 136200. [CrossRef]

160. Wu, P.; Gao, M.; Wang, Z.; Yu, S.; Feng, M.; Liu, S.; Fu, J. Nitrogen, phosphorus and sulfur tri-doped hollow carbon nanocapsules derived from core@shell zeolitic imidazolate framework@poly(cyclotriphosphazene-co-4,4'-sulfonyldiphenol) for advanced supercapacitors. Electrochim. Acta 2020, 367, 137507. [CrossRef]

161. Arulraj, A.; Ilayaraja, N.; Rajeshkumar, V.; Ramesh, M. Direct Synthesis of cubic shaped $\mathrm{Ag}_{2} \mathrm{~S}$ on Ni mesh as Binder-free Electrodes for Energy Storage Applications. Sci. Rep. 2019, 9, 10108. [CrossRef] [PubMed]

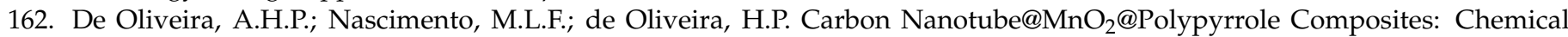
Synthesis, Characterization and Application in Supercapacitors. Mater. Res. 2016, 19, 1080-1087. [CrossRef]

163. Ray, J.; Patel, M.; Ghediya, P.; Chaudhuri, T.K. Preparation and characterization of chemically deposited nickel sulphide film and its application as a potential counter electrode. Mater. Res. Express 2016, 3, 075906. [CrossRef]

164. Rakhi, R.B.; Ahmed, B.; Anjum, D.H.; Alshareef, H.N. Direct chemical synthesis of $\mathrm{MnO}_{2}$ nanowhiskers on MXene surfaces for supercapacitor applications. ACS Appl. Mater. Interfaces 2016, 29, 18806-18814. [CrossRef]

165. Raghavendra, K.V.G.; Vinoth, R.; Zeb, K.; Gopi, C.V.M.; Sambasivam, S.; Kummara, M.R.; Obaidat, I.M.; Kim, H.J. An intuitive review of supercapacitors with recent progress and novel device applications. J. Energy Storage 2020, 31, 101652. [CrossRef]

166. Wanga, N.; Zhao, P.; Liang, K.; Yao, M.; Yang, Y.; Hu, W. CVD-grown polypyrrole nanofilms on highly mesoporous structure $\mathrm{MnO}_{2}$ for high performance asymmetric supercapacitors. Chem. Eng. J. 2017, 307, 105-112. [CrossRef]

167. Sobaszek, M.; Siuzdak, K.; Sawczak, M.; Ryl, J.; Bogdanowicz, R. Fabrication and characterization of composite TiO 2 nanotubes/boron-doped diamond electrodes towards enhanced supercapacitors. Thin Solid Film. 2015, 601, 35-40. [CrossRef]

168. Kim, Y.-S.; Kumar, K.; Fisher, F.T.; Yang, E.-H. Out-of-plane growth of CNTs on graphene for supercapacitor applications. Nanotechnology 2011, 23, 015301. [CrossRef] [PubMed]

169. Cheng, T.; Yu, B.; Cao, L.; Tan, H.; Li, X.; Zheng, X.; Li, W.; Ren, Z.; Bai, J. Synthesis and loading-dependent characteristics of nitrogen-doped graphene foam/carbon nanotube/manganese oxide ternary composite electrodes for high performance supercapacitors. J. Colloid Interface Sci. 2017, 501, 1-10. [CrossRef]

170. Pratheepa, M.I.; Lawrence, M. Synthesis of pure, $\mathrm{Cu}$ and $\mathrm{Zn}$ doped $\mathrm{CdO}$ nanoparticles by co-precipitation method for supercapacitor applications. Vacuum 2019, 162, 208-213. [CrossRef]

171. Mahmoud, B.A.; Mirghni, A.A.; Oyedotun, K.O.; Momodu, D.; Fasakin, O.; Manyala, N. Synthesis of cobalt phosphate-graphene foam material via co-precipitation approach for a positive electrode of an asymmetric supercapacitors device. J. Alloys Compd. 2019, 818, 153332. [CrossRef]

172. Naderi, H.R.; Ghaderi, A.; Seyedi, Z.S.; Eghbali-Arani, M. Facile synthesis and characterization of CeMoO 4 nanostructure via co-precipitation method and investigate its application supercapacitor. Anal. Bioanal. Electrochem. 2019, 11, 679-690.

173. Yadav, M.S. Synthesis and characterization of $\mathrm{Mn}_{2} \mathrm{O}_{3}-\mathrm{Mn}_{3} \mathrm{O}_{4}$ nanoparticles and activated charcoal based nanocomposite for supercapacitor electrode application. J. Energy Storage 2018, 27, 101079. [CrossRef]

174. Babulal, S.M.; Venkatesh, K.; Chen, T.-W.; Chen, S.-M.; Krishnapandi, A.; Rwei, S.-P.; Ramara, S.K. Synthesis of MnMoO 4 Nanorods by a Simple Co-Precipitation Method in Presence of Polyethylene Glycol for Pseudocapacitor Application. Int. J. Electrochem. Sci. 2020, 15, 7053-7063. [CrossRef]

175. Wang, H.; Wang, J.; Liang, M.; He, Z.; Li, K.; Song, W.; Tian, S.; Duan, W.; Zhao, Y.; Miao, Z. Novel Dealloying-Fabricated $\mathrm{NiS} / \mathrm{NiO}$ Nanoparticles with Superior Cycling Stability for Supercapacitors. ACS Omega 2021, 28, 17999-18007. [CrossRef] [PubMed]

176. Wang, H.; Liang, M.; Ma, C.; Shi, W.; Duan, D.; He, G.; Sun, Z. Novel dealloying-fabricated $\mathrm{NiCo}_{2} \mathrm{~S}_{4}$ nanoparticles with excellent cycling performance for supercapacitors. Nanotechnology 2019, 30, 235402. [CrossRef] [PubMed]

177. Zheng, D.; Li, M.; Li, Y.; Qin, C.; Wang, Y.; Wang, Z. A Ni(OH $)_{2}$ nanopetals network for high-performance supercapacitors synthesized by immersing Ni nanofoam in water. Beilstein J. Nanotechnol. 2019, 10, 281-293. [CrossRef]

178. Wang, R.; Sui, Y.; Yang, F.; Qi, J.; Wei, F.; He, Y.; Meng, Q.; Sun, Z. Synthesis of $\mathrm{Cu}_{2} \mathrm{O}$ by oxidation-assisted dealloying method for flexible all-solid-state asymmetric supercapacitors. J. Mater. Sci. Mater. Electron. 2018, 29, 2080-2090. [CrossRef]

179. Liu, F.; Wang, Z.; Zhang, H.; Jin, L.; Chu, X.; Gu, B.; Huang, H.; Yang, W. Nitrogen, oxygen and sulfur co-doped hierarchical porous carbons toward high-performance supercapacitors by direct pyrolysis of kraft lignin. Carbon 2019, 149, 105-116. [CrossRef]

180. Zhang, S.; Su, Y.; Zhu, S.; Zhang, H.; Zhang, Q. Effects of pretreatment and $\mathrm{FeCl}_{3}$ preload of rice husk on synthesis of magnetic carbon composites by pyrolysis for supercapacitor application. J. Anal. Appl. Pyrolysis 2018, 135, 22-31. [CrossRef]

181. Reimer, C.; Snowdon, M.R.; Vivekanandhan, S.; You, X.; Misra, M.; Gregori, S.; Mielewski, D.F.; Mohanty, A.K. Synthesis and characterization of novel nitrogen doped biocarbons from distillers dried grains with solubles (DDGS) for supercapacitor applications. Bioresour. Technol. Rep. 2020, 9, 100375. [CrossRef]

182. Ding, Y.; Li, Y.; Dai, Y.; Han, X.; Xing, B.; Zhu, L.; Qiu, K.; Wang, S. A novel approach for preparing in-situ nitrogen doped carbon via pyrolysis of bean pulp for supercapacitors. Energy 2021, 216, 119227. [CrossRef]

183. Du, J.; Liu, L.; Yu, Y.; Zhang, Y.; Lv, H.; Chen, A. N-doped ordered mesoporous carbon spheres derived by confined pyrolysis for high supercapacitor performance. J. Mater. Sci. Technol. 2019, 35, 2178-2186. [CrossRef]

184. Wang, Q.; Gao, H.; Qin, X.; Dai, J.; Li, W. Fabrication of $\mathrm{NiFe}_{2} \mathrm{O}_{4} @ \mathrm{CoFe}_{2} \mathrm{O}_{4}$ core-shell nanofibers for high-performance supercapacitors. Mater. Res. Express 2020, 7, 015020. [CrossRef] 
185. Lu, Y.; Zhao, M.; Luo, R.; Yu, Q.; Lv, J.; Wang, W.; Yan, H.; Peng, T.; Liu, X.; Luo, Y. Electrospun porous $\mathrm{MnMoO}_{4}$ nanotubes as high-performance electrodes for asymmetric supercapacitors. J. Solid State Electrochem. 2018, 22, 657-666. [CrossRef]

186. Subramani, S.; Rajiv, S. Electrospun based polythioaniline/polyvinylalcohol/graphene oxide composite nanofibers for supercapacitor application. Ionics 2021, 27, 2203-2218. [CrossRef]

187. Pant, B.; Park, M.; Park, S.-J. $\mathrm{TiO}_{2} \mathrm{NPs}$ Assembled into a Carbon Nanofiber Composite Electrode by a One-Step Electrospinning Process for Supercapacitor Applications. Polymers 2019, 11, 899. [CrossRef] [PubMed]

188. Lan, Z.; Luo, L.; Ye, J.; Luo, Q.; Zhao, L. Preparation of novel morning glory structure $\gamma-\mathrm{MnO}_{2} /$ carbon nanofiber composite materials with the electrospinning method and their high electrochemical performance. RSC Adv. 2020, 10, 36546-36553. [CrossRef]

189. Levitt, A.S.; Alhab, M.; Hatter, C.B.; Sarycheva, A.; Dion, G.; Gogotsi, Y. Electrospun MXene/carbon nanofibers as supercapacitor electrodes. J. Mater. Chem. A 2018, 7, 269-277. [CrossRef]

190. Cheng, Y.; Wu, L.; Fang, C.; Li, T.; Chen, J.; Yang, M.; Zhang, Q. Synthesis of porous carbon materials derived from laminaria japonica via simple carbonization and activation for supercapacitors. J. Mater. Res. Technol. 2020, 9, 3261-3271. [CrossRef]

191. Zequine, C.; Ranaweera, C.K.; Wang, Z.; Singh, S.; Tripathi, P.; Srivastava, O.N.; Gupta, B.K.; Ramasamy, K.; Kahol, P.K.; Dvornic, P.R.; et al. High Per formance and Flexible Supercapacitors based on Carbonized Bamboo Fibers for Wide Temperature Applications. Sci. Rep. 2016, 6, 31704. [CrossRef]

192. Sankari, M.S.; Vivekanandhan, S. Jatropha Oil Cake Based Activated Carbon for Symmetric Supercapacitor Application: A Comparative Study on Conventional and Hydrothermal Carbonization Processes. Energy Technol. Environ. Sci. 2020, 5, 1375-1384. [CrossRef]

193. Rantho, M.N.; Madito, M.J.; Oyedotun, K.O.; Tarimo, D.J.; Manyala, N. Hybrid electrochemical supercapacitor based on birnessitetype $\mathrm{MnO}_{2}$ /carbon composite as the positive electrode and carbonized iron-polyaniline/nickel graphene foam as a negative electrode. AIP Adv. 2020, 10, 065113. [CrossRef]

194. Hendriansyah, R.; Prakoso, T.; Widiatmoko, P.; Nurdin, I.; Devianto, H. Manufacturing Carbon Material by Carbonization of Cellulosic Palm Oil Waste for Supercapacitor Material. In Proceedings of the 24th Regional Symposium on Chemical Engineering (RSCE 2017), Semarang, Indonesia, 15-16 November 2017.

195. Kim, H.; Sohail, M.; Wang, C.; Rosillo-Lopez, M.; Baek, K.; Koo, J.; Seo, M.W.; Kim, S.; Foord, J.S.; Han, S.O. Facile one-pot synthesis of Bimetallic Co/Mn-MoFs@Rice Husks, and its Carbonization for supercapacitor electrodes. Sci. Rep. 2019 , 9, 8984. [CrossRef] [PubMed]

196. Balakrishnan, K.; Kumar, M.; Subramania, A. Synthesis of Polythiophene and its Carbonaceous Nanofibers as Electrode Materials for Asymmetric Supercapacitors. Adv. Mat. Res. 2014, 938, 151-157. [CrossRef]

197. Arunachalam, S.; Kirubasankar, B.; Pan, D.; Liu, H.; Yan, C.; Guo, Z.; Angaiah, S. Research progress in rare earths and their composites based electrode materials for supercapacitors. Green Energy Environ. 2020, 5, 259-273. [CrossRef]

198. Kim, H.P.; Vasilopoulou, M.; Ullah, H.; Bibi, S.; Macedo, A.G.; Silva, W.J.; Schneider, F.K.; Tahir, A.A.; Teridi, M.A.M.; Gao, P.; et al. Hysteresis-free perovskite transistor with exceptional stability through molecular cross-linking and amine-based surface passivation. Nanoscale 2020, 12, 7650. [CrossRef]

199. Chougalea, U.M.; Thombarea, J.V.; Fularia, V.J.; Kadam, A.B. Synthesis of polyaniline nanofibres by SILAR method for supercapacitor application. In Proceedings of the 2013 International Conference on Energy Efficient Technologies for Sustainability, Nagercoil, India, 10-12 April 2013.

200. Hung, S.-C.; Chou, Y.-R.; Dong, C.-D.; Tsai, K.-C.; Yang, W.-D. Enhanced Activity of Hierarchical Nanostructural Birnessite-MnO ${ }_{2-}$ Based Materials Deposited onto Nickel Foam for Efficient Supercapacitor Electrodes. Nanomaterials 2020, 10, 1933. [CrossRef]

201. Parveen, S.; Sharma, S.K.; Pandey, S.N. Solid-state symmetric supercapacitor based on Y doped $\mathrm{Sr}(\mathrm{OH})_{2}$ using SILAR method Energy 2020, 197, 117163.

202. Lei, Y.; Li, J.; Wang, Y.; Gu, L.; Chang, Y.; Yuan, H.; Xiao, D. Rapid Microwave-Assisted Green Synthesis of 3D Hierarchical Flower-Shaped $\mathrm{NiCo}_{2} \mathrm{O}_{4}$ Microsphere for High-Performance Supercapacitor. ACS Appl. Mater. Interfaces 2014, 6, 1773-1780. [CrossRef] [PubMed]

203. Sun, D.; Jin, L.; Chen, Y.; Zhang, J.R.; Zhu, J.J. Microwave-Assisted In Situ Synthesis of Graphene/PEDOT Hybrid and Its Application in Supercapacitors. ChemPlusChem 2013, 78, 227-234. [CrossRef]

204. Zou, J.Z.; Liu, S.Y.; Wu, H.L.; Luo, Q.; Huang, L.; Zeng, X.R.; Ma, J.; Yao, Y.C.; Zhang, Q.; Peng, B.L. Hierarchical Porous Carbon Materials Derived from Microwave-assisted Heating of Zeolitic Imidazolate Frameworks for Use as Supercapacitor Electrodes. In Proceedings of the International Workshop on Materials, Chemistry and Engineering, Xiamen, China, 16-17 June 2018; Science and Technology Publications: Setúbal, Portugal; pp. 571-583.

205. Jablonskiene, J.; Simkunaite, D.; Vaiciuniene, J.; Stalnionis, G.; Drabavicius, A.; Jasulaitiene, V.; Pakstas, V.; TamasauskaiteTamasiunaite, L.; Norkus, E. Synthesis of Carbon-Supported $\mathrm{MnO}_{2}$ Nanocomposites for Supercapacitors Application. Crystals 2021, 11, 784. [CrossRef]

206. Tian, Y.; Du, H.; Zhang, M.; Zheng, Y.; Guo, Q.; Zhang, H.; Luo, J.; Zhang, X. Microwave synthesis of $\mathrm{MoS}_{2} / \mathrm{MoO}_{2} @ C N T$ nanocomposites with excellent cycling stability for supercapacitor electrodes. J. Mater. Chem. C 2019, 7, 9545-9555. [CrossRef]

207. Zhang, J.; Dong, L.; Xu, C.; Hao, J.; Kang, F.; Li, J. Comprehensive approaches to three-dimensional flexible supercapacitor electrodes based on $\mathrm{MnO}_{2}$ /carbon nanotube/activated carbon fiber felt. J. Mater. Sci. 2017, 52, 5788-5798. [CrossRef] 
208. Su, S.; Lai, L.; Li, R.; Lin, Y.; Dai, H.; Zhu, X. Annealing-Assisted Dip-Coating Synthesis of Ultrafine $\mathrm{Fe}_{3} \mathrm{O}_{4} \mathrm{Nanoparti-}^{-}$ cles/Graphene on Carbon Cloth for Flexible Quasi-Solid-State Symmetric Supercapacitors. ACS Appl. Energy Mater. 2020, 3, 9379-9389. [CrossRef]

209. Karade, S.S.; Nimbalkar, A.S.; Eum, J.-H.; Kim, H. Lichen-like anchoring of $\mathrm{MoSe}_{2}$ on functionalized multiwalled carbon nanotubes: An efficient electrode for asymmetric supercapacitors. RSC Adv. 2020, 10, 40092. [CrossRef]

210. Qu, G.; Zhou, Y.; Zhang, J.; Xiong, L.; Yue, Q.; Kang, Y. Alternately Dipping Method to Prepare Graphene Fiber Electrodes for Ultra-high-Capacitance Fiber Supercapacitors. iScience 2020, 23, 101396. [CrossRef] [PubMed]

211. Xiao, C.-y.; Zhang, W.-1.; Lin, H.-b.; Tian, Y.-X.; Li, X.-x.; Tian, Y.-y.; Lu, H.-y. Modification of a rice husk-based activated carbon by thermal treatment and its effect on its electrochemical performance as a supercapacitor electrode. New Carbon Mater. 2019, 34, 341-348. [CrossRef]

212. Ni, J.; Yang, L.; Wang, H.; Gao, L. A high-performance hybrid supercapacitor with $\mathrm{Li}_{4} \mathrm{Ti}_{5} \mathrm{O}_{12}-\mathrm{C}$ nano-composite prepared by in situ and ex situ carbon modification. J. Solid State Electrochem. 2012, 16, 2791-2796. [CrossRef]

213. Karuppaiah, M.; Sakthivel, P.; Asaithambi, S.; Murugan, R.; Babu, G.A.; Yuvakkumar, R.; Ravi, G. Solvent dependent morphological modification of micro-nano assembled $\mathrm{Mn}_{2} \mathrm{O}_{3} / \mathrm{NiO}$ composites for high performance supercapacitor applications. Ceram. Int. 2018, 45, 4298-4307. [CrossRef]

214. Jana, M.; Khanra, P.; Murmu, N.C.; Samanta, P.; Lee, J.H.; Kuil, T. Covalent surface modification of chemically derived graphene and its application as supercapacitor electrode material. Phys. Chem. Chem. Phys. 2014, 16, 7618-7626. [CrossRef] [PubMed]

215. Liu, E.H.; Li, W.; Li, J.; Meng, X.Y.; Ding, R.; Tan, S.T. Preparation and characterization of nanostructured $\mathrm{NiO} / \mathrm{MnO}_{2}$ composite electrode for electrochemical supercapacitors. Mater. Res. Bull. 2009, 44, 1122-1126. [CrossRef]

216. Wang, X.W.; Zheng, D.L.; Yang, P.Z.; Wang, X.E.; Zhu, Q.Q.; Ma, P.F.; Sun, L.Y. Preparation and electrochemical properties of $\mathrm{NiO}-\mathrm{Co}_{3} \mathrm{O}_{4}$ composite as electrode materials for supercapacitors. Chem. Phys. Lett. 2016, 667, 260-266. [CrossRef]

217. Zhang, Y.X.; Li, F.; Huang, M. One-step hydrothermal synthesis of hierarchical $\mathrm{MnO}_{2}$-coated CuO flower-like nanostructures with enhanced electrochemical properties for supercapacitor. Mater. Lett. 2013, 112, 203-206. [CrossRef]

218. Xu, G.; Wang, F.; Jin, C. Synthesis and electrochemical performance of $\mathrm{ZnO@MnO} 2$ core-shell column arrays on Ni Foam as electrode for supercapacitors. J. Mater. Sci. Mater. Electron. 2017, 28, 18262-18268. [CrossRef]

219. Ouyang, Y.; Xia, X.; Ye, H.; Wang, L.; Jiao, X.; Lei, W.; Hao, Q. Three-dimensional hierarchical structure ZnO@C@NiO on carbon cloth for asymmetric supercapacitor with enhanced cycle stability. ACS Appl. Mater. Interfaces 2018, 10, 3549-3561. [CrossRef] [PubMed]

220. Ates, M.; Kuzgun, O.; Yıldırım, M.; Yoruk, O.; Bayrak, Y. Supercapacitor performances of $\mathrm{RuO}_{2} / \mathrm{MWCNT} \mathrm{RuO} / \mathrm{Fullerene}$ nanocomposites. Energy Storage 2019, 1, e86. [CrossRef]

221. Li, X.; Zheng, F.; Luo, Y.; Wu, Y.; Lu, F. Preparation and electrochemical performance of $\mathrm{TiO}_{2}-\mathrm{SnO}_{2}$ doped $\mathrm{RuO}_{2}$ composite electrode for supercapacitors. Electrochim. Acta 2017, 237, 177-184. [CrossRef]

222. Yedluri, A.K.; Anitha, T.; Kim, H.-J. Fabrication of Hierarchical $\mathrm{NiMoO}_{4} / \mathrm{NiMoO}_{4}$ Nanoflowers on Highly Conductive Flexible Nickel Foam Substrate as a Capacitive Electrode Material for Supercapacitors with Enhanced Electrochemical Performance. Energies 2019, 12, 1143. [CrossRef]

223. Pang, H.; Ma, Y.; Li, G.; Chen, J.; Zhang, J.; Zheng, H.; Du, W. Facile synthesis of porous ZnO-NiO composite micropolyhedrons and their application for high power supercapacitor electrode materials. Dalton Trans. 2012, 41, 13284-13291. [CrossRef] [PubMed]

224. Ajami, N. Synthesis and Electrochemical Capacitor Characterization of Novel Composite Materials with p-Type Conductive Polymer. Int. J. Electrochem. 2019, 2019, 3409568. [CrossRef]

225. Melo, J.P.; Schulz, E.N.; Morales-Verdejo, C.; Horswell, S.L.; Camarada, M.B. Synthesis and Characterization of Graphene/ Polythiophene (GR/PT) Nanocomposites: Evaluation as High-Performance Supercapacitor Electrodes. Int. J. Electrochem. Sci. 2017, 12, 2933-2948. [CrossRef]

226. Anjana Anandan Vannathan, T.K. Debaprasad Shee, and Sib Sankar Mal, One-Pot Synthesis of Polyoxometalate Decorated Polyindole for Energy Storage Supercapacitors. ACS Omega 2021, 6, 11199-11208. [CrossRef] [PubMed]

227. Ajami, N. PANOA $/ \mathrm{MnO}_{2} / \mathrm{MWCNT}$ nanocomposite: Synthesis, characterization, and electrochemical performance as efficient electrode materials for supercapacitors. J. Macromol. Sci. Part. A 2019, 57, 1-8. [CrossRef]

228. Zhang, Z.J.; Song, Q.Z.; He, W.X.; Liu, P.; Xiao, Y.H.; Liang, J.Y.; Chen, X.Y. Dual surface modification of carbon materials by polydopamine and phosphomolybdic acid for supercapacitor application. R. Soc. Chem. 2019, 48, 17321-17330. [CrossRef] [PubMed]

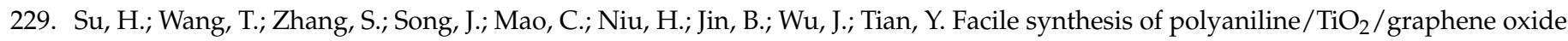
composite for high performance supercapacitors. Solid State Sci. 2012, 14, 677-681. [CrossRef]

230. Gao, H.; Wu, F.; Wang, X.; Hao, C.; Ge, C. Preparation of $\mathrm{NiMoO}_{4}$-PANI core-shell nanocomposite for the high-performance all-solid-state asymmetric supercapacitor. Int. J. Hydrog. Energy 2018, 43, 18349-18362. [CrossRef]

231. Ramesh, S.; Yadav, H.M.; Karuppasamy, K.; Vikraman, D.; Kim, H.-S.; Kim, J.-H.; Kim, H.S. Fabrication of manganese oxide@nitrogen doped graphene oxide/polypyrrole $\left(\mathrm{MnO}_{2} @ \mathrm{NGO} / \mathrm{PPy}\right)$ hybrid composite electrodes for energy storage devices. J. Mater. Res. Technol. 2019, 8, 4227-4238. [CrossRef]

232. Feng, M.; Lu, W.; Zhou, Y.; Zhen, R.; He, H.; Wang, Y.; Li, C. Synthesis of polypyrrole/nitrogen-doped porous carbon matrix composite as the electrode material for supercapacitors. Sci. Rep. 2020, 10, 15370. [CrossRef] 
233. Wang, X.; Wang, T.; Liu, D.; Guo, J.; Liu, P. Synthesis and Electrochemical Performance of $\mathrm{CeO}_{2} /$ PPy Nanocomposites: Interfacial Effect. Ind. Eng. Chem. Res. 2016, 55, 866-874. [CrossRef]

234. Yu, H.; Jang, K.; Chung, D.; Ahn, H. Fabrication and Electrochemical Characterization of Polyaniline/Titanium Oxide Nanoweb Composite Electrode for Supercapacitor Application. J. Nanosci. Nanotechnol. 2016, 16, 2937-2943. [CrossRef]

235. Banerjee, S.; De, B.; Sinha, P.; Cherusseri, J.; Kar, K.K. Applications of Supercapacitors. In Handbook of Nanocomposite Supercapacitor Materials I: Characteristics; Kar, K.K., Ed.; Springer: Cham, Switzerland, 2020; pp. 341-350.

236. Ashraf, M.; Shah, S.S.; Khan, I.; Aziz, M.A.; Ullah, N.; Khan, M.; Adil, S.F.; Liaqat, Z.; Usman, M.; Tremel, W.; et al. A HighPerformance Asymmetric Supercapacitor Based on Tungsten Oxide Nanoplates and Highly Reduced Graphene Oxide Electrodes. Chem. Eur. J. 2021, 27, 6973-6984. [CrossRef] [PubMed]

237. Cai, G.; Wang, X.; Cui, M.; Darmawan, P.; Wang, J.; Eh, A.L.-S.; Lee, P.S. Electrochromo-supercapacitor based on direct growth of NiO nanoparticles. Nano Energy 2015, 12, 258-267. [CrossRef]

238. Dubal, D.P.; Chodankar, N.R.; Kim, D.-H.; Gomez-Romero, P. Towards flexible solid-state supercapacitors for smart and wearable electronics. Chem. Soc. Rev. 2018, 47, 2065-2129. [CrossRef] [PubMed]

239. Zhang, F.; Zhang, T.; Yang, X.; Zhang, L.; Leng, K.; Huang, Y.; Chen, Y. A high-performance supercapacitor-battery hybrid energy storage device based on graphene-enhanced electrode materials with ultrahigh energy density. Energy Environ. Sci. 2013, 6, 1623-1632. [CrossRef]

240. Peng, X.; Shuhai, Q.; Changjun, X. A new supercapacitor and li-ion battery hybrid system for electric vehicle in ADVISOR. J. Phys. Conf. Ser. 2017, 806, 012015. [CrossRef]

241. Lu, K.; Li, D.; Gao, X.; Dai, H.; Wang, N.; Ma, H. An advanced aqueous sodium-ion supercapacitor with a manganous hexacyanoferrate cathode and $\mathrm{Fe}_{3} \mathrm{O}_{4}$ /rGO anode. J. Mater. Chem. A 2015, 3, 16013-16019. [CrossRef]

242. Komaba, S.; Hasegawa, T.; Dahbi, M.; Kubota, K. Potassium intercalation into graphite to realize high-voltage/high-power potassium-ion batteries and potassium-ion capacitors. Electrochem. Commun. 2015, 60, 172-175. [CrossRef]

243. Peng, X.; Xu, W.; Chen, L.; Ding, Y.; Chen, S.; Wang, X.; Hou, H. Polyimide complexes with high dielectric performance: Toward polymer film capacitor applications. J. Mater. Chem. C 2016, 4, 6452-6456. [CrossRef]

244. Presser, V.; Dennison, C.R.; Campos, J.; Knehr, K.W.; Kumbur, E.C.; Gogotsi, Y. The electrochemical flow capacitor: A new concept for rapid energy storage and recovery. Adv. Energy Mater. 2012, 2, 895-902. [CrossRef]

245. Boota, M.; Hatzell, K.; Kumbur, E.; Gogotsi, Y. Towards high-energy-density pseudocapacitive flowable electrodes by the incorporation of hydroquinone. ChemSusChem 2015, 8, 835-843. [CrossRef] [PubMed]

246. Wang, F.; Wu, X.; Yuan, X.; Liu, Z.; Zhang, Y.; Fu, L.; Zhu, Y.; Zhou, Q.; Wu, Y.; Huang, W. Latest advances in supercapacitors: From new electrode materials to novel device designs. Chem. Soc. Rev. 2017, 46, 6816-6854. [CrossRef]

247. Rangom, Y.; Tang, X.; Nazar, L.F. Carbon nanotube-based supercapacitors with excellent ac line filtering and rate capability via improved interfacial impedance. ACS Nano 2015, 9, 7248-7255. [CrossRef] [PubMed]

248. Wu, Z.; Li, L.; Lin, Z.; Song, B.; Li, Z.; Moon, K.-S.; Wong, C.-P.; Bai, S.-L. Alternating current line-filter based on electrochemical capacitor utilizing template-patterned graphene. Sci. Rep. 2015, 5, 1-7. [CrossRef] [PubMed]

249. Kurra, N.; Hota, M.K.; Alshareef, H.N. Conducting polymer micro-supercapacitors for flexible energy storage and Ac line-filtering. Nano Energy 2015, 13, 500-508. [CrossRef]

250. Qi, D.; Liu, Y.; Liu, Z.; Zhang, L.; Chen, X. Design of architectures and materials in in-plane micro-supercapacitors: Current status and future challenges. Adv. Mater. 2017, 29, 1602802. [CrossRef] [PubMed]

251. Shao, Y.; Li, J.; Li, Y.; Wang, H.; Zhang, Q.; Kaner, R.B. Flexible quasi-solid-state planar micro-supercapacitor based on cellular graphene films. Mater. Horiz. 2017, 4, 1145-1150. [CrossRef]

252. Liu, Z.; Wang, H.I.; Narita, A.; Chen, Q.; Mics, Z.; Turchinovich, D.; Kläui, M.; Bonn, M.; Müllen, K. Photoswitchable microsupercapacitor based on a diarylethene-graphene composite film. J. Am. Chem. Soc. 2017, 139, 9443-9446. [CrossRef] [PubMed]

253. Lee, J.; Seok, J.Y.; Son, S.; Yang, M.; Kang, B. High-energy, flexible micro-supercapacitors by one-step laser fabrication of a self-generated nanoporous metal/oxide electrode. J. Mater. Chem. A 2017, 5, 24585-24593. [CrossRef]

254. Yin, Y.; Feng, K.; Liu, C.; Fan, S. A polymer supercapacitor capable of self-charging under light illumination. J. Phys. Chem. C 2015, 119, 8488-8491. [CrossRef]

255. Humayun, M.; Ullah, H.; Usman, M.; Habibi-Yangjeh, A.; Tahir, A.A.; Wang, C.; Luo, W. Perovskite-type lanthanum ferrite based photocatalysts: Preparation, properties, and applications. J. Energy Chem. 2022, 66, 314-338. [CrossRef]

256. Xu, J.; Wu, H.; Lu, L.; Leung, S.F.; Chen, D.; Chen, X.; Fan, Z.; Shen, G.; Li, D. Integrated photo-supercapacitor based on bi-polar $\mathrm{TiO}_{2}$ nanotube arrays with selective one-side plasma-assisted hydrogenation. Adv. Funct. Mater. 2014, 24, 1840-1846. [CrossRef]

257. Usman, M.; Helal, A.; Abdelnaby, M.M.; Alloush, A.M.; Zeama, M.; Yamani, Z.H. Trends and Prospects in UiO-66 Metal-Organic Framework for $\mathrm{CO}_{2}$ Capture, Separation, and Conversion. Chem. Rec. 2021, 21, 1771-1791. [CrossRef] [PubMed]

258. Härtel, A.; Janssen, M.; Weingarth, D.; Presser, V.; van Roij, R. Heat-to-current conversion of low-grade heat from a thermocapacitive cycle by supercapacitors. Energy Environ. Sci. 2015, 8, 2396-2401. [CrossRef]

259. Kim, S.L.; Lin, H.T.; Yu, C. Thermally Chargeable Solid-State Supercapacitor. Adv. Energy Mater. 2016, 6, 1600546. [CrossRef]

260. Al-zubaidi, A.; Ji, X.; Yu, J. Thermal charging of supercapacitors: A perspective. Sustain. Energy Fuels 2017, 1, 1457-1474. [CrossRef]

261. Wang, J.; Feng, S.-P.; Yang, Y.; Hau, N.Y.; Munro, M.; Ferreira-Yang, E.; Chen, G. "Thermal charging" phenomenon in electrical double layer capacitors. Nano Lett. 2015, 15, 5784-5790. [CrossRef] [PubMed] 
262. Chaharsoughi, M.S. Hybrid Plasmonics for Energy Harvesting and Sensing of Radiation and Heat; Linköping University Electronic Press: Linköping, Switzerland, 2020; Volume 2045.

263. Guan, C.; Liu, X.; Ren, W.; Li, X.; Cheng, C.; Wang, J. Rational Design of Metal-Organic Framework Derived Hollow $\mathrm{NiCo}_{2} \mathrm{O}_{4}$ Arrays for Flexible Supercapacitor and Electrocatalysis. Adv. Energy Mater. 2017, 7, 1602391. [CrossRef]

264. Wang, S.; Liu, N.; Su, J.; Li, L.; Long, F.; Zou, Z.; Jiang, X.; Gao, Y. Highly stretchable and self-healable supercapacitor with reduced graphene oxide based fiber springs. ACS Nano 2017, 11, 2066-2074. [CrossRef] [PubMed]

265. Huang, Y.; Zhu, M.; Pei, Z.; Xue, Q.; Huang, Y.; Zhi, C. A shape memory supercapacitor and its application in smart energy storage textiles. J. Mater. Chem. A 2016, 4, 1290-1297. [CrossRef]

266. Xing, L.; Nie, Y.; Xue, X.; Zhang, Y. PVDF mesoporous nanostructures as the piezo-separator for a self-charging power cell. Nano Energy 2014, 10, 44-52. [CrossRef]

267. Ramadoss, A.; Saravanakumar, B.; Lee, S.W.; Kim, Y.-S.; Kim, S.J.; Wang, Z.L. Piezoelectric-driven self-charging supercapacitor power cell. ACS Nano 2015, 9, 4337-4345. [CrossRef] [PubMed]

268. Song, R.; Jin, H.; Li, X.; Fei, L.; Zhao, Y.; Huang, H.; Chan, H.L.-W.; Wang, Y.; Chai, Y. A rectification-free piezo-supercapacitor with a polyvinylidene fluoride separator and functionalized carbon cloth electrodes. J. Mater. Chem. A 2015, 3, 14963-14970. [CrossRef]

269. Maitra, A.; Karan, S.K.; Paria, S.; Das, A.K.; Bera, R.; Halder, L.; Si, S.K.; Bera, A.; Khatua, B.B. Fast charging self-powered wearable and flexible asymmetric supercapacitor power cell with fish swim bladder as an efficient natural bio-piezoelectric separator. Nano Energy 2017, 40, 633-645. [CrossRef] 